\title{
الأيام المدارية في مصر دراسة منافية
}

\section{د. محمد توفيق محمد (*)}

\section{مقدمة}

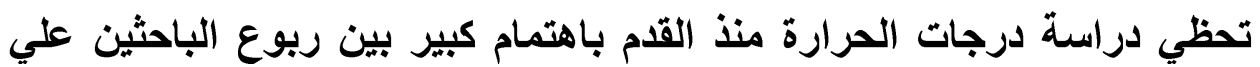

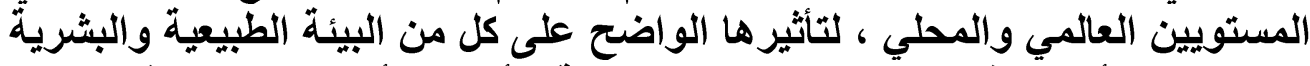

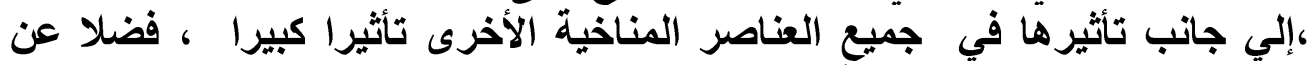

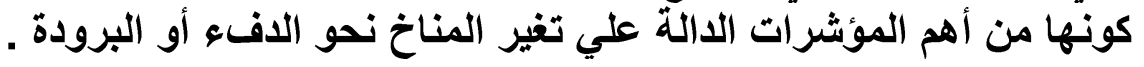

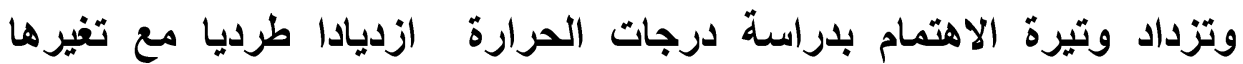

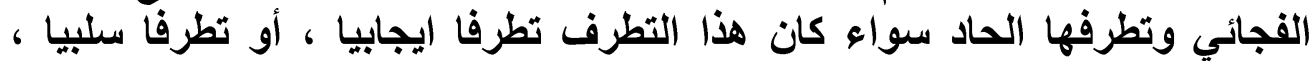
لوضوح بصمات وتداعيات هذه التغيرات والتطرفات على مختلف مناحى الحياة. وعن الأيام المدارية (Tropical Days (TD) موضوع الدراسة ـ فهي أحدي مؤشرات التطرف المناخى Climate Extreme') وتحديدا تطرف درجات

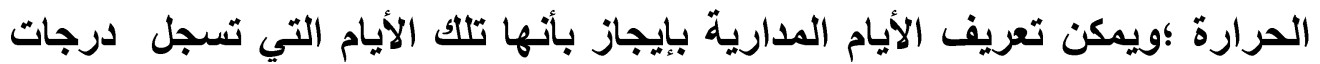

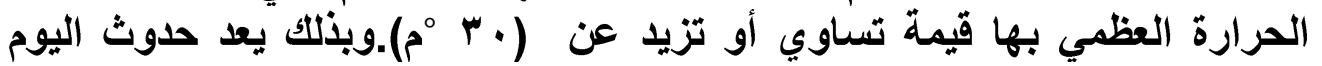

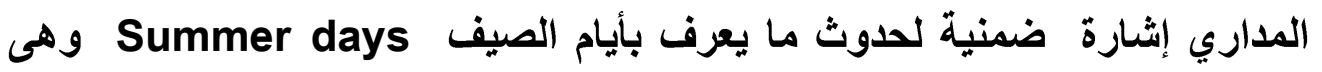

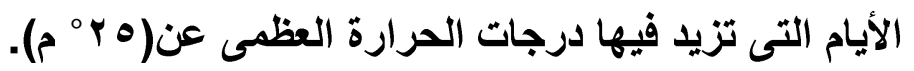

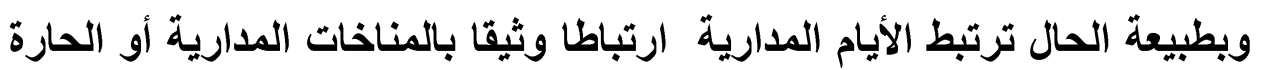
أكثر من ارتباطها بغيرها من المناخات الأخرى لكون الثانية (المناخات المدارية)

$$
\text { أستاذ الجغر افيا الطييعية المساعد كلية الآداب جامعة سوهاج }
$$

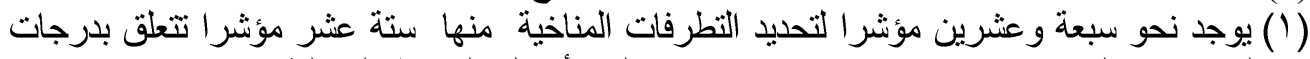

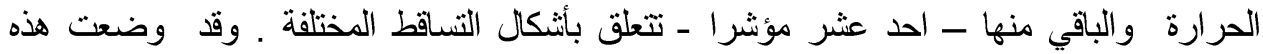

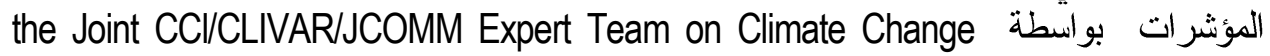
ومن بين المؤشرات الخاصة بتحليد التطرفات الحرارية ؛ Detection and Indices (ETCCDI),

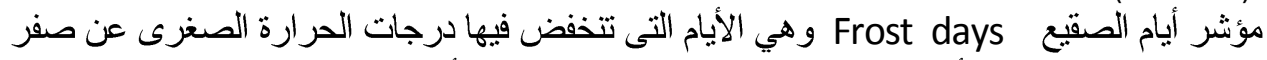

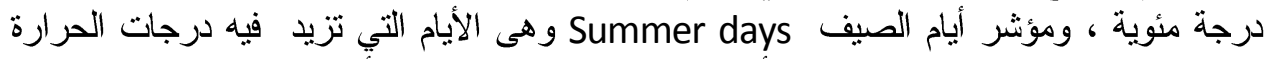

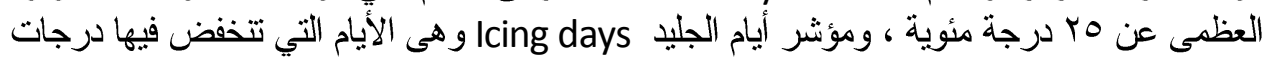

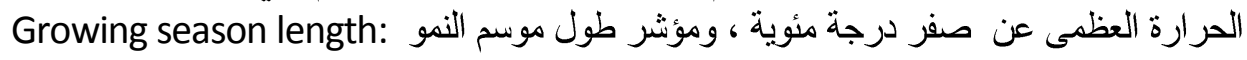

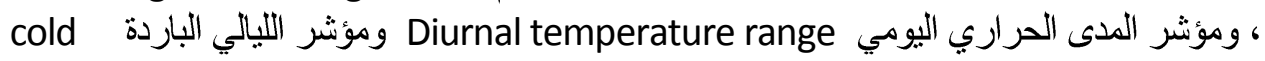

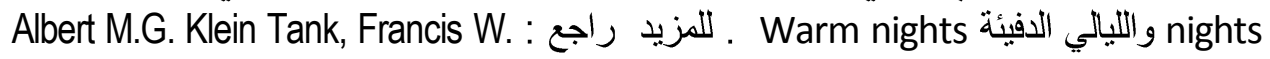


مجلة كلية الآداب، جامعة سوهاج، العدد الخامس والأربعون، الجزء الأول، أكتوبر YY P P

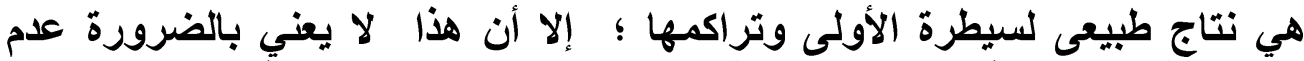

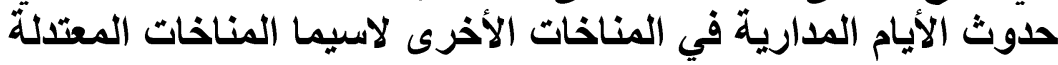

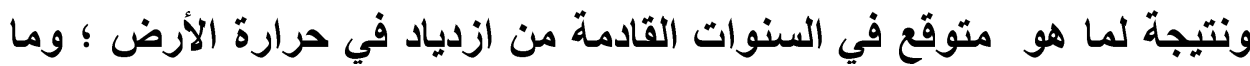

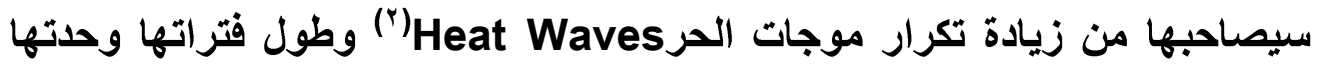

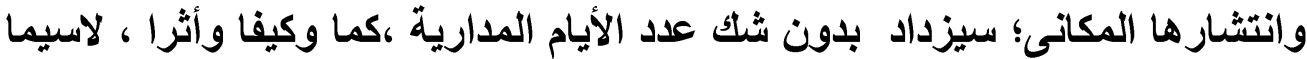

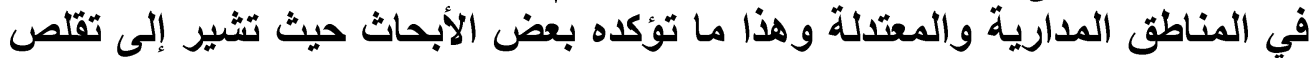

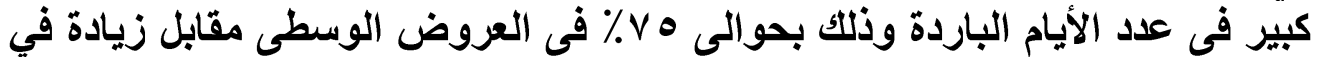

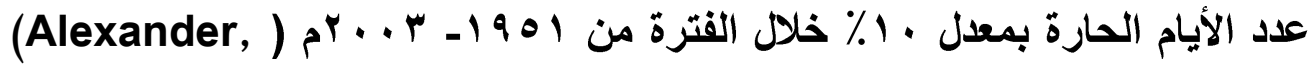

.etal., 2006

ومما ينبفي الإثارة إليه أن حرارة الأيام المدارية في المناطق المدارية الجافية البهافة

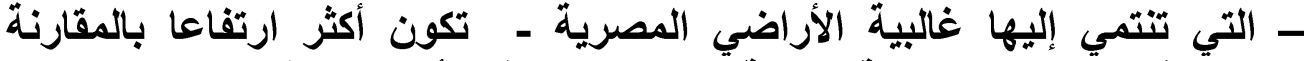

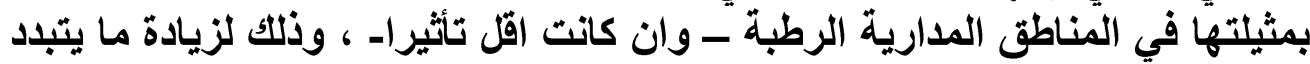

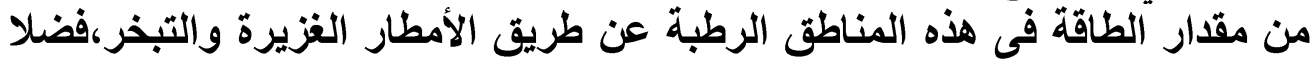

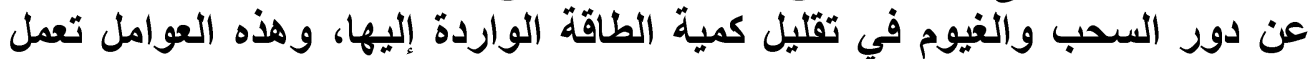

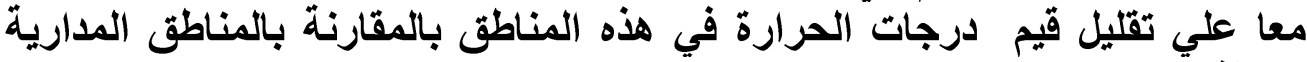

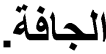

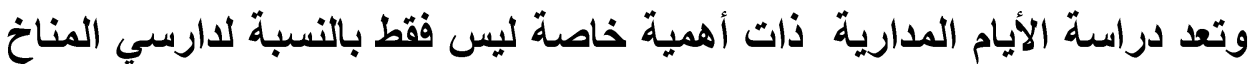

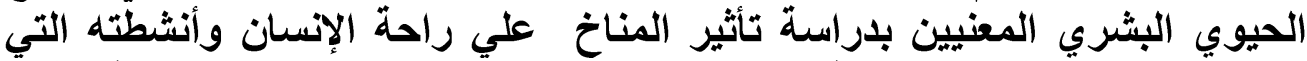

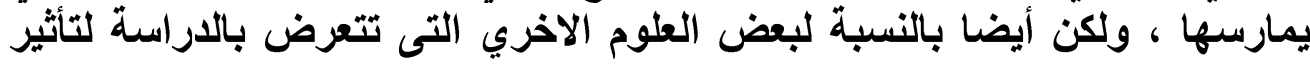

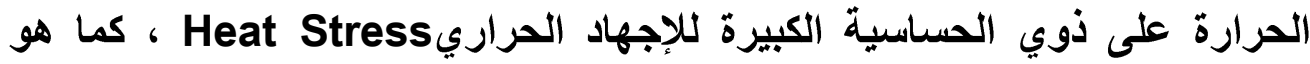

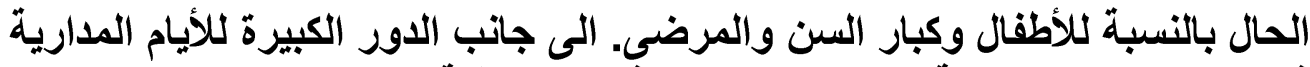

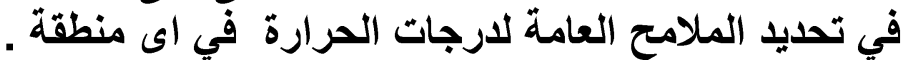

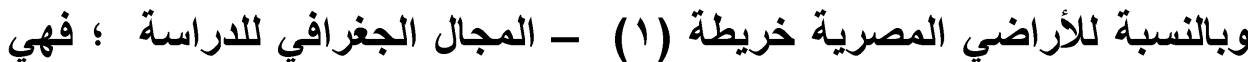

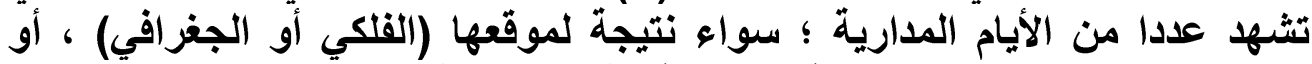

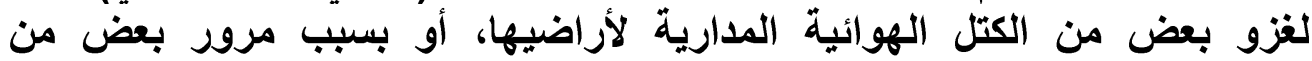

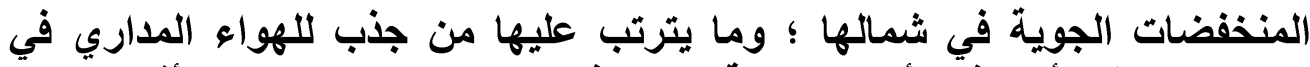
مقدماتها ، غير أن هذه الأيام المدارية تتباين في ملامحها في ـ كما وكيفا وتأثير اـ تباينا

(Y) رغم عدم الاتفاق على تعريف محدد للموجات الحارة سواء من ناحية العتبة الحرارية أو مدتها

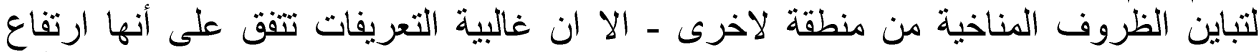

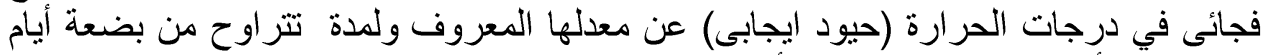

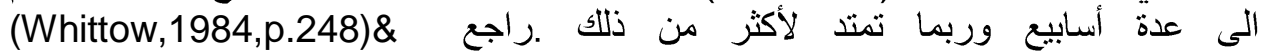


مكانيا وزمانيا علي طول امتداد الأراضي المصرية من منطقة إلي أخري ، و من من عام

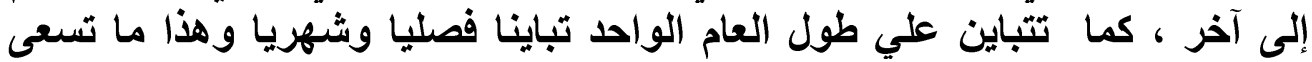

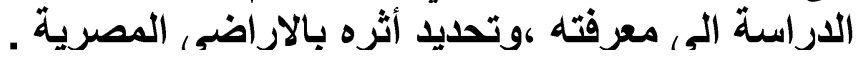

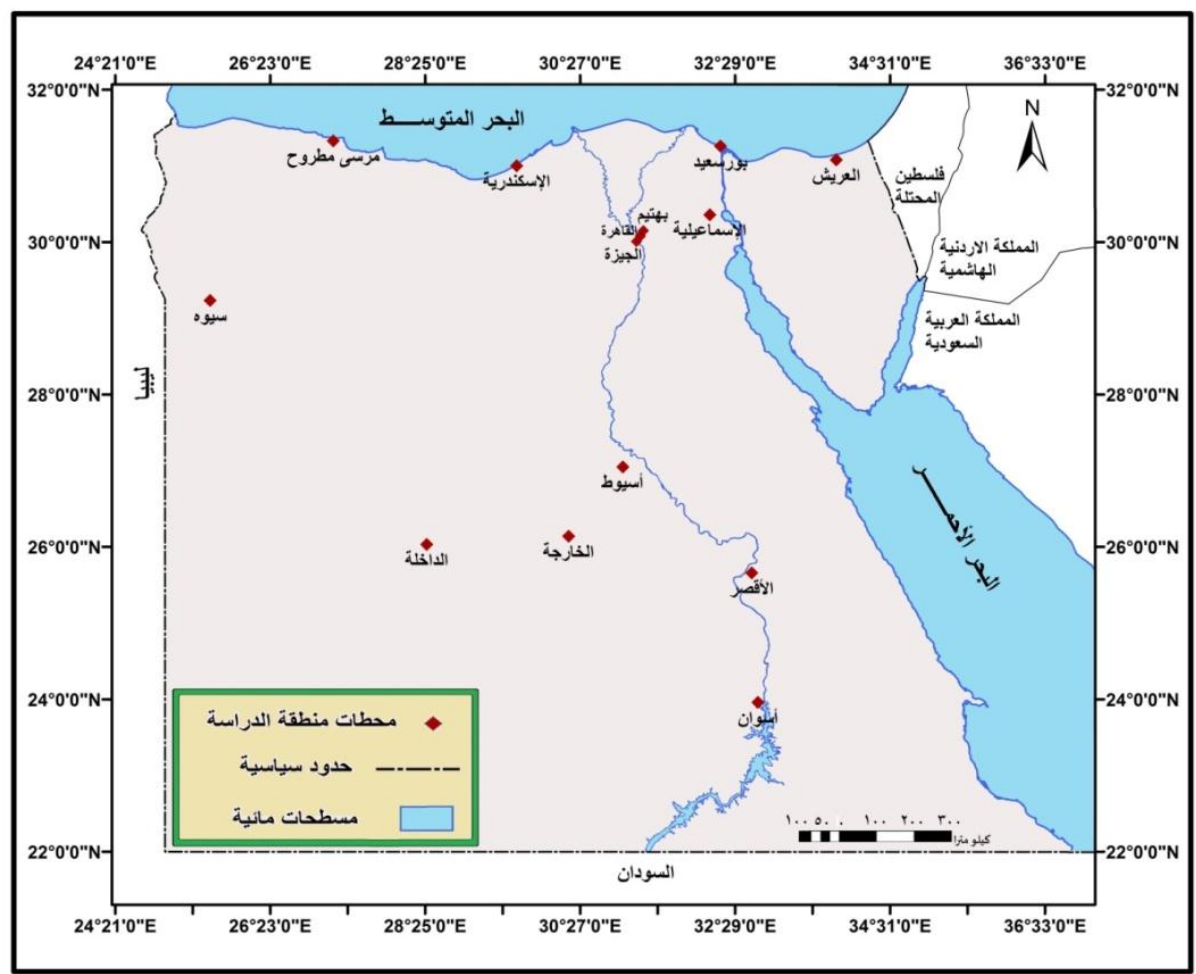

خريطه (1) المجال المكاتي للبحث ومحطات الارصاد الجويه التي اعتمد عليها

أولا : أهمية الدراسة ودوافعها :

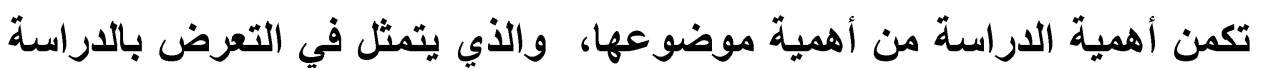

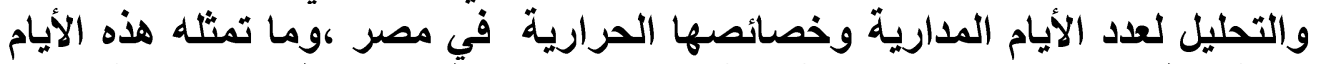

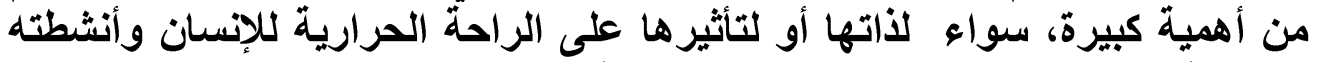

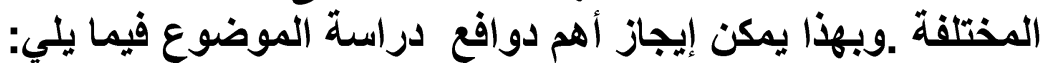

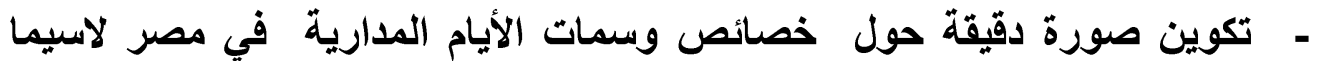

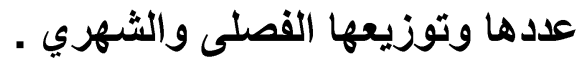

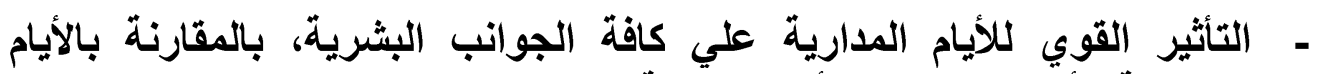

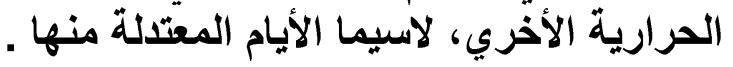

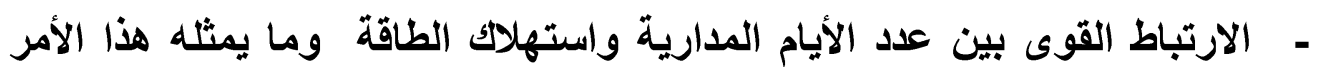

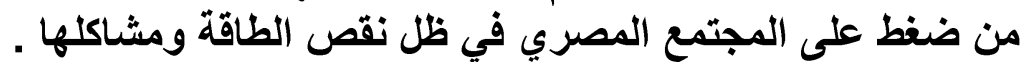


- عدم تعرض أي من الاراسات الجغرافية للموضوع في بحث على مستقل . نانبا :أهداف الدراسةة :

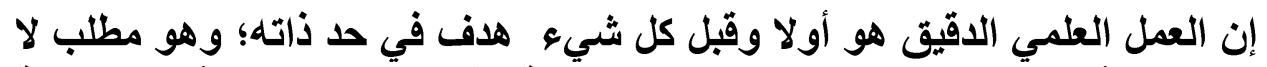

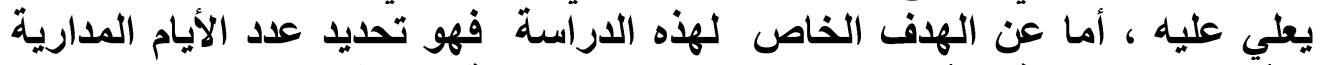

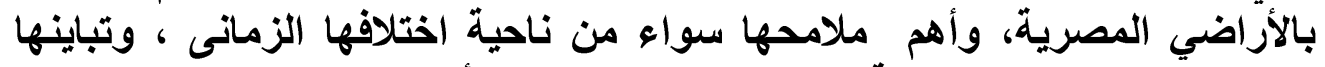

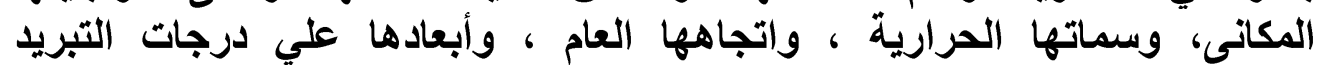

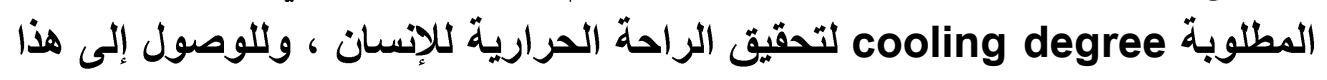

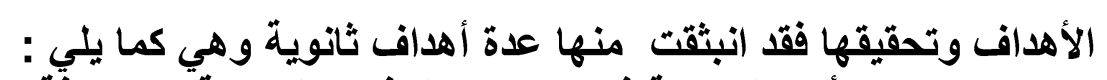

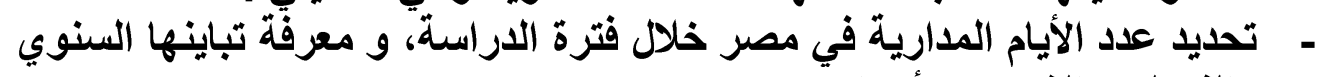
والفصلي والشهري وأسبابه. - معرفة مجموع الساعات المدارية ونسبتها من المجموع الكلى لساعات النهار

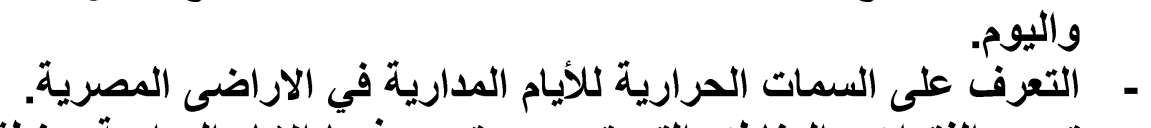

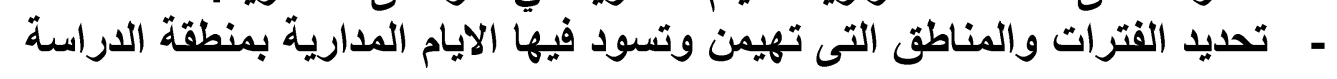
- - تساب الحمل الحراري الزائد للائيام المدارية وطبيعته في مختلف الثهور.

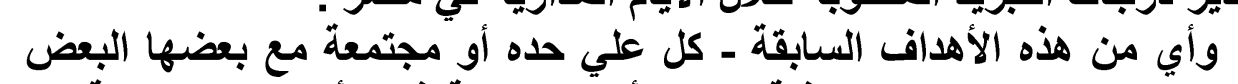

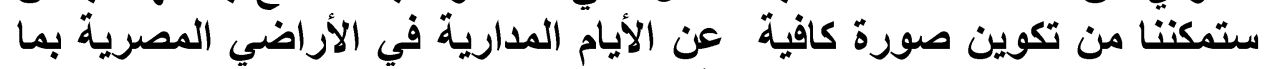

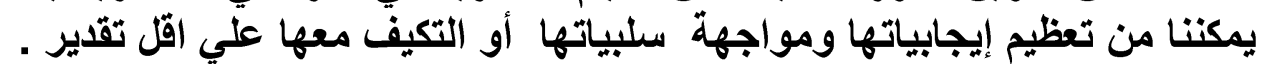

\section{نالنا : الدراسات السابقةة :}

تنوعت الدراسات السابقة ذات العلاقة بالموضوع ؛ فابة ؛ فمنها ما ركز على دراسة الأيام

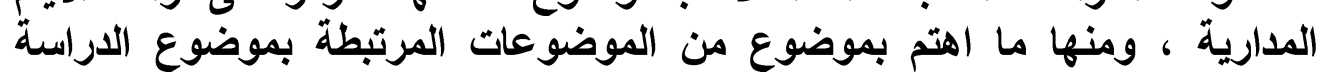

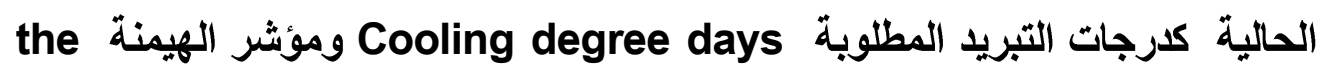
primacy index والحمل الحراري Heat stress، وعن الدراسات التى اهتمت

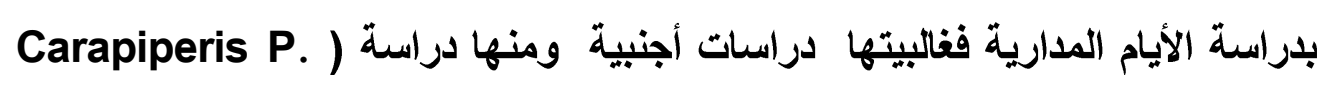

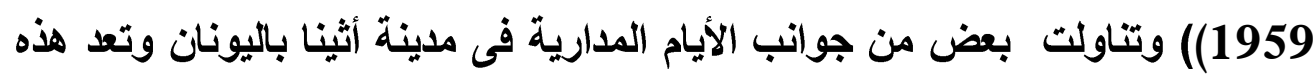

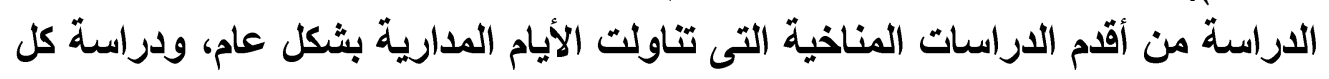
من :Nastos,P.T. ,Matzarakis,A.P . (2008), وقد تعرضت لمعرفة المعدل The Annual Number of Tropical السنوي لعدد الأيام المدارية 
واتجاهها العام في الاراضى اليونانية خلال النصف الثانى من القرن

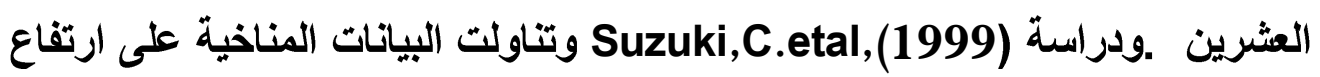
10 متر فى المنطقة الحضرية بطوكيو وكان من بين ما تعرضت له مفهوم اليوم

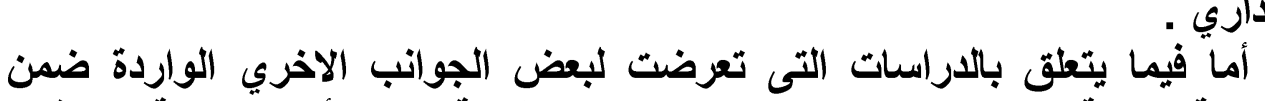

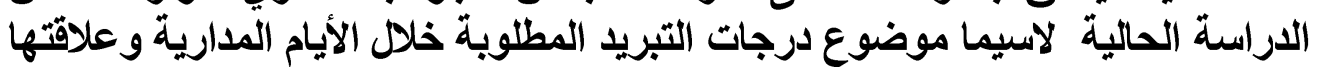

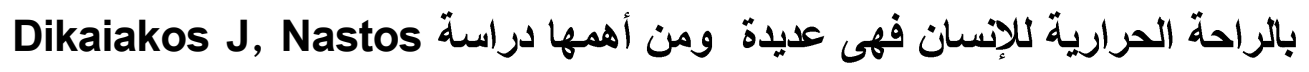
و وتناولت المناخ الحيوي خلان الأيام المدارية .

رابعا: بيانات الدراسة ومنهمية المعالهة :

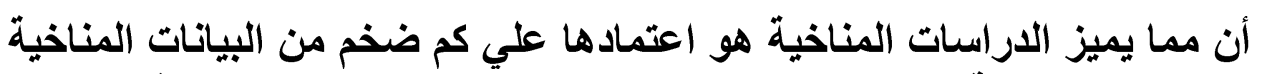

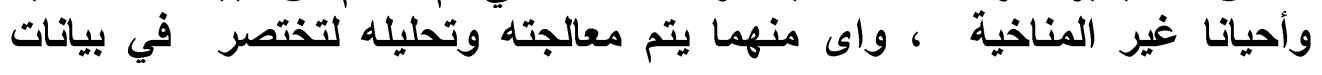

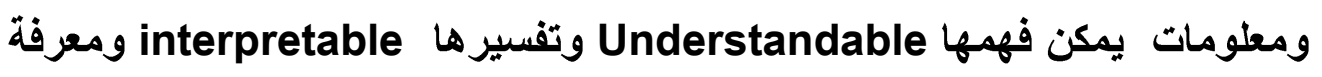

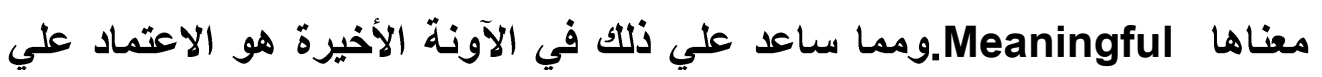

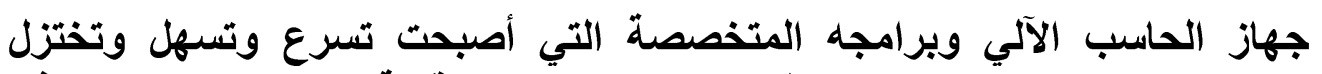

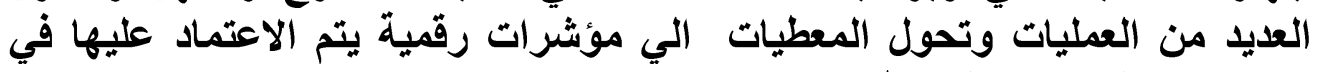
استخلاص الدالات والترابطات.

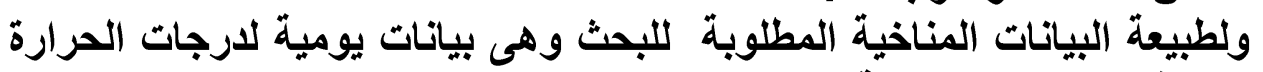

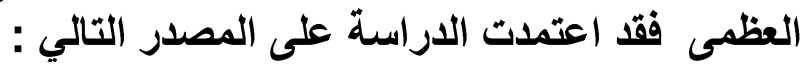

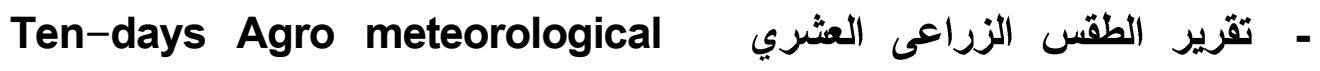
-Weather Report

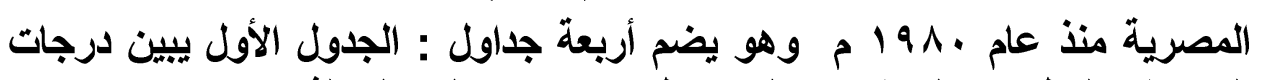

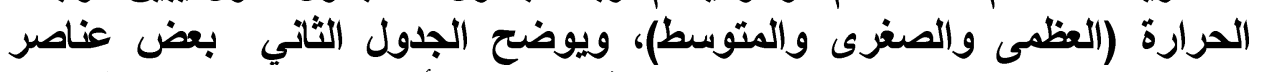

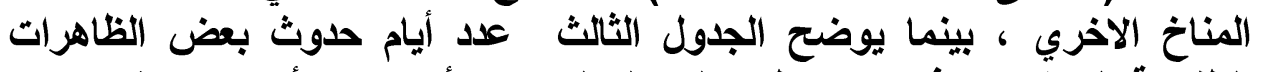

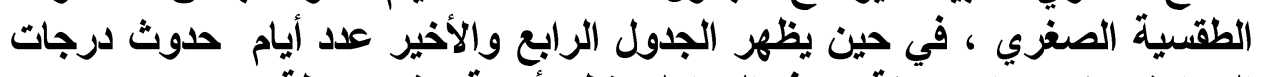

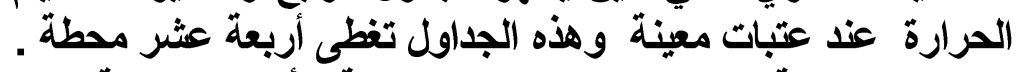

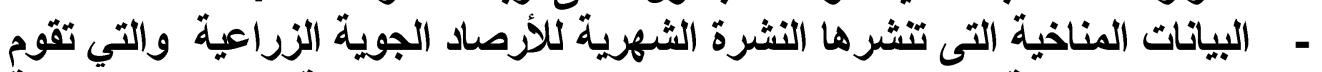

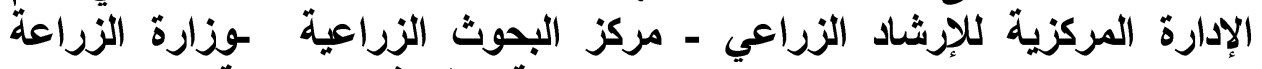

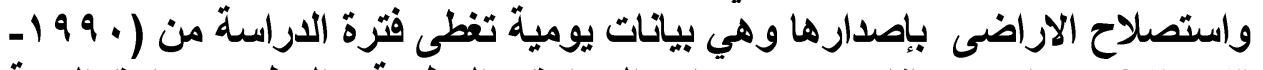

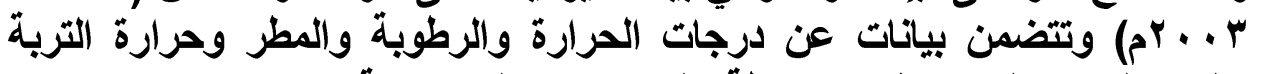
والبخر اليومى لنحو عثرين محطة على مستوى الجمهورية . 


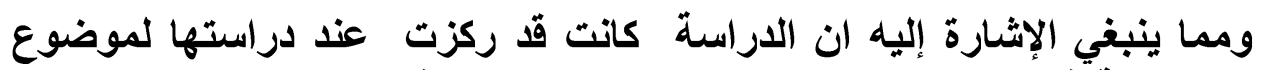

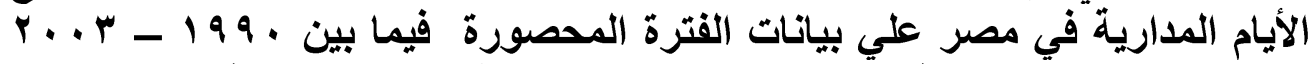

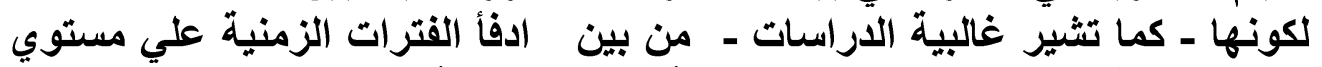

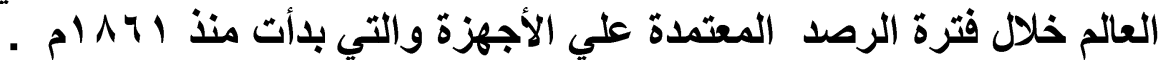
أما فيما يتعلق بمنهجية المعالجة للموضوع وخطواتها فقد تمثلت فيما يلى : لماتل - معرفة الإطار النظري لمفهوم الأيام المدارية وآليات تحديدها كميا .

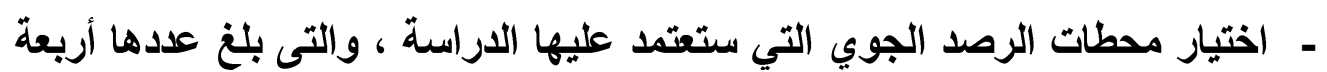

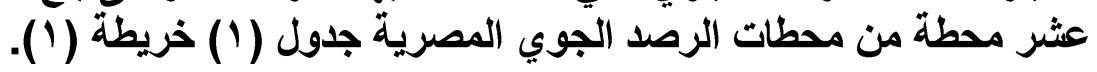

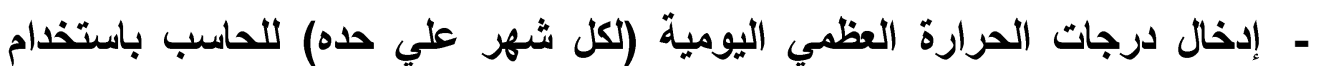

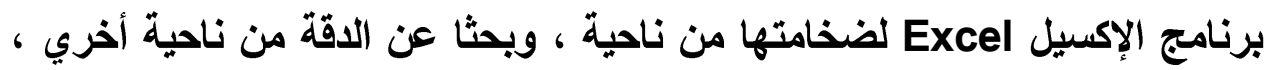

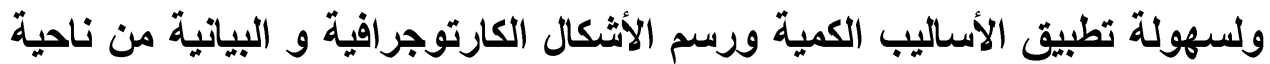

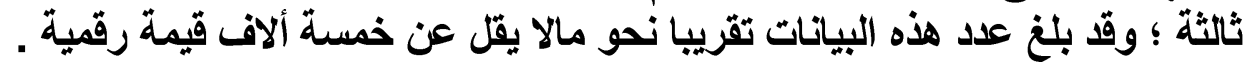
- القيام بعمل فرز)(Sorting (القيم وترتيبها تنازليا/أو تصاعديا لتحديد وتسجيل

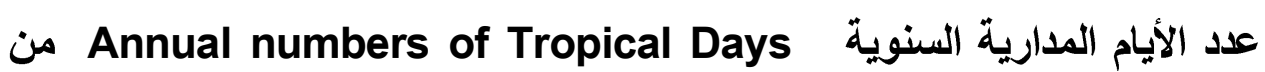
واقع بيانات الأرصاد الجوية للمحطات المذكورة .

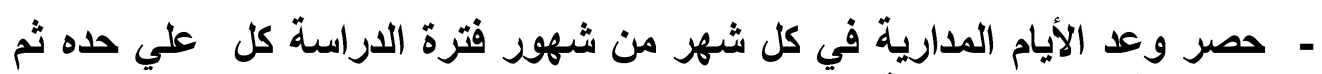

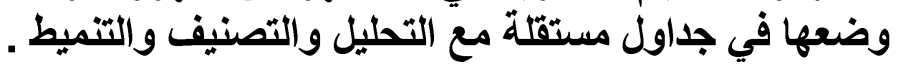

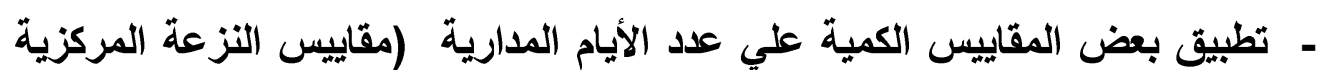

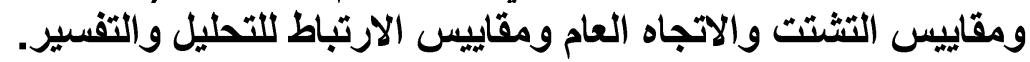

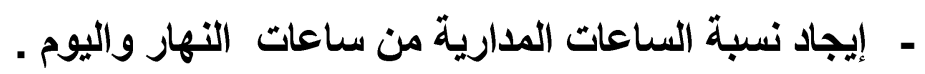
- حساب ما يمكن تسميته بالحمل الحرارة الزائد للشهور المدارية وطبيعة هذا الحمل هل

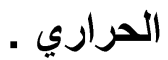
- حساب هيمنة الأيام المدارية في منطقة الاراسة سواء بالنسبة للفصول او الثهور .

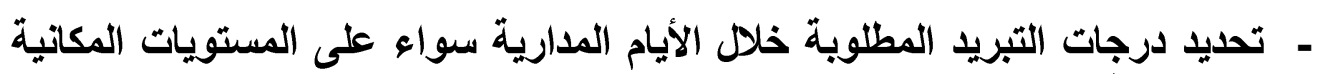

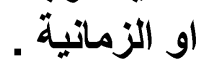
- رسم الخرائط والأثكال البيانية الخاصة بالاراسة وكتابة الاراسة وعرض نتائجها واقتراح التوصيات . 
جدول( ) محطات الأرصاد الجوية التي اعتمدت عليها الدراسة

\begin{tabular}{|c|c|c|c|c|c|c|c|}
\hline \multirow{2}{*}{ 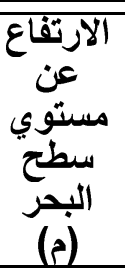 } & \multicolumn{2}{|c|}{ الموقع الفلكي } & \multirow[b]{2}{*}{ المحطة } & \multirow{2}{*}{ 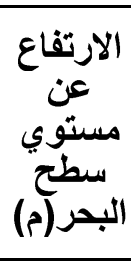 } & \multicolumn{2}{|c|}{ الموقع القلكح } & \multirow[b]{2}{*}{ المحطة } \\
\hline & خطوط الطول & العرض دوائر & & & 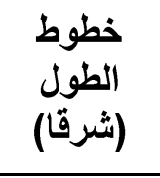 & العرض دوائر & \\
\hline 11 & r ו וpo & r. & الجيزة & ro & $\circ r V I r$ & $\circ r_{1} r$. & مطروحي \\
\hline 79 & ${ }^{\circ}+1$ & $\circ r V \cdot r$ & أسيوط & $r_{-}$ & ०Yq OV & $\circ M_{1} \mid r$ & الإسكندرية \\
\hline$\Lambda \mu$ & ${ }^{\circ} H Y \leqslant Y$ & O YO E. & الأقصر & or & orr ls & ${ }^{\circ} \mathrm{HIV}$ & بورسعيد \\
\hline 198 & orr $\& V$ & ${ }^{\circ} Y \mu \Delta \Lambda$ & أسوان & $\Delta V$ & ${ }^{\circ} p r \leq q$ & ${ }^{\circ}{ }^{\circ}$ & العريش \\
\hline 10 & ${ }^{\circ} Y 0 \quad 19$ & ० Yq Ir & سيوه & 10 & ory le & ${ }^{\circ} \boldsymbol{\mu}, \mu$ & الأسماعلية \\
\hline 9 & ${ }^{\circ}$ p $\ldots$ & opo rq & الاخلة & 9 & ${ }^{\circ} 110$ & ${ }^{\circ} \mu .11$ & بهتيم \\
\hline$V V$ & orr rr & ${ }^{\circ}$ Y Y YV & |الخارجة & Ir & & ${ }^{\circ} \mu .11$ & القاهرة \\
\hline
\end{tabular}

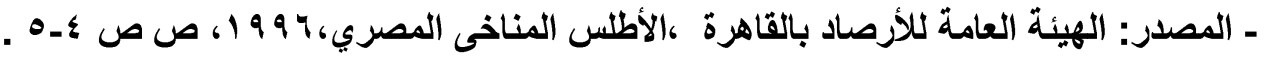

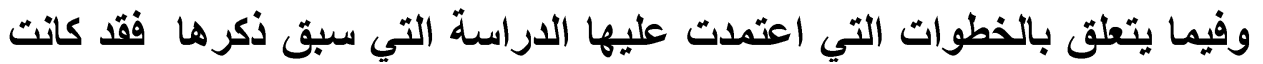

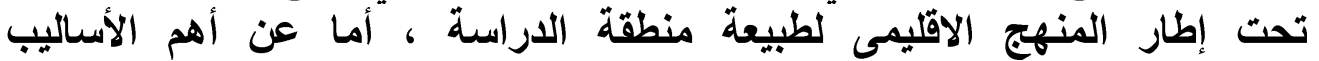

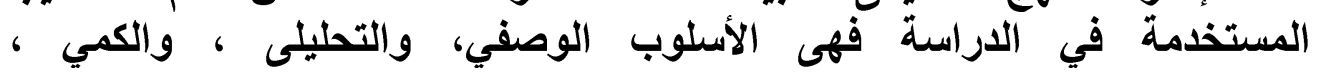
والكارتوجرافى، ونظم المعلومات الجغرافية من خلال برنامج

\section{خامسا :مغاهيم الدراسة :}

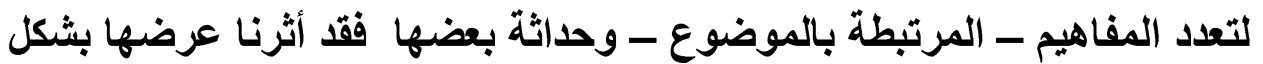

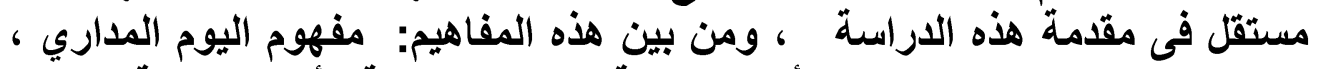

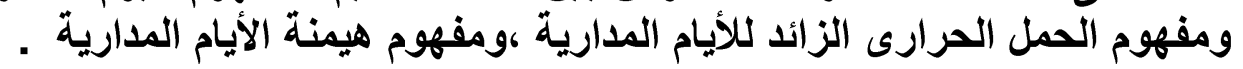
ايرتبط مفهوم اليوم المدارى : المدارى ارتباطا كبيرا بدرجة الحرارة بشكل عام ودرجة

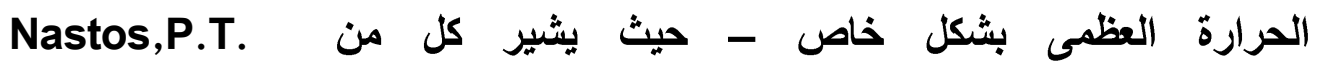
Matzarakis,A.P

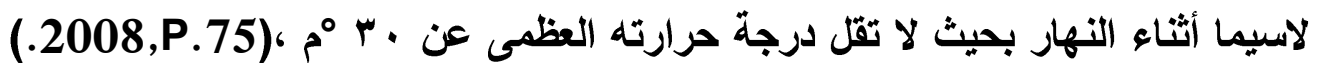

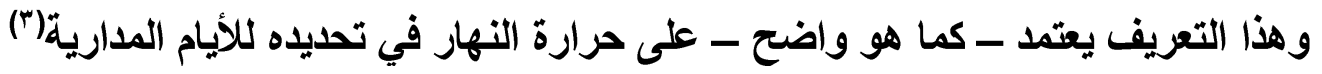


مجلة كلية الآداب، جامعة سوهاج، العدد الخامس والأربعون، الجزء الأول، أكتوبر IV P P

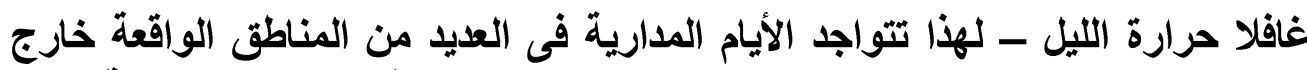

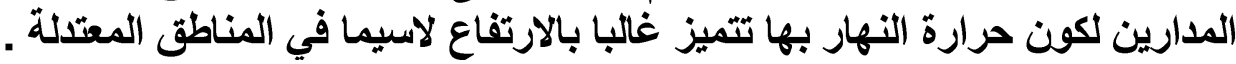
ويمكن القول أن اليوم المداري هو اليوم الأي يبلغ متوسطه الحرارى ^ا

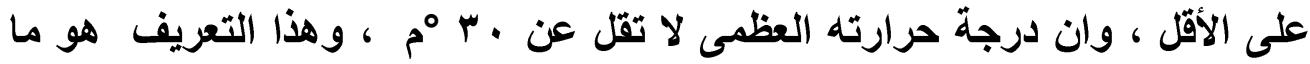

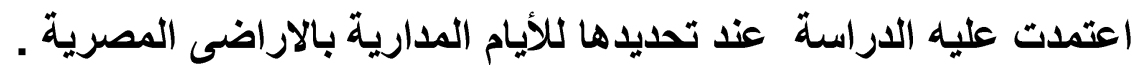
r- مفهوم الحمل الحرارى للأيام المدارية وطيعته :

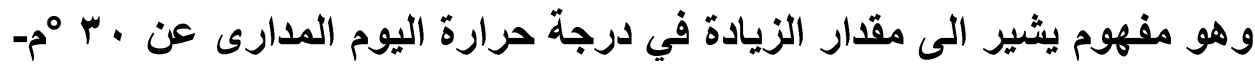

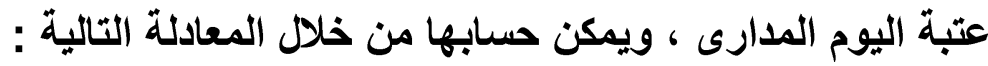

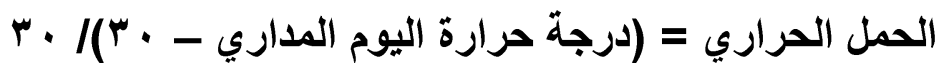

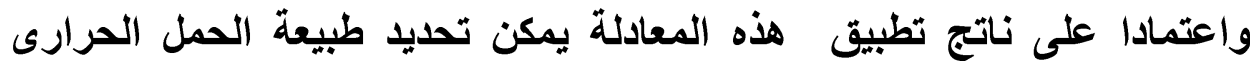

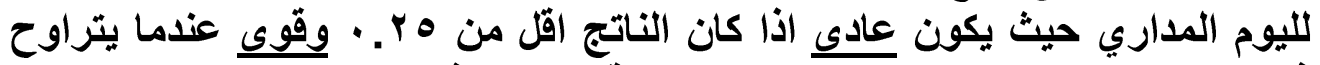

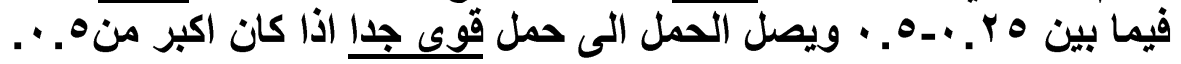
ب- مفهوم هيمنة الأيام المدارية (؛). كغيرها من الظاهرات المناخية تسود الأيام المدارية في أوقات اومناطق محددة

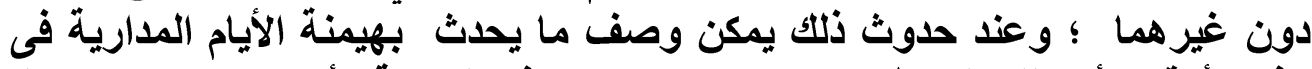

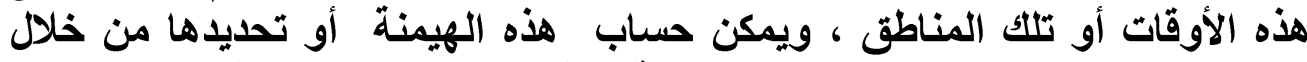

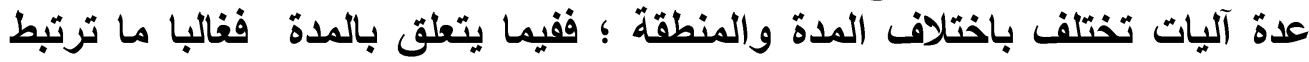

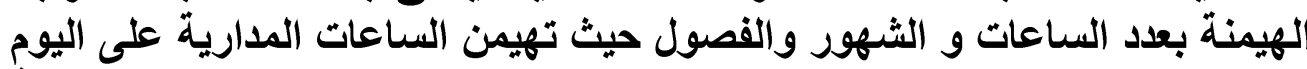

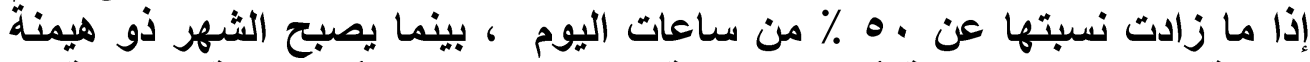

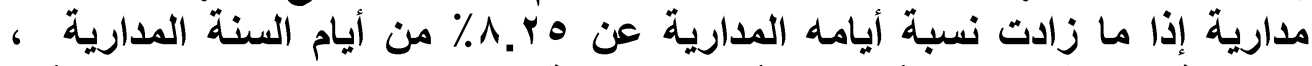

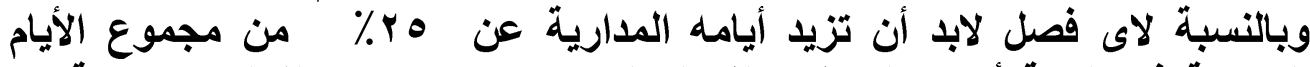

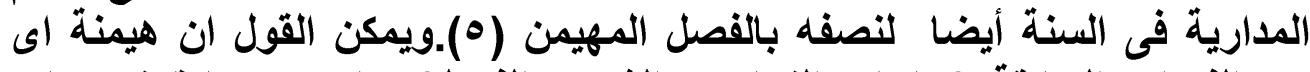

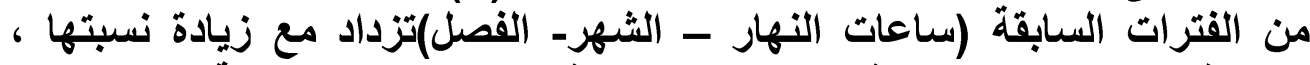
وكلما قل الفرق بين نسب هذه الفترات كلما دل ذلك التجانس التهات واللاهيمنة.

(ع) تم تطبيق هذا المفهوم بتصرف ؛و هو مستوحي من مفهوم الهيمنة الحضرية للمدن راجع (حمدى احمد

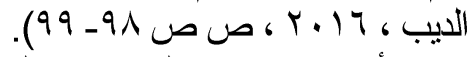

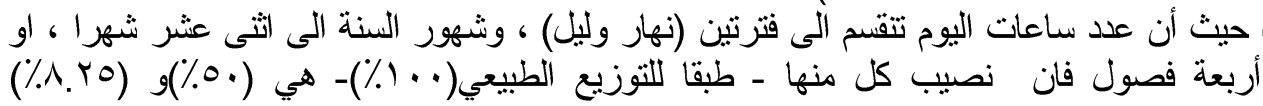

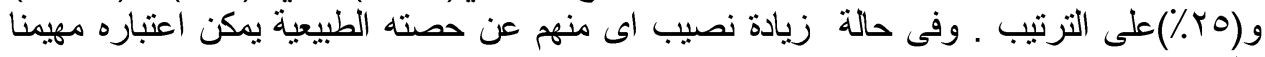


أما فيما يتعلق بالمناطق؛ فالهيمنة المدارية لاى منها تختلف باختلاف عدادها

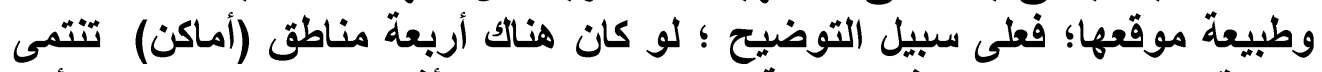

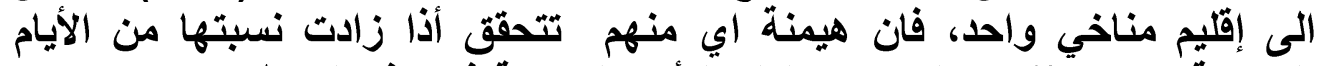

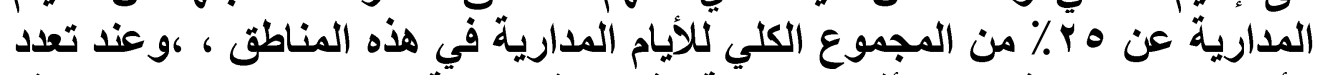

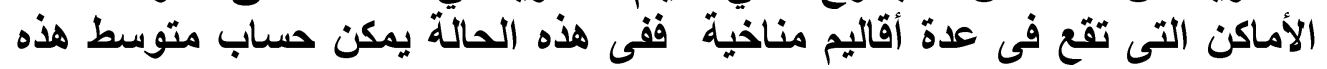

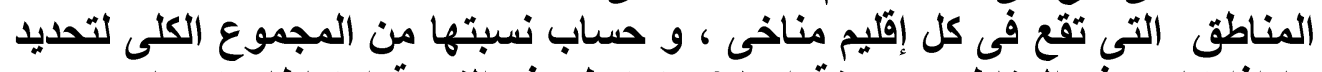

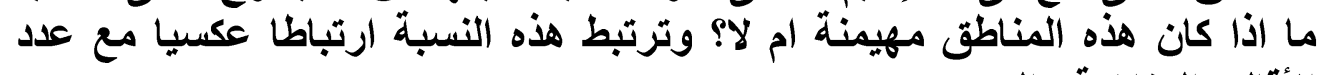

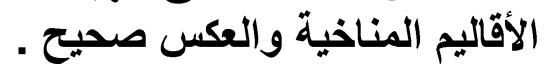

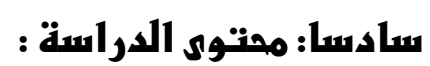
في ضوء ما سبق ذكره الفواه تتضمن هذه الاراسة أربعة محاور تسبقها مقدمة

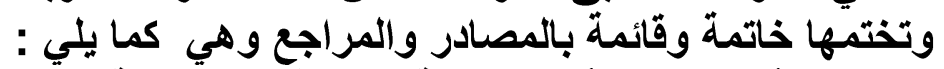

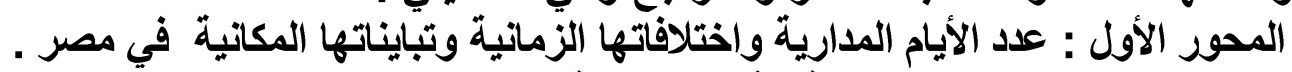

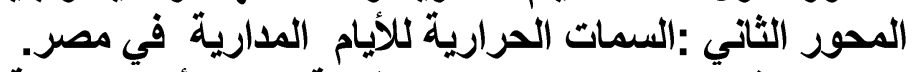

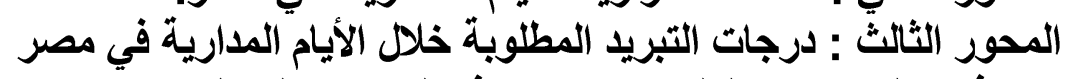

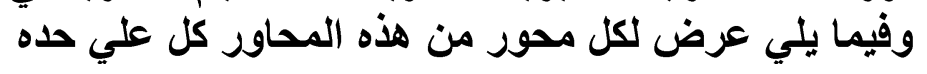

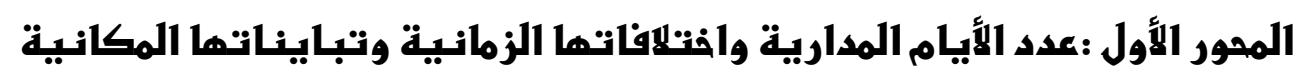

يعرض هذا المحور لكل من عدد الأيام المدارية، واختلافاتها الزمانية ، وتبايناتها

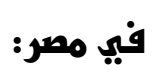

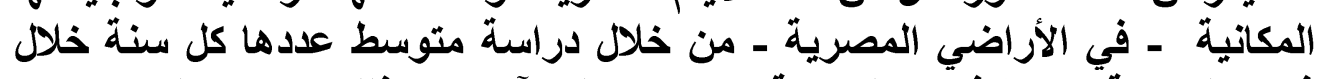

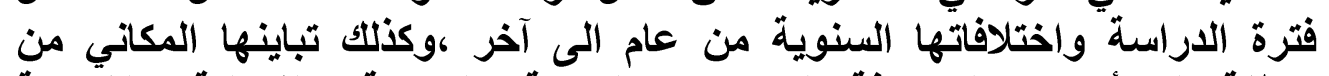

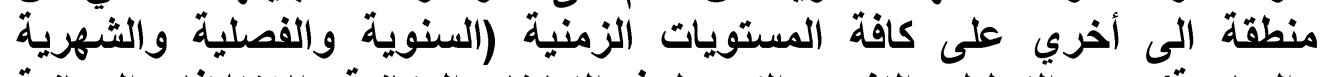
والساعية) ، مع التحليل والتفسير الكمي لهذه التباينات المكانية والاختلافات الزمانية الثية

\section{أولا :عدد الأيام المدارية وافتنافاتها الزمانية بالأراضي المصرية :}

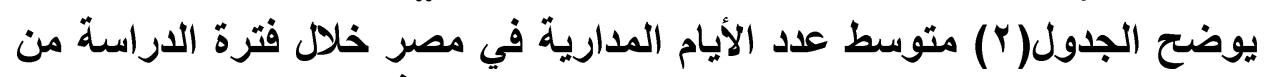

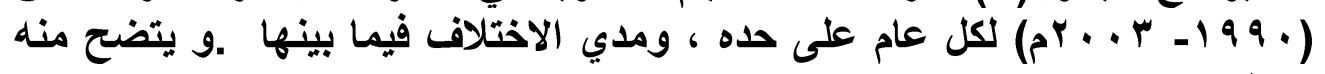

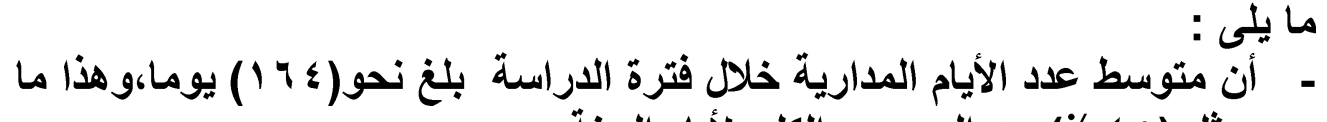

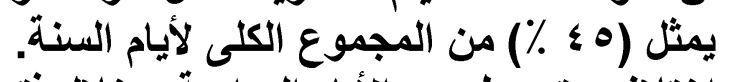

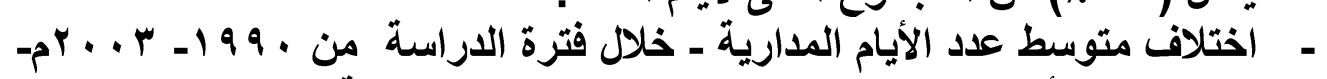

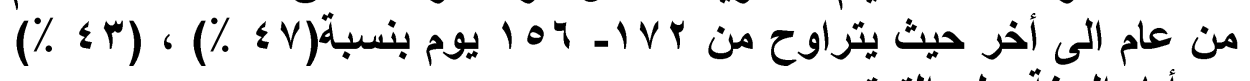

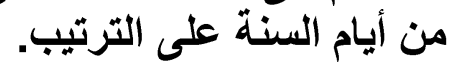




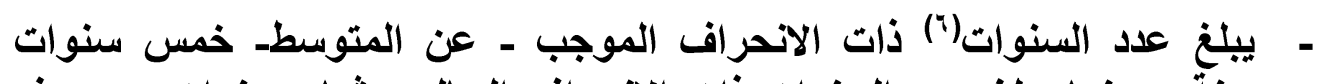

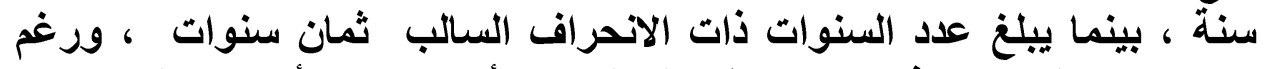

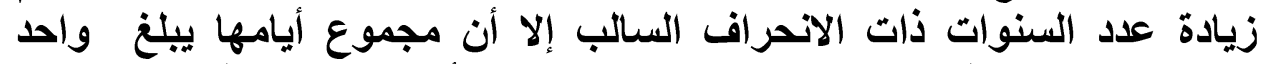

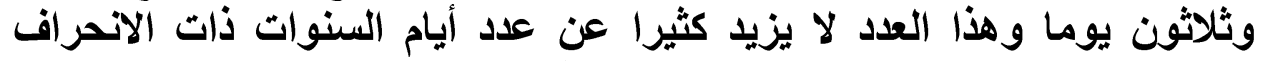

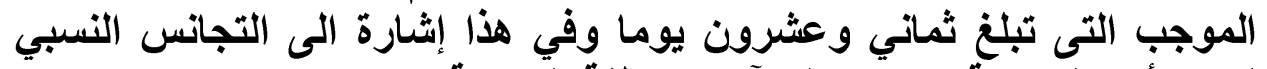

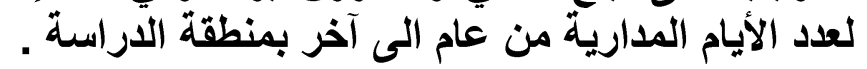

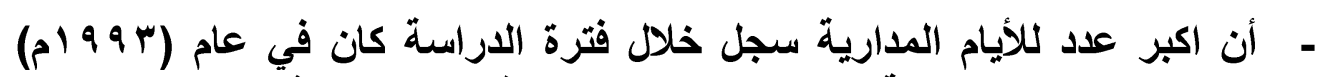

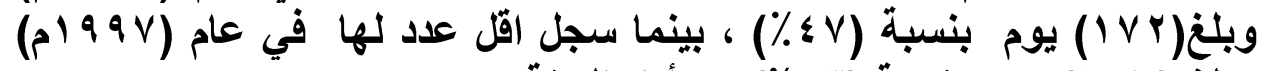

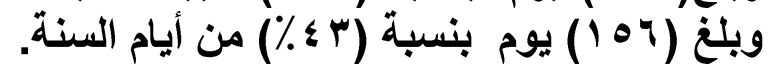

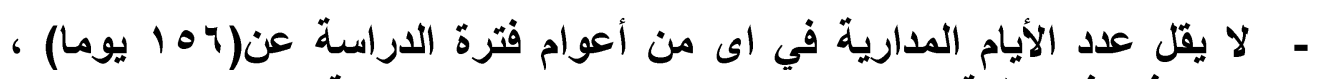

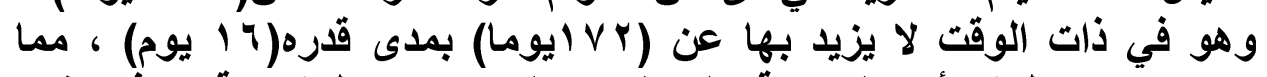

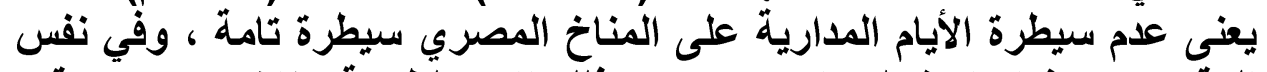

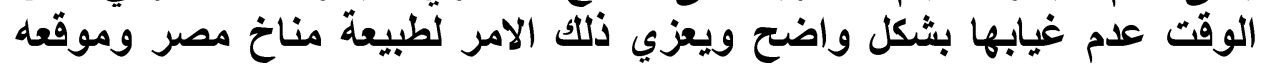

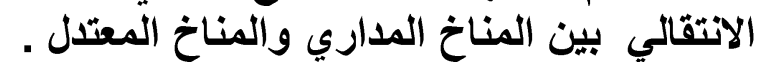

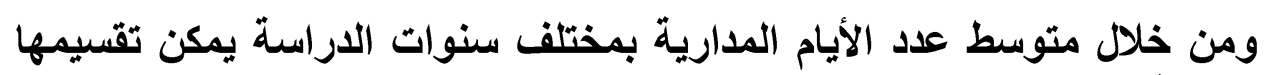

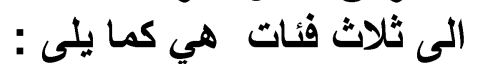

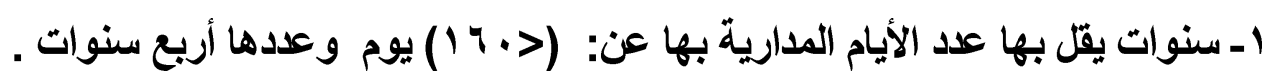

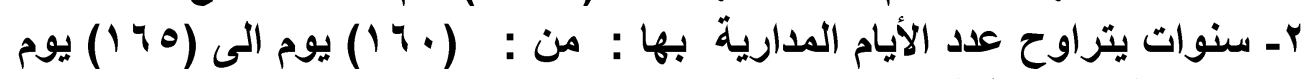

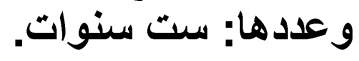

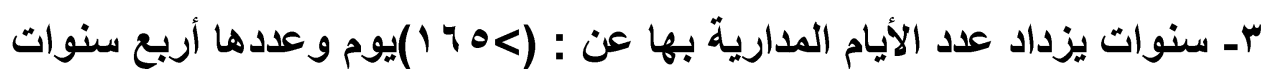

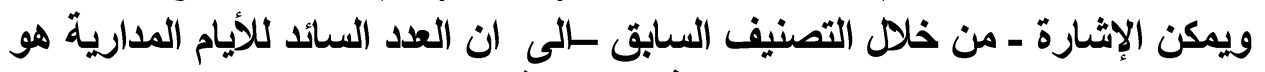

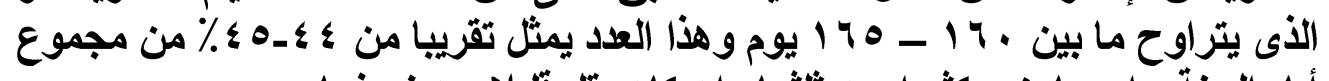

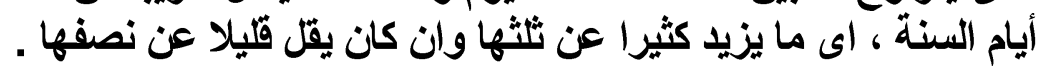

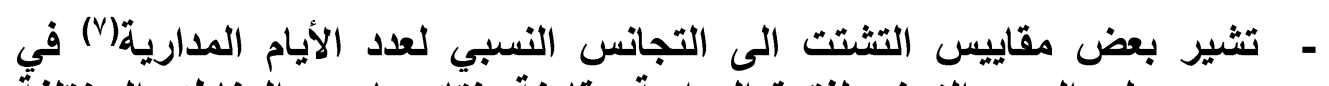

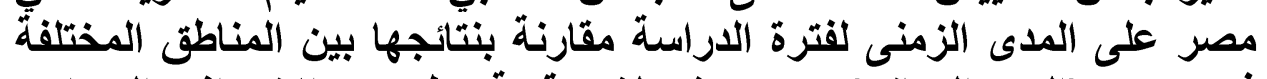

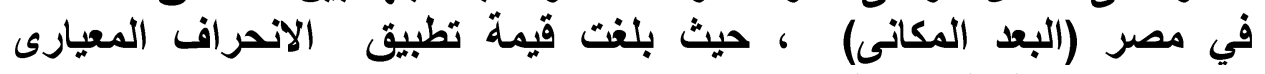
نحو(0)، ووصل (البط التباين الى (ro) (ro).

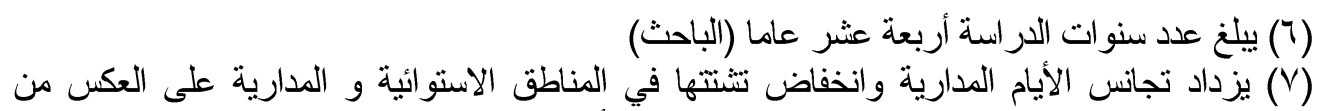

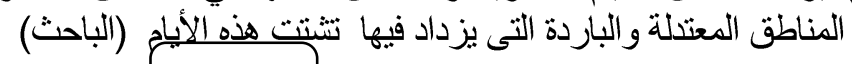




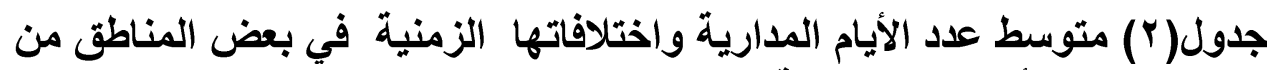

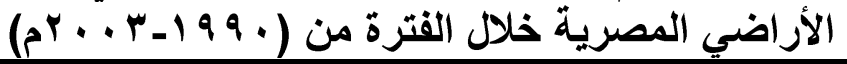

\begin{tabular}{|c|c|c|c|c|c|c|c|c|c|c|c|c|c|c|}
\hline$\ldots r$ & $r \ldots r$ & Y... & r... & 1999 & 1991 & $199 \mathrm{~V}$ & 1997 & 1990 & 1995 & 1994 & 1994 & 1991 & 199. & العام \\
\hline $17 \varepsilon$ & $I V Y$ & 174 & 195 & 101 & 178 & 107 & $10 \mathrm{~V}$ & $17 \varepsilon$ & 109 & IVY & 170 & $17 V$ & 190 & م.ع. ا. م (A) \\
\hline$\leq 0$ & $\leq V, Y$ & $\leqslant \leqslant .7$ & $\leq 0$ & $\leq r . Y$ & $\leqslant 0 . V$ & $\leqslant Y . \wedge$ & $\leqslant r . q$ & $\leq 0$ & $\leq 4.7$ & $\leqslant V$ & $\leqslant 0.1$ & $\leqslant 0 . V$ & $\leqslant 0 . r$ & \% من السنة \\
\hline \multicolumn{14}{|c|}{$17 \varepsilon$} & المتوسط \\
\hline$\cdot$ & $\Lambda$ & & - & & $r$ & & & - & & $\Lambda$ & 1 & $r$ & 1 & $(+)_{2.1}$ \\
\hline$\cdot$ & & 1 & - & 9 & & $\Lambda$ & $\mathrm{V}$ & - & 0 & & & & & $(-)+.1$ \\
\hline \multicolumn{14}{|c|}{.17.} & المدى \\
\hline \multicolumn{14}{|c|}{$0 . r$} & ا \\
\hline \multicolumn{14}{|c|}{$r 0 . r$} & 1. \\
\hline
\end{tabular}

المصدر : الجدول من حساب الباحث اعتمادا على : الهيئة العامة للأرصاد الجوية بالقاهرة ، قسم

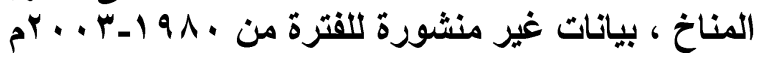

\section{ثانبا :التباينات المكانية لعدد الأيام المدارية في مصر :}

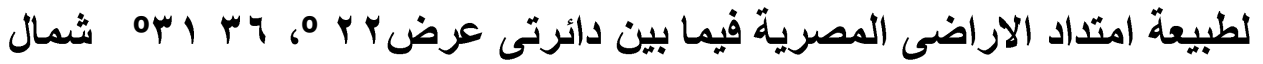

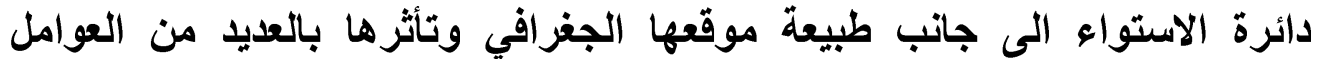

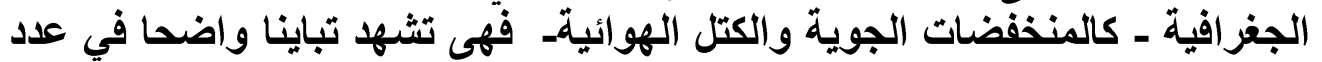

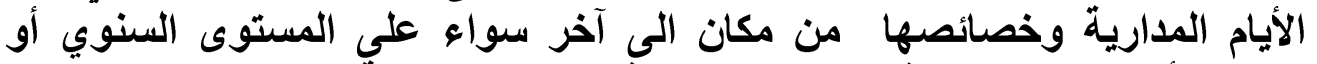

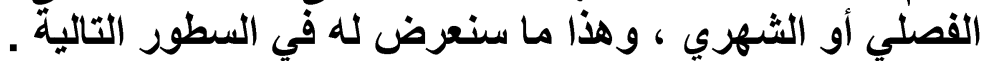

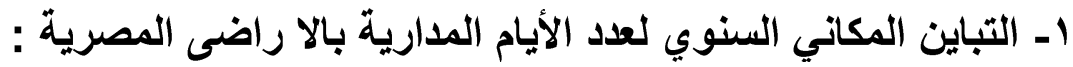

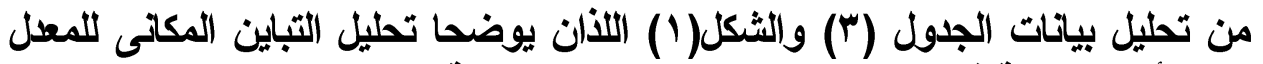

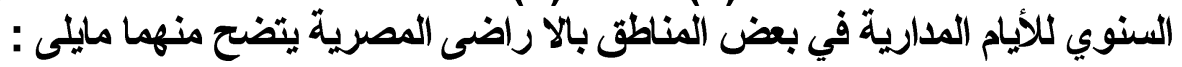

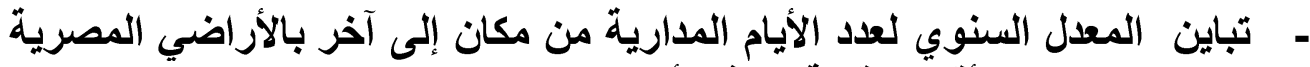

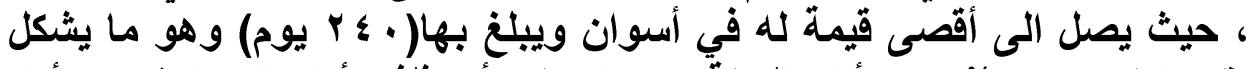

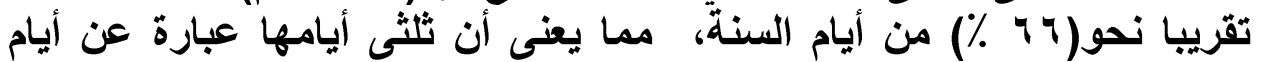

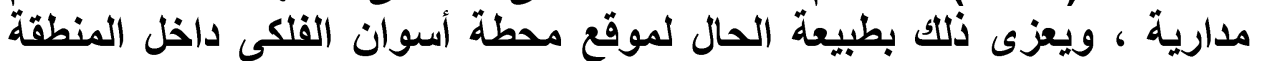

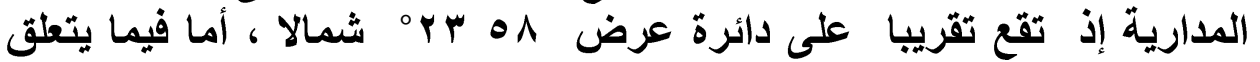

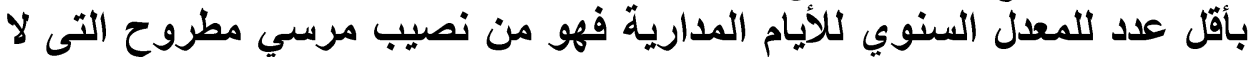

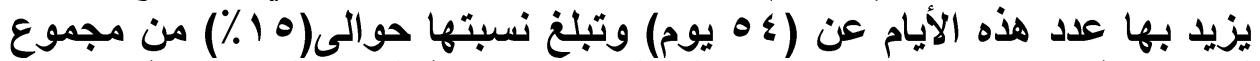

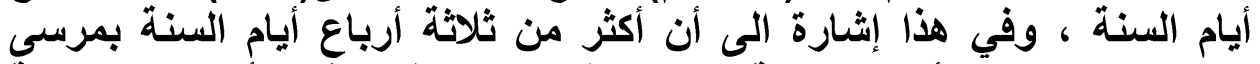

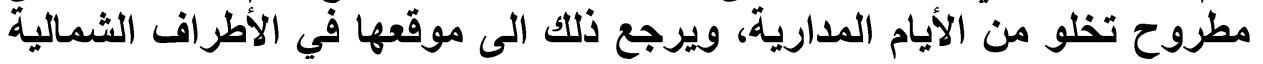

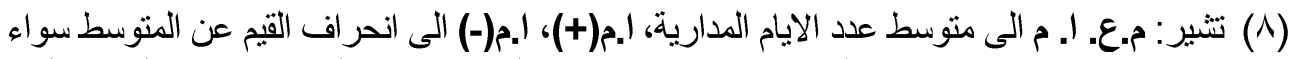

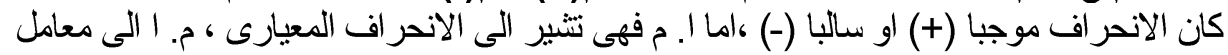

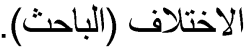


مجلة كلية الآداب، جامعة سوهاج، العدد الخامس والأربعون، الجزء الأول، أكتوبر Y P P

من الأراضي المصرية من ناحية ، وإطلالها مباشرة علي البحر المتوسط

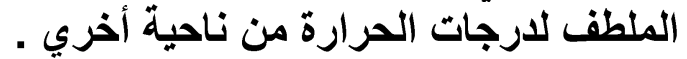

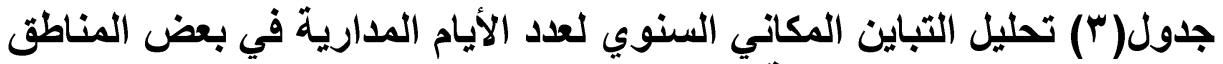

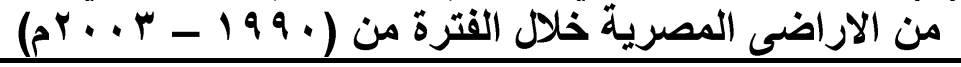

\begin{tabular}{|c|c|c|c|c|c|c|c|c|c|c|c|c|c|c|}
\hline ד. & $\frac{\overline{7}}{\overline{1}}$ & 岁; & $\frac{\overline{3}}{\overline{3}}$ & 盆 & $\overline{\mathbf{3}}$ & $\overline{7}$ & $\frac{\overline{9}}{3}$ & 就 & 年: & 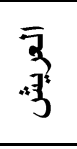 & $\begin{array}{l}3 \\
3 \\
3\end{array}$ & 翟 & $\begin{array}{ll}3 & -1 \\
3 & 2\end{array}$ & المحطة \\
\hline r rq & YYE & 114 & $r \leq$. & $r r$. & 191 & 11. & 177 & 179 & 178 & 111 & $V \cdot$ & $V \cdot$ & $0 \leq$ & \\
\hline r & r & 01 & 79 & $7 r$ & or & $\leq 9$ & $\leq 7$ & $\leqslant 7$ & $\leqslant 7$ & rr & 19 & 19 & 10 & $\%$ \\
\hline 70 & 7. & Yr & VI & 79 & rV & 17 & $r$ & $r$ & $r$ & $\leq 7-$ & $9 \leq-$ & $90_{-}$ & $11 \cdot-$ & ا. عن م. \\
\hline rrq & Yr.O & $1 \wedge \varepsilon$ & $r r \Lambda .0$ & $r Y V .0$ & 191 & $1 \wedge r$ & 179 & 177.0 & 175.0 & Ir. & $V r$ & VI & $\Delta r .0$ & الوسيط \\
\hline rry & FrY & $1 \wedge r$ & $r \leq 1$ & & 191 & $1 \wedge r$ & $|V|$ & 179 & 17 & 110 & $v r$ & 7. & $\leq 1$ & المنوال \\
\hline rq & ro & r. & r & rq & IV & $r \leq$ & $r$. & 11 & rr & $r v$ & rᄉ & rr & $\varepsilon r$ & المدى \\
\hline 111 & 91.1 & 70 & QV & $11 \%$ & rr & rv & 14.9 & 19.1 & rᄉ. $q$ & 1.0 & IrA & 117 & IrV & التباين \\
\hline $1 . .7$ & 9.0 & 1.1 & 9.9 & $1 . .7$ & $\varepsilon .1$ & 7.1 & 7.1 & $\varepsilon . \varepsilon$ & $7 . r$ & $1 . . r$ & 11.1 & $1 \cdot .1$ & 11.1 & م.1 \\
\hline 0 & $\varepsilon$ & $\varepsilon$ & $\varepsilon$ & $\bullet$ & $r$ & r. & $\varepsilon$ & $r$ & $\varepsilon$ & 9 & iv & 10 & $r$. & م.خ \\
\hline
\end{tabular}

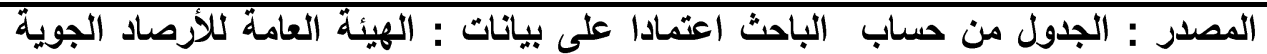

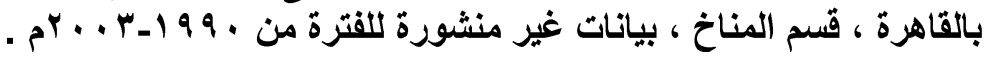

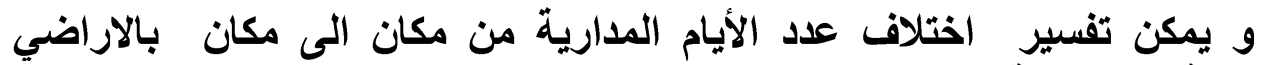

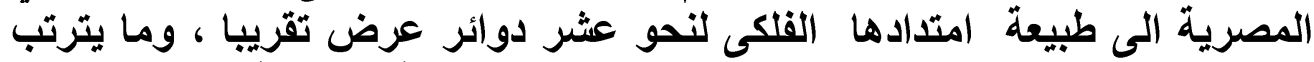

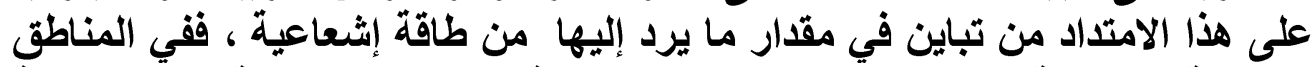

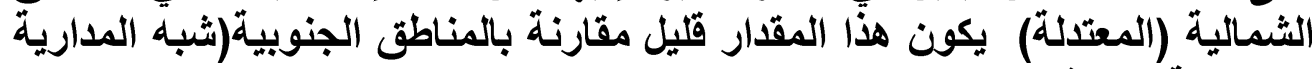

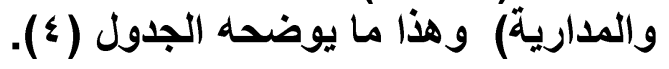

جدول (ع)تباين مجموع طاقة الإشعاع الشمسى الواردة الى الأقاليم المناخية المختلفة

\begin{tabular}{|c|c|c|c|}
\hline \multicolumn{2}{|c|}{ التباين الفصلي لطاقة الإثعاع الثمسي / الثوم) } & مجموع طاقة الإشعاع الشمسي / السنة) (كيلو & \multirow[t]{2}{*}{ |إِقليم } \\
\hline الصيف & الثتاء & المعدل السنوي & \\
\hline$\varepsilon V \cdot-\varepsilon 1 \cdot$ & $1 r \cdot .0$. & $110-1 \varepsilon$ & |المعتّل \\
\hline $0 \wedge \cdot-01$. & $19 .-11$. & $1 V \cdot-1 \leq 0$ & ثبه المداري \\
\hline $00 \cdot-r \ldots$ & $r \leq \cdot-r \mid$. & $11 \cdot-10$ & |المداري \\
\hline
\end{tabular}

Webster,C.C.,\&Wilson,P.N.,(1992) Second Ed., Agriculture in the tropics,

Longman.p.15

واعتمادا علي المعدل السنوي لعدد الأيام المدارية لبعض المناطق في الاراضي

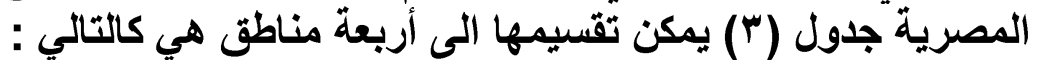




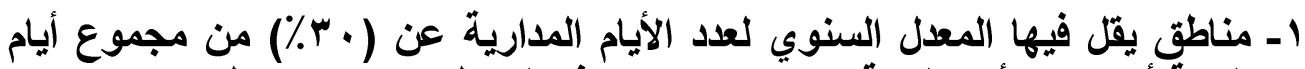

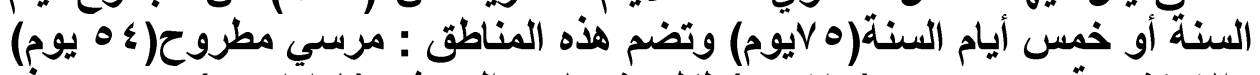

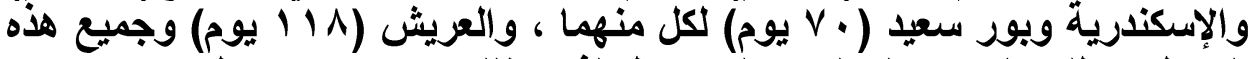

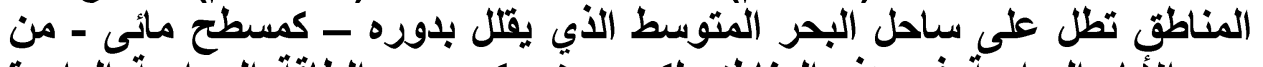

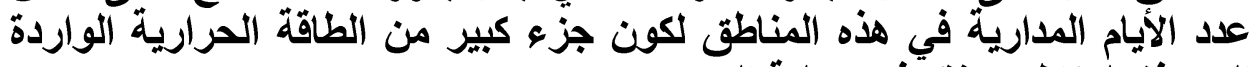

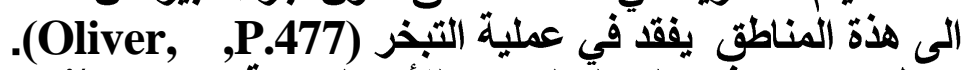

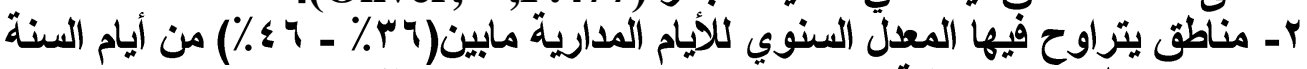

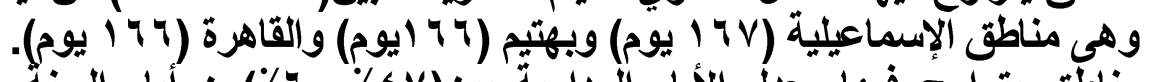

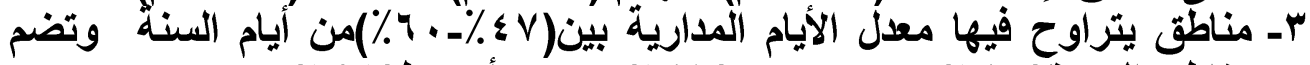

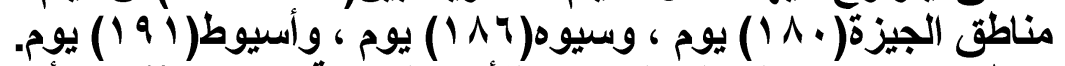

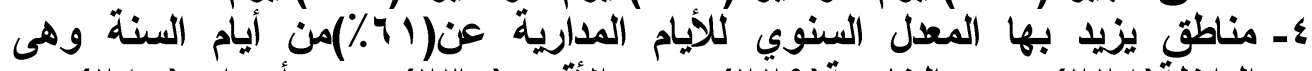

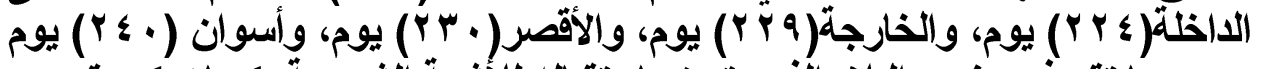

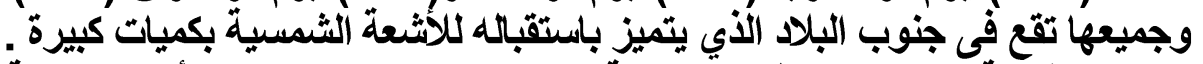

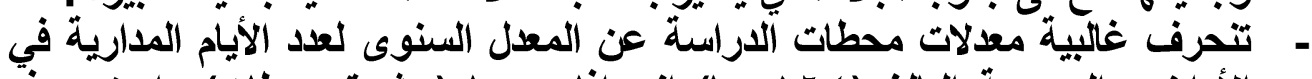

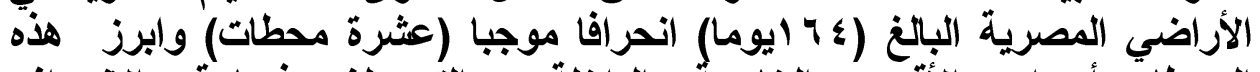

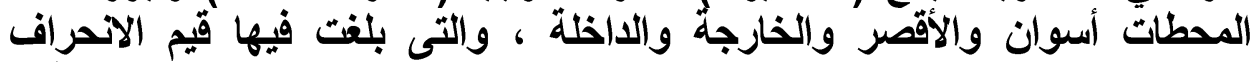

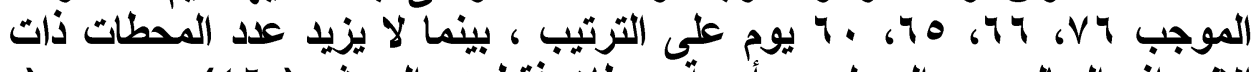

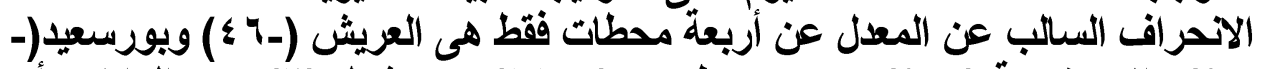

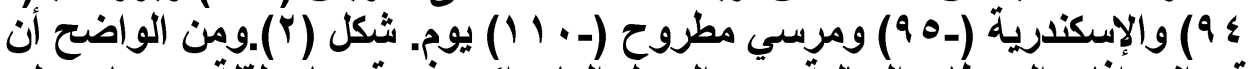

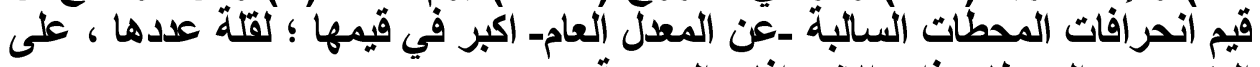
العكس من المحطات ذات الانحرافات الموجبة.

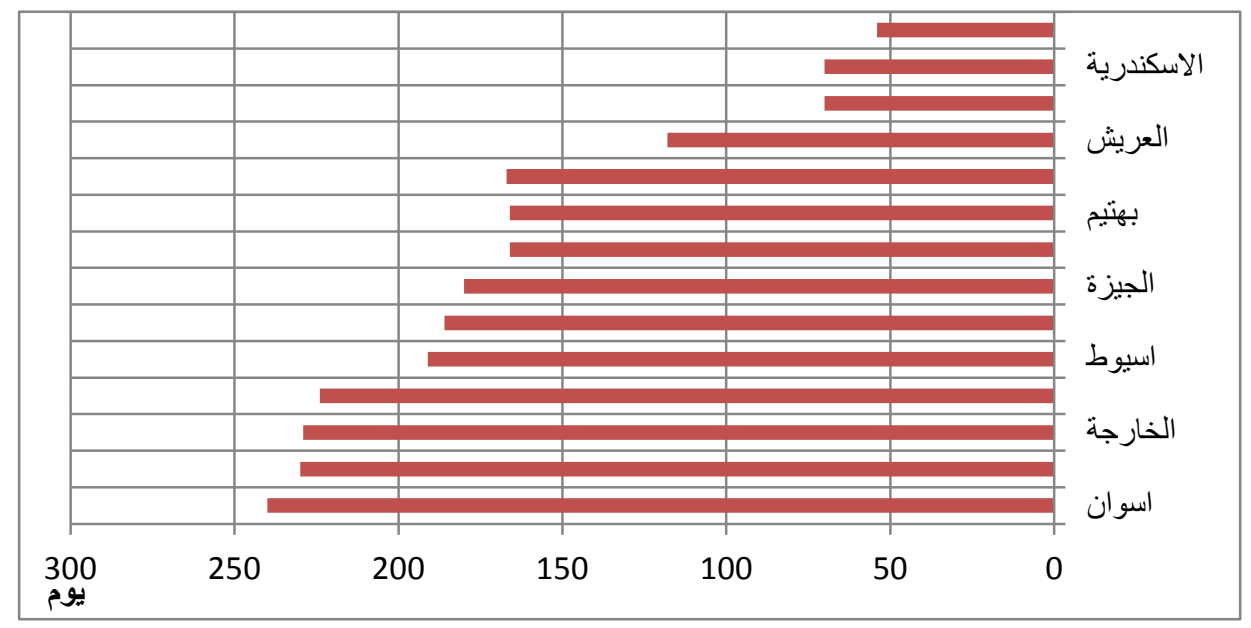

شكل( () المعدل السنوي لعدد الأيام المدارية (باليوم) في مناطق مختلفة من الاراضى المصرية الإية

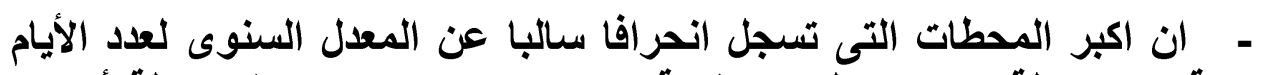

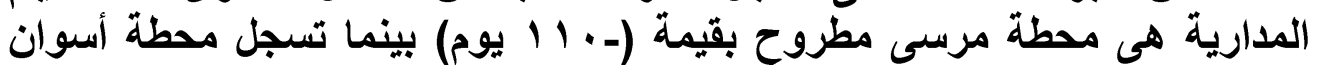




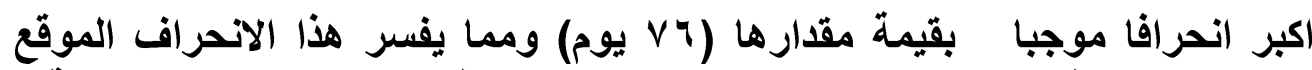

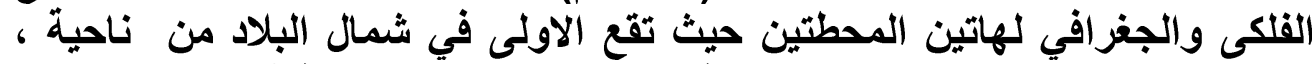

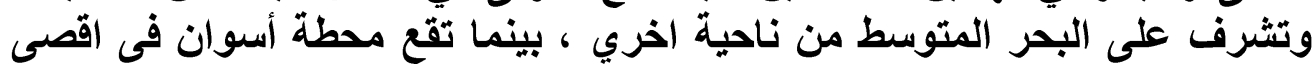

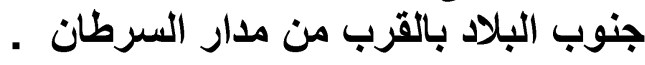

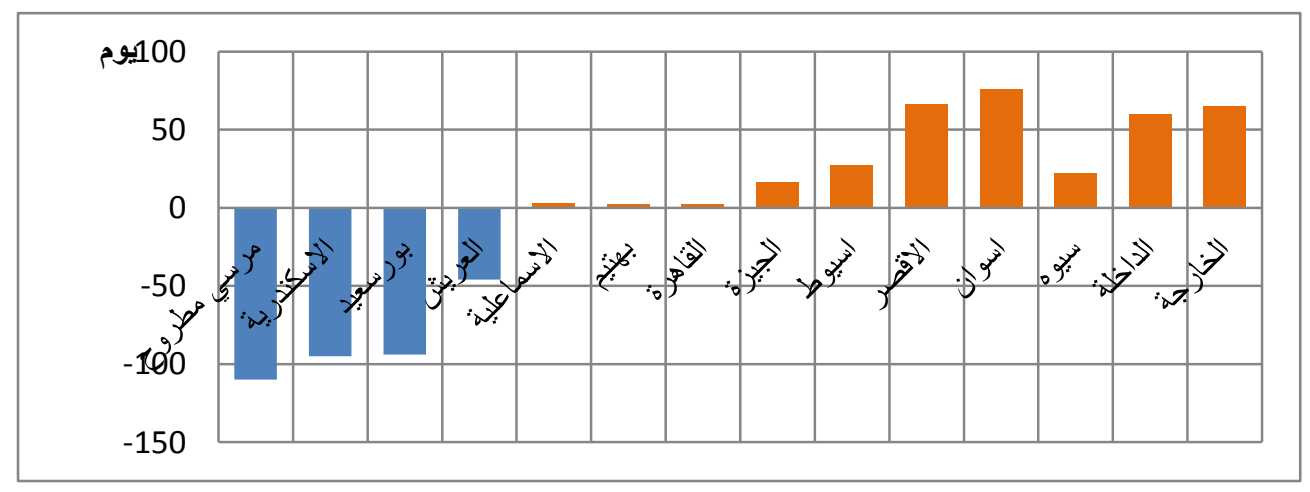

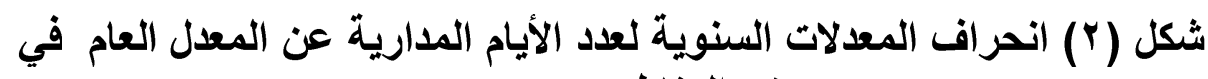

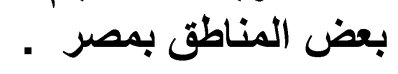

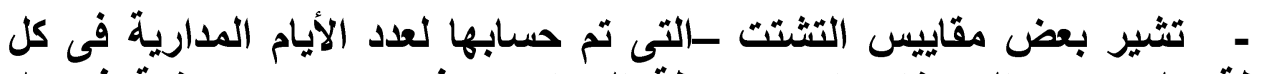

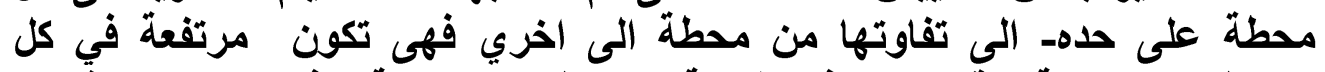

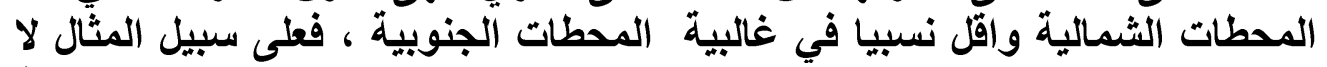

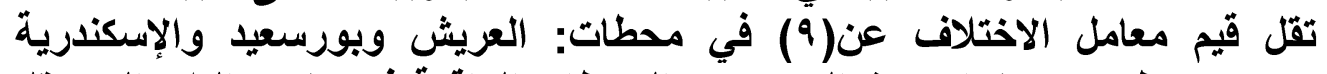

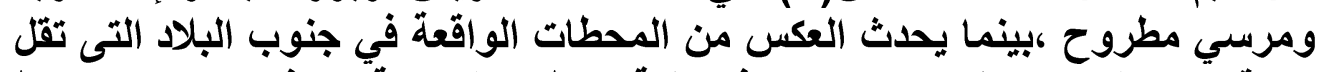

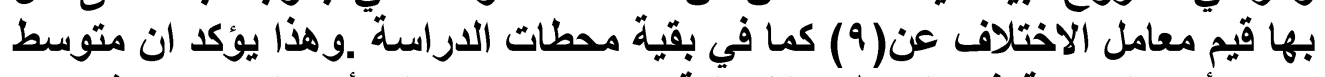

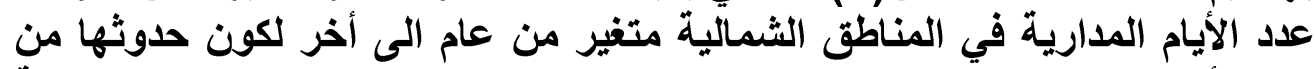

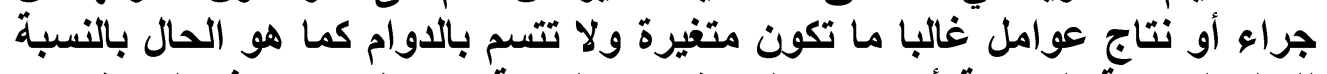

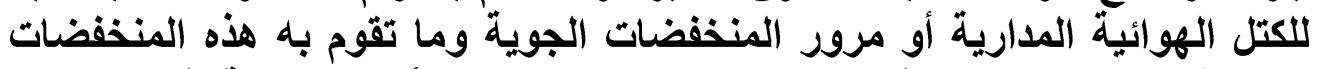

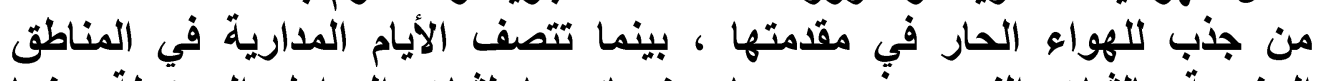

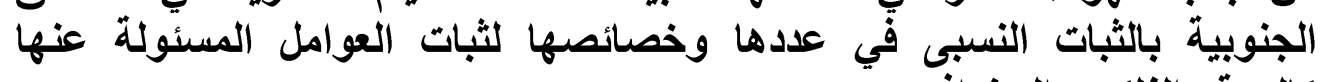

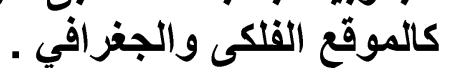

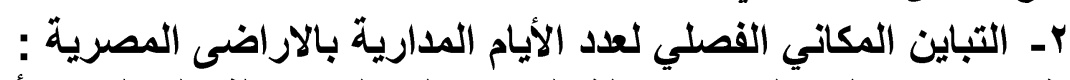

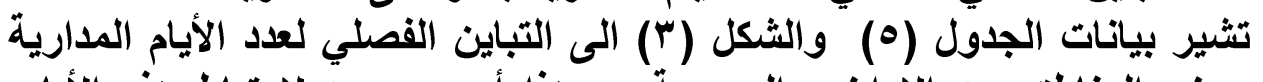

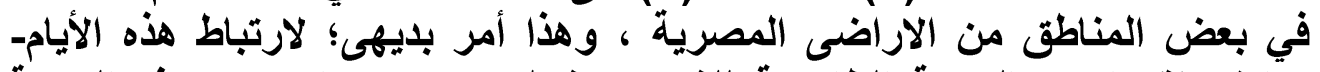

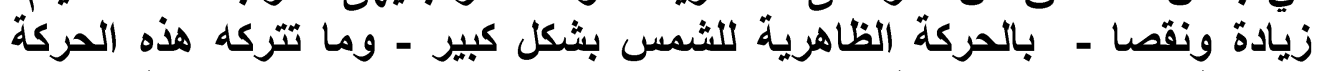

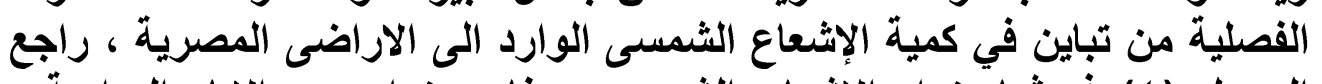

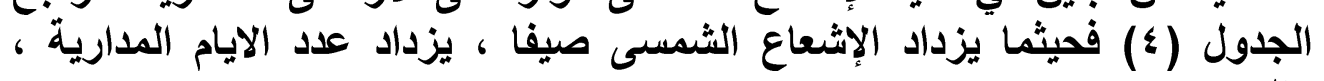

والعكس صحيح . (4) ف 
ويظهر من الجدول (0) زيادة عداد الأيام المدارية بمنطقة الاراسة خلال فترة

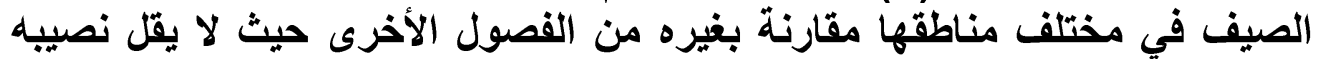

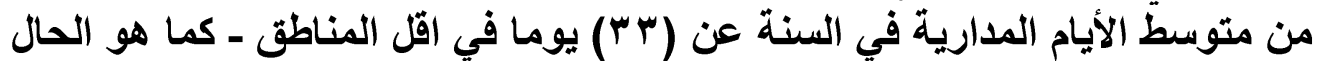

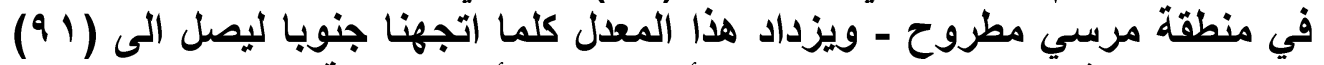

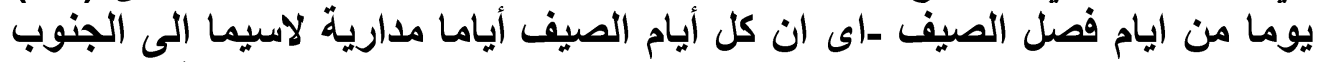

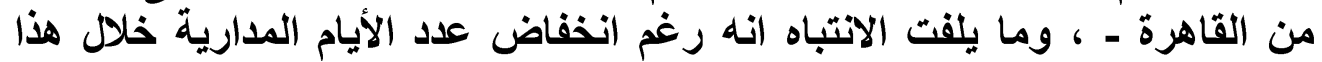

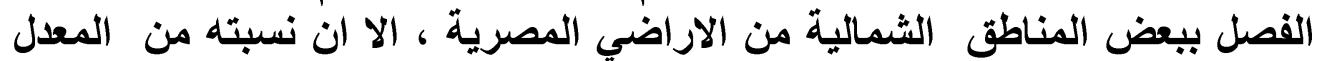

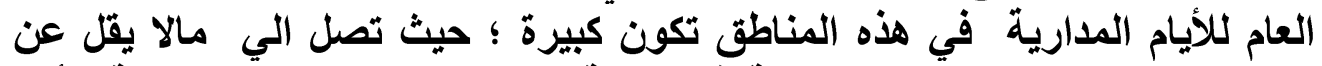

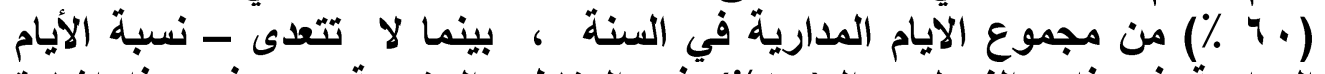

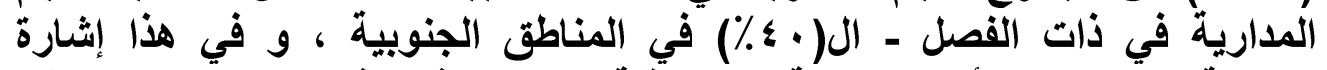

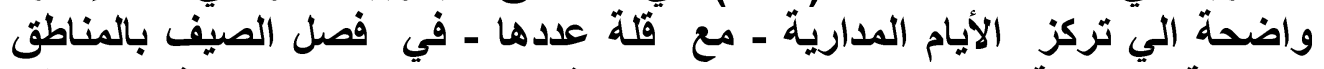

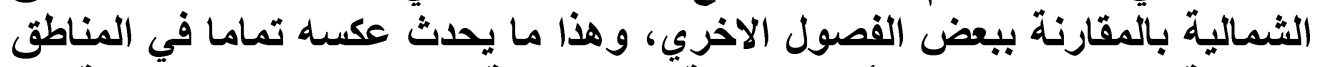

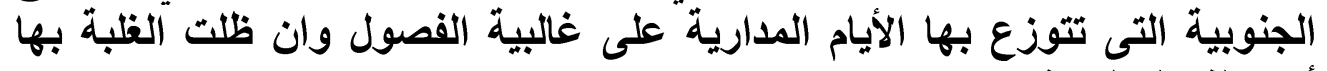

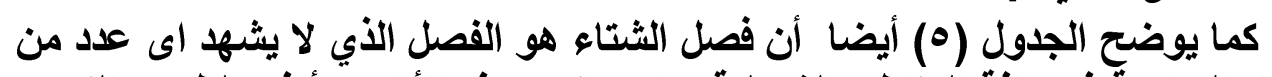

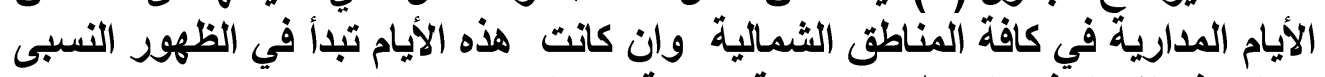

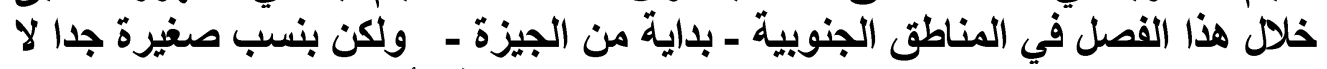

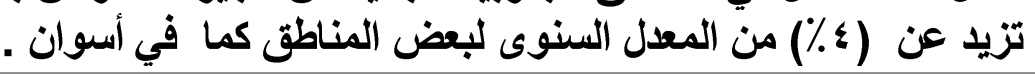

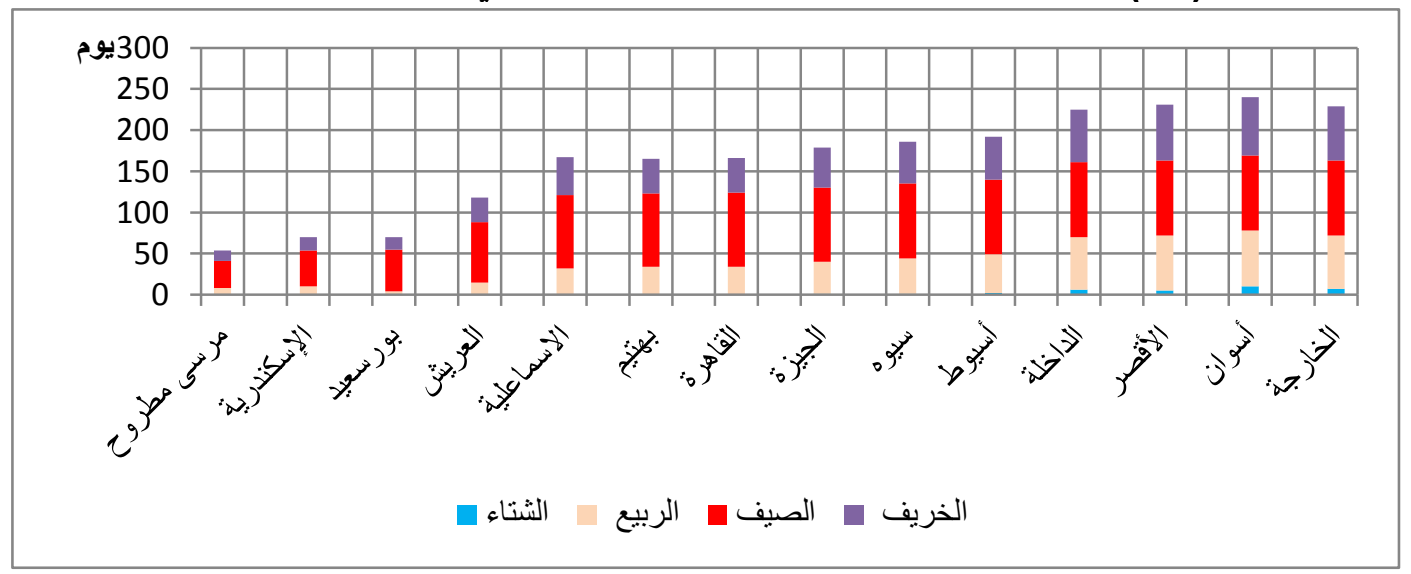

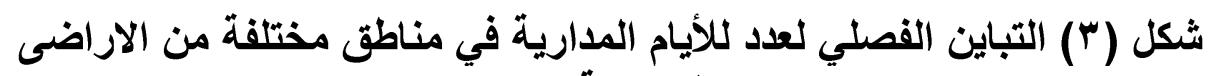

$$
\text { المصرية. }
$$

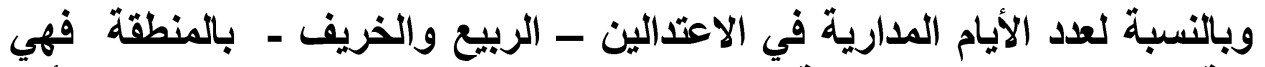

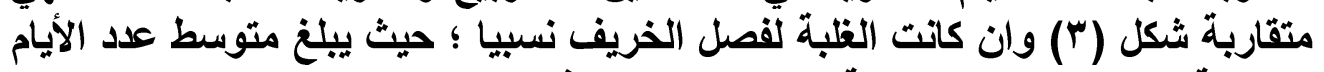

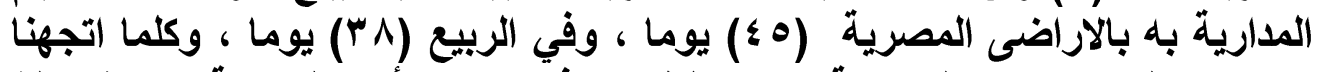

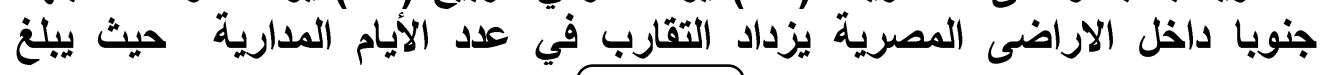


مجلة كلية الآداب، جامعة سوهاج، العدد الخامس والأربعون، الجزء الأول، أكتوبر VI + Pم

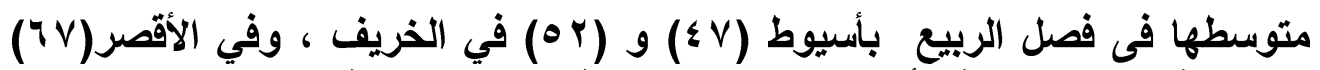

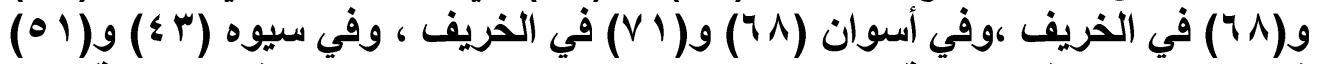

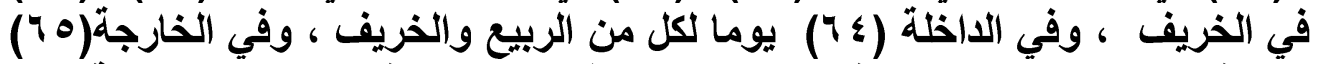

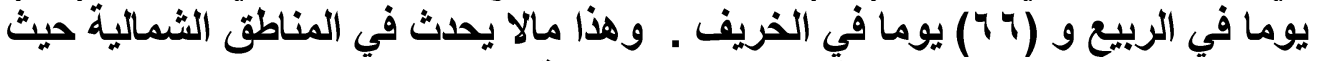
يكون الاختلاف واضحا لاسيما في المناطق الساحلية

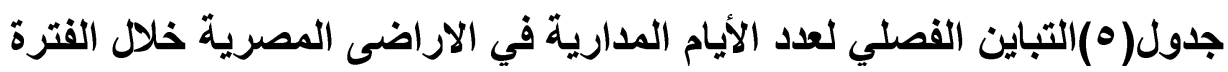
(مr..r-199.)

\begin{tabular}{|c|c|c|c|c|c|c|c|c|c|c|c|c|c|c|}
\hline 高 & 雲 & \$; & $\frac{\overline{3}}{\overline{3}}$ & 离 & \begin{tabular}{l}
$\overline{3}$ \\
\multirow{3}{*}{}
\end{tabular} & $\overline{\overline{7}}$ & 河 & 蜼 & $\begin{array}{l}\bar{x} \\
3 \\
\bar{y} \\
\bar{y}\end{array}$ & 象 & 尔 & 药 & $3-1$ & $\bar{y}$ \\
\hline$V$ & 7 & 1 & 1. & 0 & $r$ & 1 & - & . & . & . & - & . & - & الثتاء \\
\hline$r$ & $r$ & 1 & $\varepsilon$ & $r$ & 1 & 1 & . & . & . & . & . & . & . & $\%$ \\
\hline 70 & $7 \leq$ & $\leq r$ & 71 & $7 V$ & $\leq V$ & rq & $r \leq$ & $r \varepsilon$ & rr & 10 & $\varepsilon$ & 1. & $\wedge$ & الربيع \\
\hline$r \Lambda$ & $r \wedge$ & $r r$ & $r \wedge$ & rq & ro & Yr & $r$. & YI & 19 & Ir & 7 & $1 \varepsilon$ & $1 \leq$ & $\%$ \\
\hline 91 & 91 & 91 & 91 & 91 & 91 & 9. & 9. & 19 & 19 & Vr & 01 & $\leq \leqslant$ & rr & الصيف \\
\hline$\varepsilon$. & $\varepsilon$. & $\leq 9$ & $\mu \wedge$ & rq & $\leq V$ & o. & $0 \leq$ & $0 \leq$ & or & 97 & $V \mu$ & 4 & 71 & $\%$ \\
\hline 97 & $7 \leq$ & 01 & VI & 71 & or & $\leq 9$ & $\varepsilon r$ & $\varepsilon r$ & $\leq 7$ & $r$ & 10 & 17 & $1 T$ & الخريف \\
\hline rq & rq & $r \Lambda$ & $r$ & $r q$ & YV & rV & ro & ro & YV & YY & YI & $r r$ & ro & $\%$ \\
\hline rrq & YrE & 1117 & $r \leq$. & rr. & 191 & $1 \wedge$. & 179 & 179 & 178 & 111 & V. & $V$. & 0 & المعدل \\
\hline
\end{tabular}

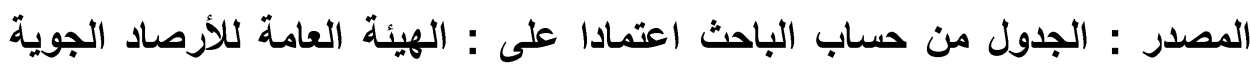

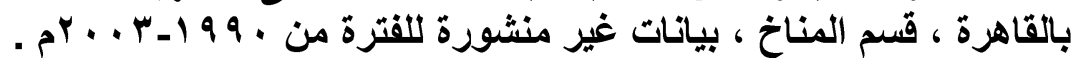

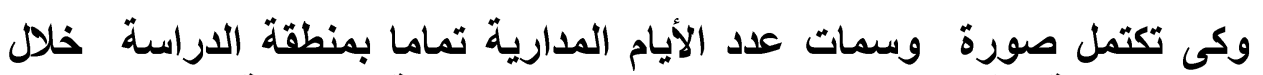

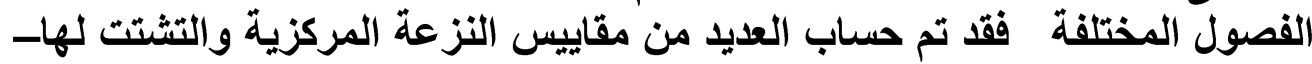

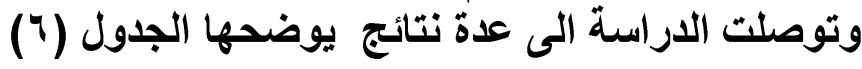


جدول (؟) التحليل الكمى لعدد الأيام المدارية خلال الفصول المختلفة في

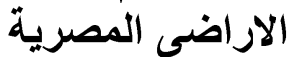

\begin{tabular}{|c|c|c|c|c|c|}
\hline الخريف & الصيف & الرابع & الشتاع & \multicolumn{2}{|l|}{ الفصل } \\
\hline 45 & 79 & 38 & 2 & المعدل & \\
\hline 48 & 90 & 37 & 1 & الوسيط & \\
\hline 42 & 91 & 34 & $\mathbf{0}$ & المنوال & \\
\hline 58 & 58 & 64 & 10 & المدى & \\
\hline 20 & 20 & 23 & 3 & الاتحراف المعياري & 9 \\
\hline 392 & 416 & 518 & 10 & التباين & \\
\hline 44 & 26 & 60 & 138 & معامل الاختلاف & \\
\hline
\end{tabular}

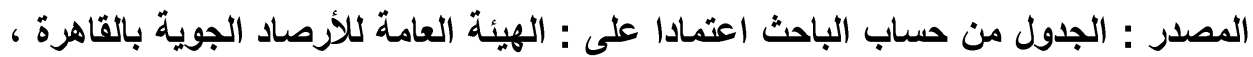

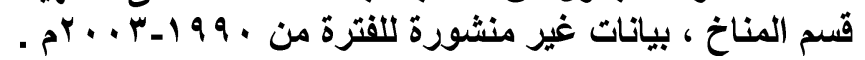

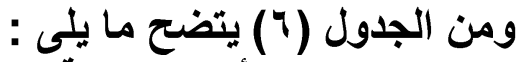

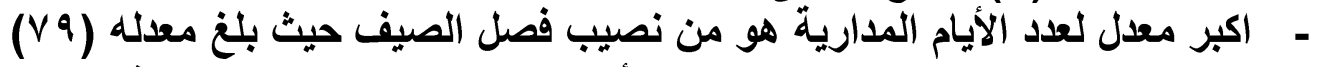

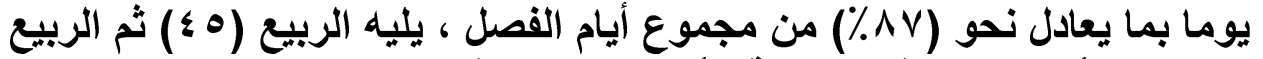

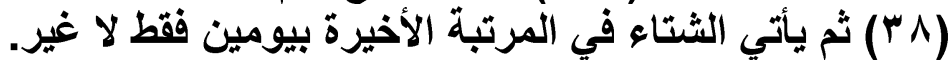

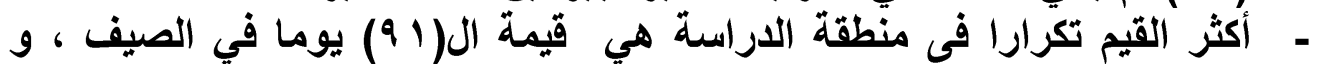

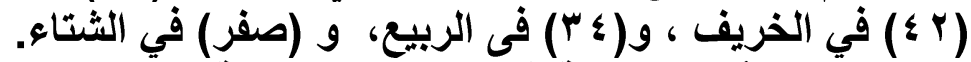

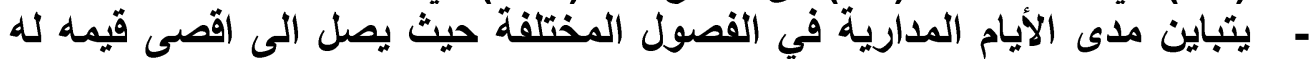

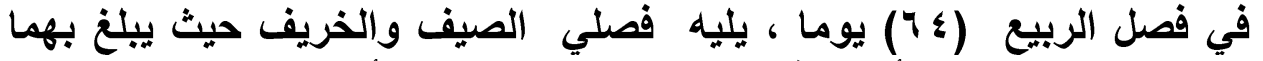

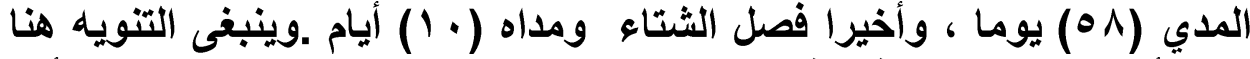

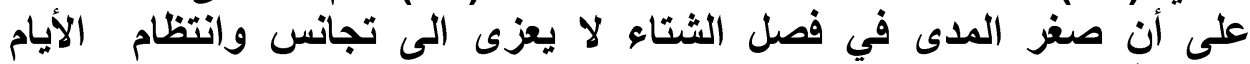

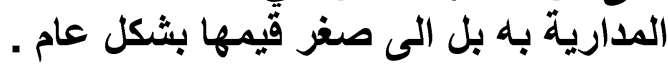

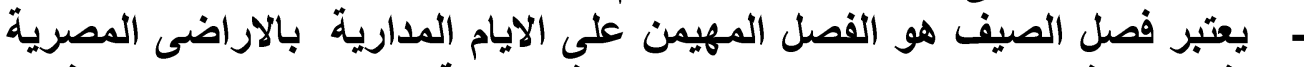

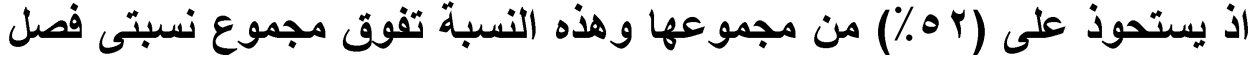

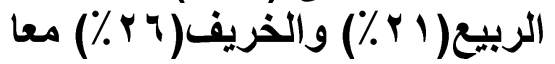

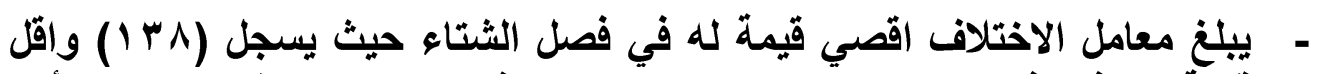

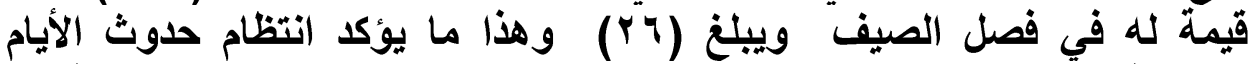

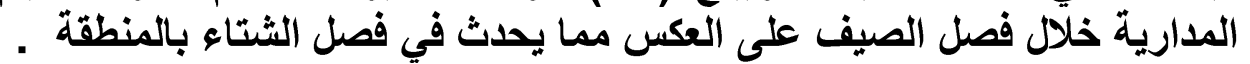




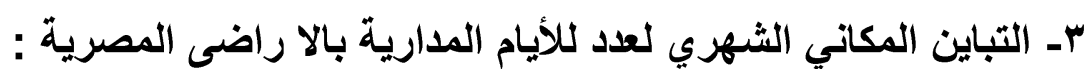

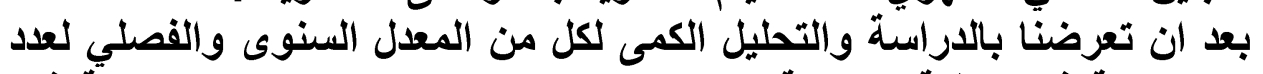

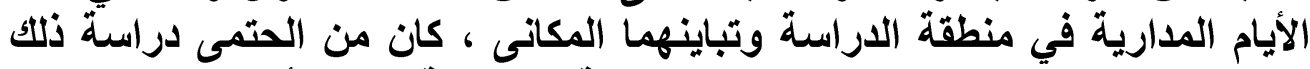

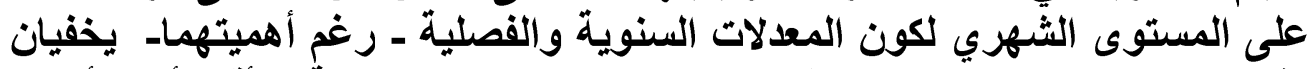

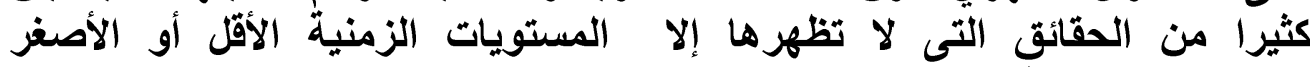

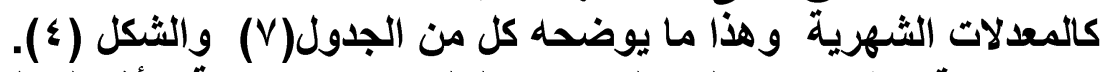

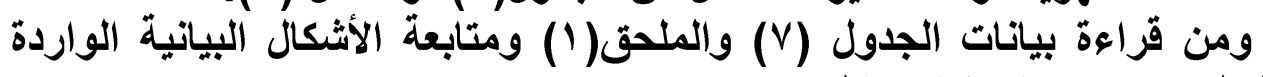

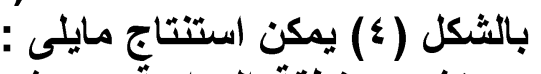

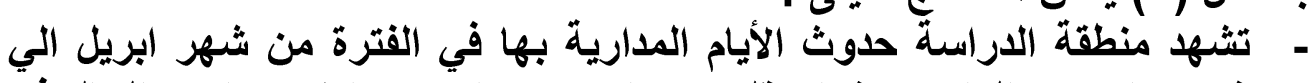

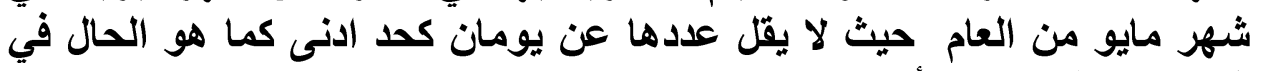

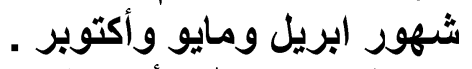
- اختلاف متوسط الأيام المدارية من شهر الى آثر آخر اذ يبلغ أقصاه في شهر

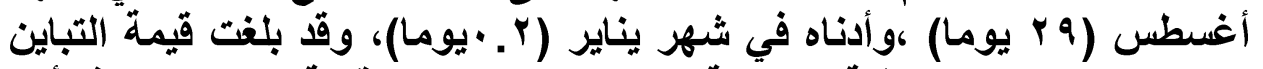

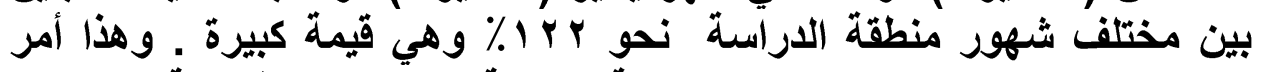

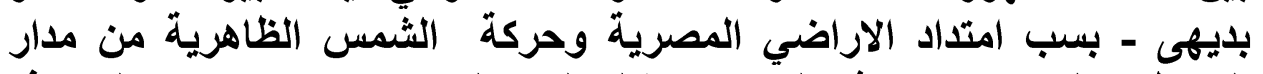

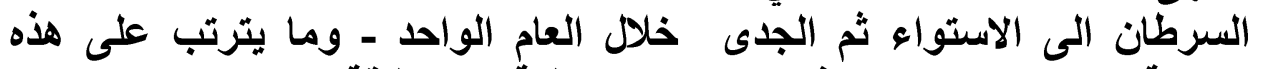

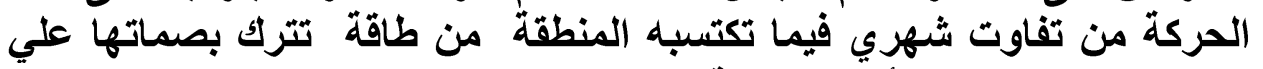

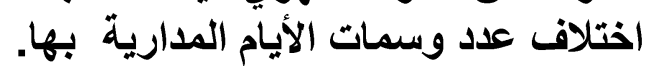

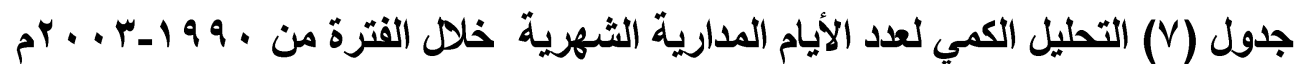

\begin{tabular}{|c|c|c|c|c|c|c|c|c|c|c|c|c|}
\hline$د$ & ن & 1 & س & 1 & ي & ي & م & 1 & p & ف & ي & الشهر \\
\hline 0.7 & 3.2 & 15.8 & 24.6 & 28.5 & 25.7 & 23.1 & 20.8 & 12.6 & 3.6 & 1.1 & 0.2 & المعدل \\
\hline 0 & 0 & 2 & 10 & 18.6 & 11 & 3 & 2 & 2 & 0 & 0 & 0 & |دني قيمة | \\
\hline 3 & 13 & 29 & 30 & 31 & 30 & 30 & 31 & 27 & 11 & 5 & 1 & قُقصية \\
\hline 3 & 13 & 27 & 20 & 12.4 & 19 & 27 & 29 & 25 & 11 & 5 & 1 & المدى \\
\hline $\mid 1.2$ & 18.5 & 85.3 & 56.0 & 18.5 & 46.6 & 105.2 & 120.3 & 83.2 & 13.4 & 3.1 & 0.2 & التباين \\
\hline 0.4 & 1.7 & 8.8 & 16.1 & 20.9 & 17.2 & 13.7 & 11.8 & 7.2 & 1.8 & 0.5 & 0.1 & \% من من \\
\hline
\end{tabular}

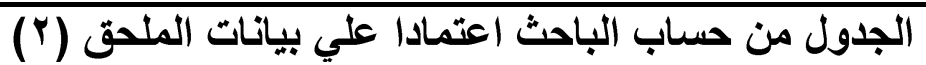

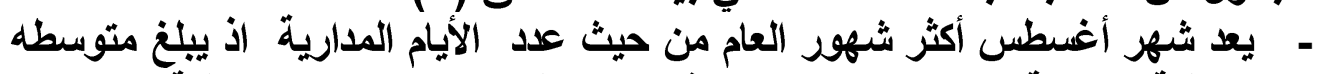

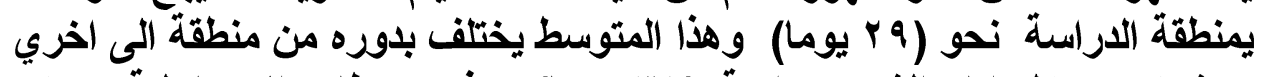

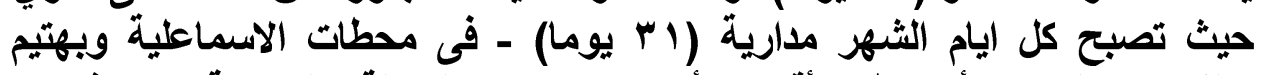

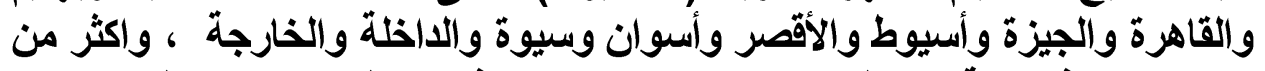

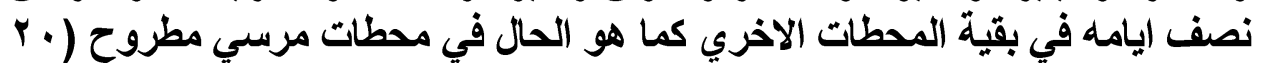




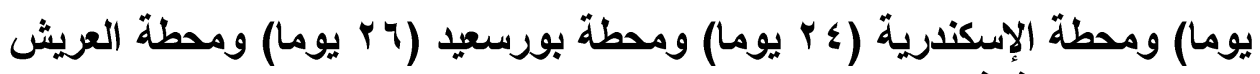

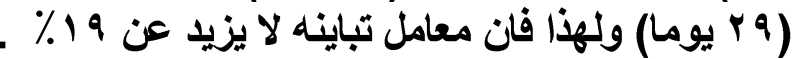

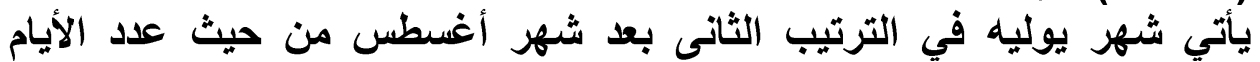

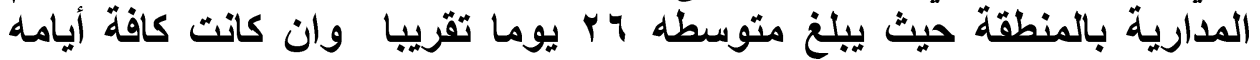

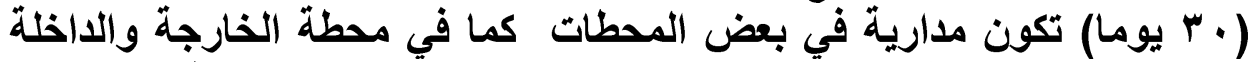

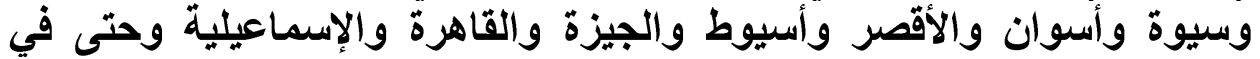

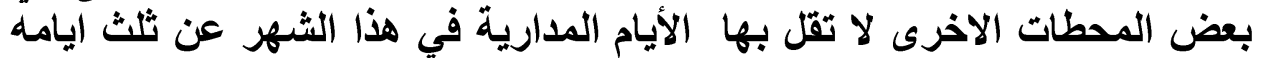

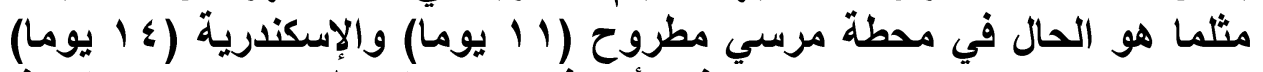

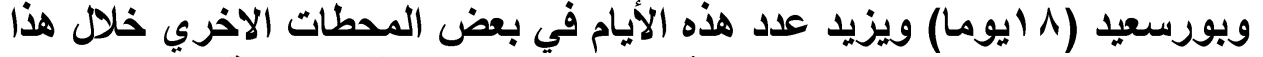

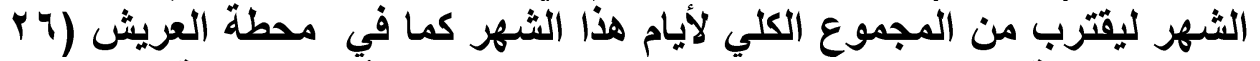

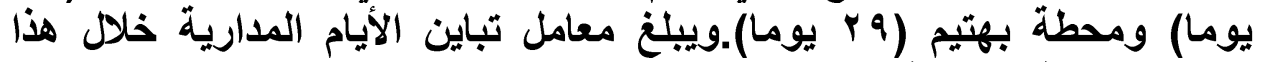

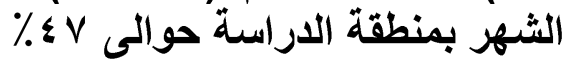

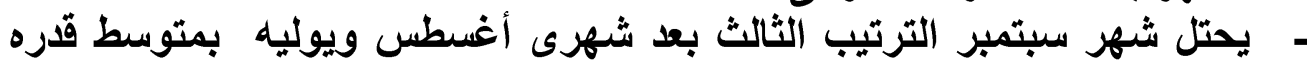

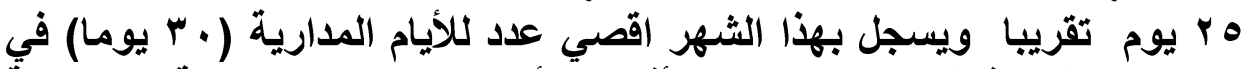

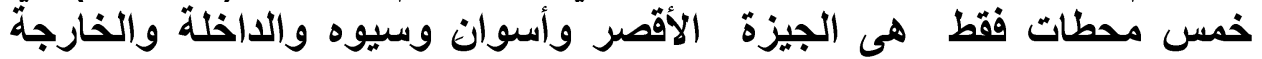
وجميعها تنمى الي مصر الوسطي واتطي والعيليا

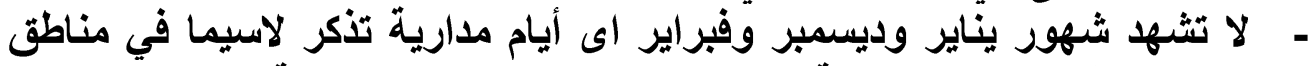

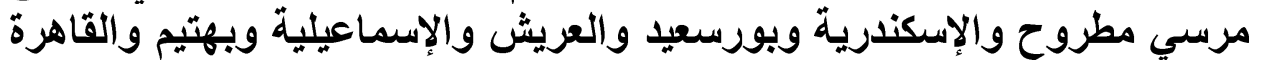

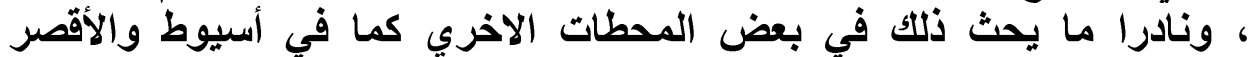

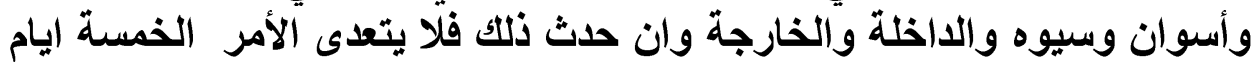

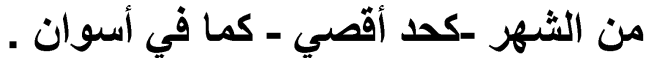

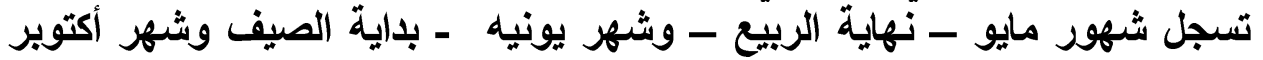

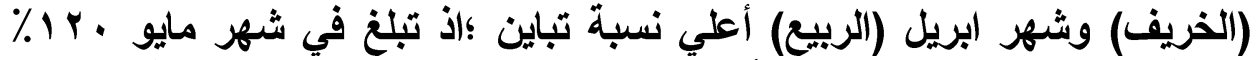

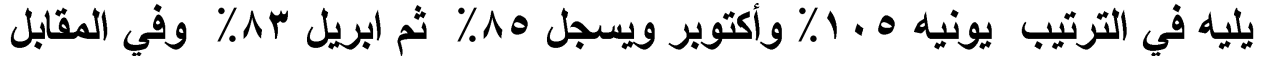

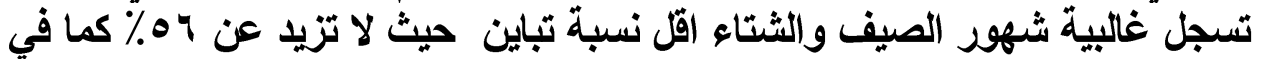

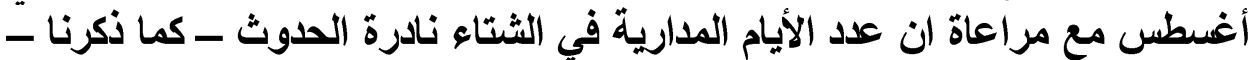

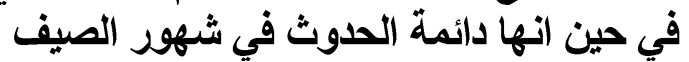

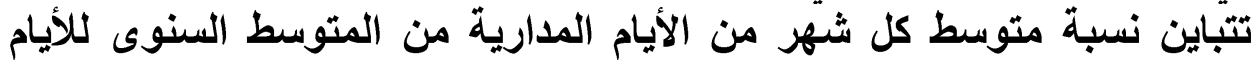

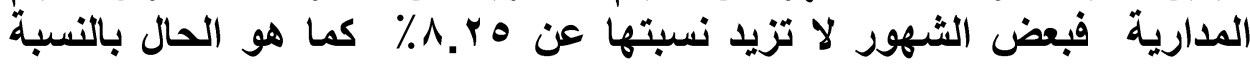

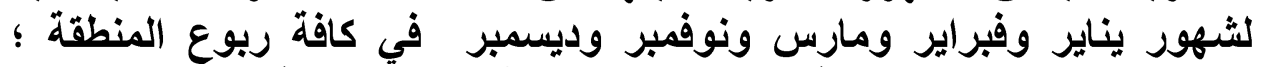

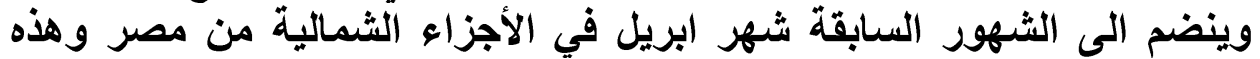

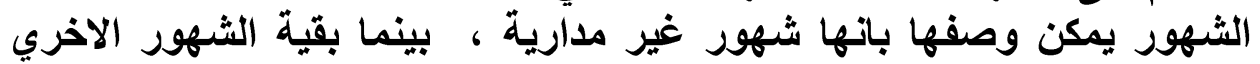

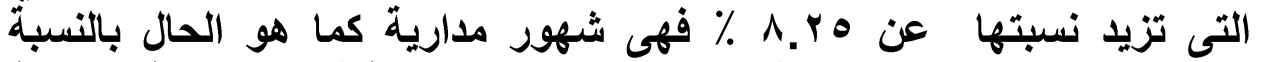

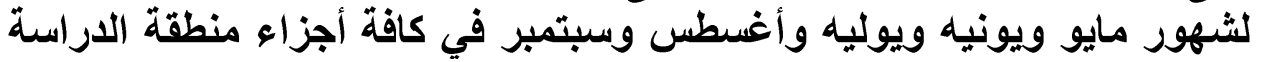

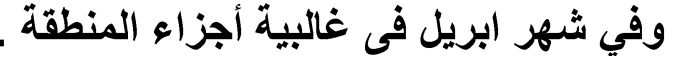


مجلة كلية الآداب، جامعة سوهاج، العدد الخامس والأربعون، الجزء الأول، أكتوبر Y P Pم

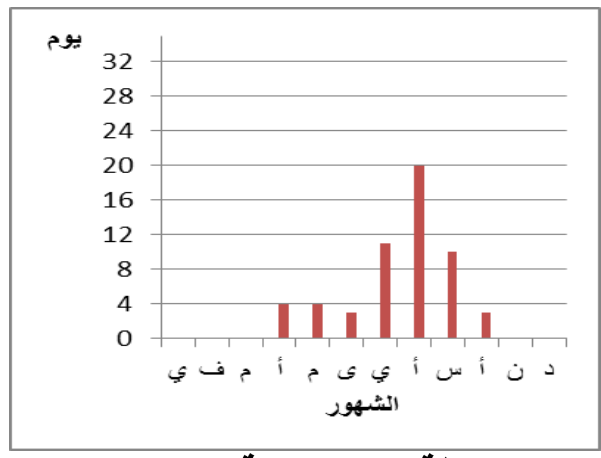

محطة الاسكندرية

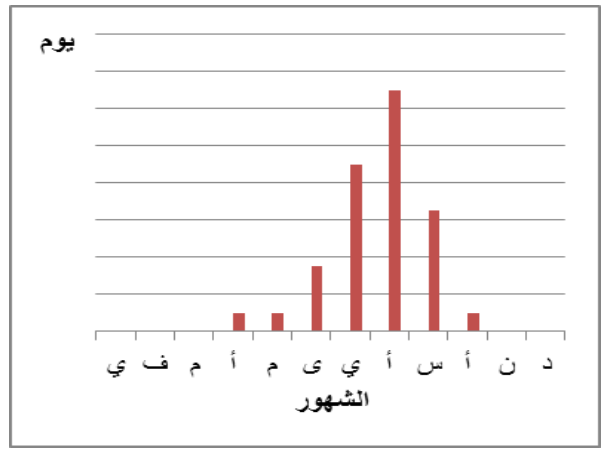

محطة الأسماعلية

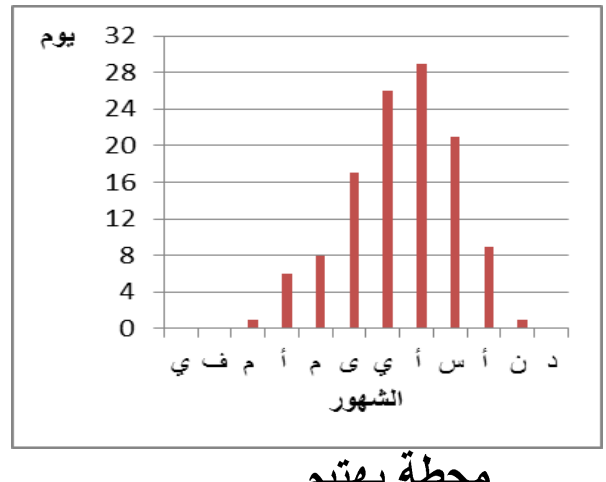

محطة بهتيم

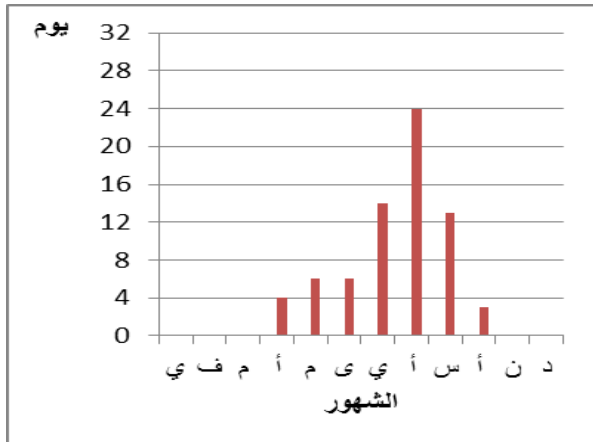

محطة مرسى مطروح

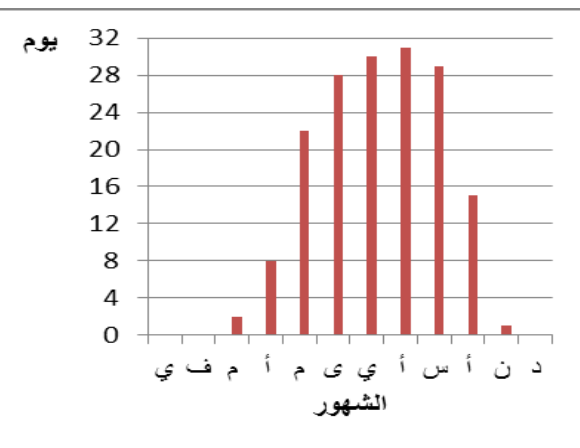

محطة بورسعيد

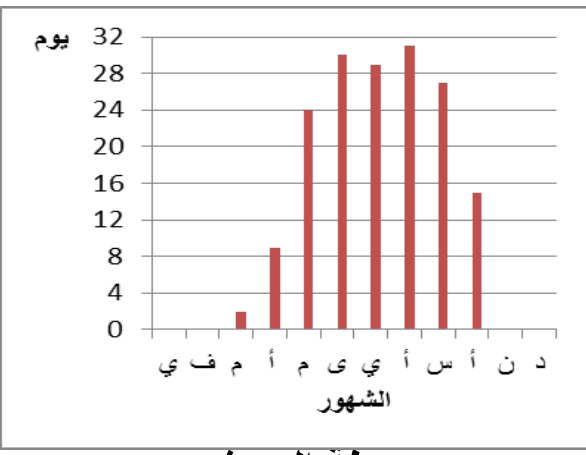

محطة العريش (ع) التوزيش الثرن

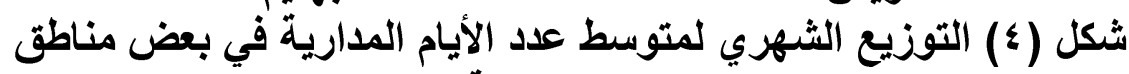
الار اضى المصرية 
الأيام المدارية في مصر دراسة مناخية

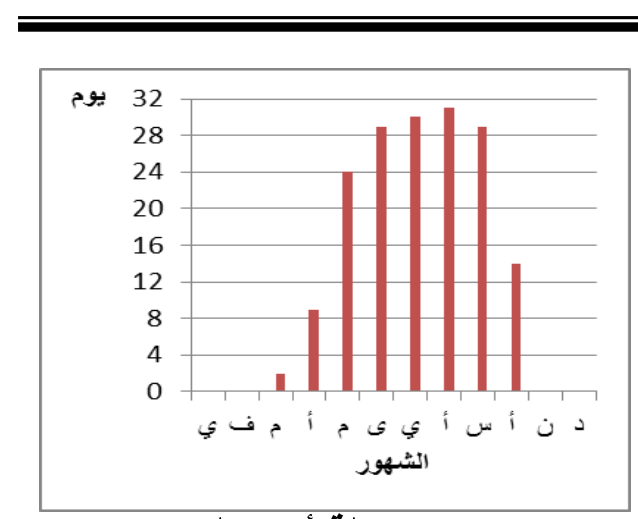

محطة أسيوط

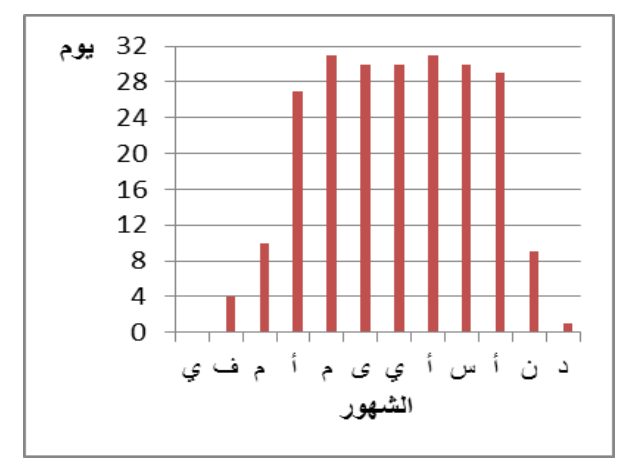

محطة سيوة

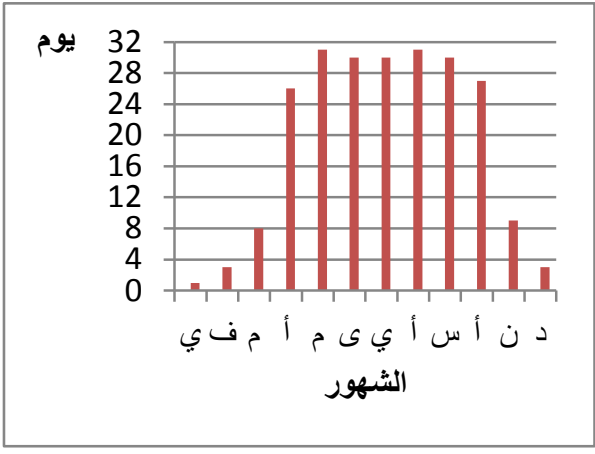

محطة اسوان

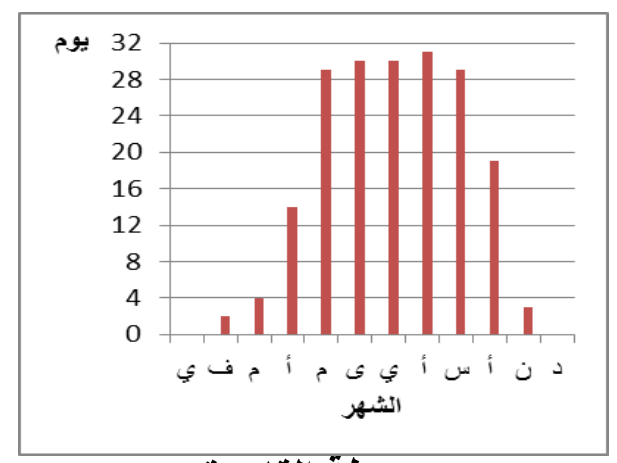

محطة القاهرة

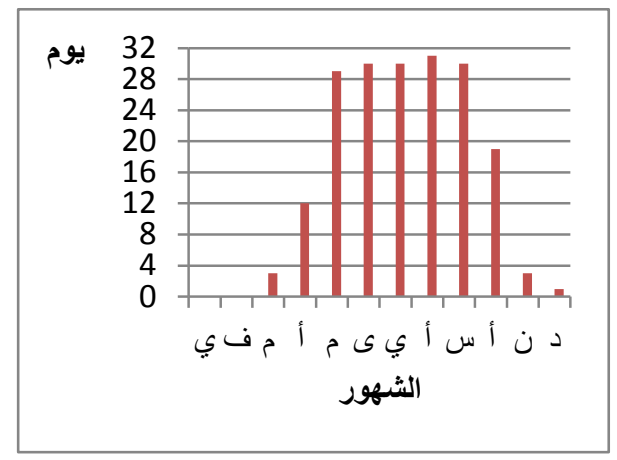

محطة الأقصر

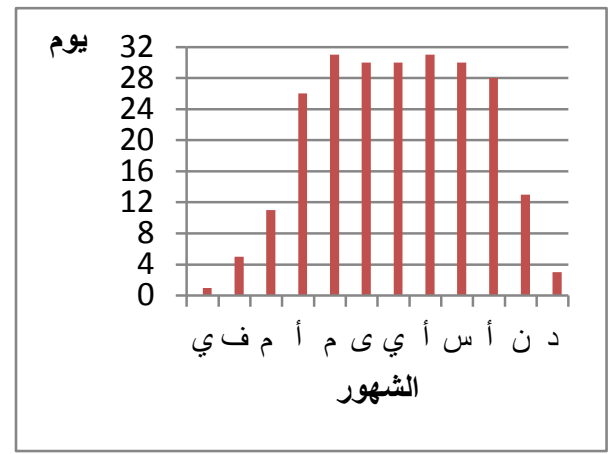

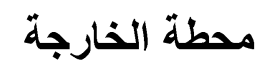

تابع شكل (؛ ) التوزيع الثهري لمتوسط عدد الأيام المدارية في بعض مناطق

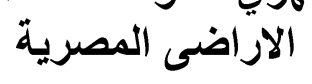

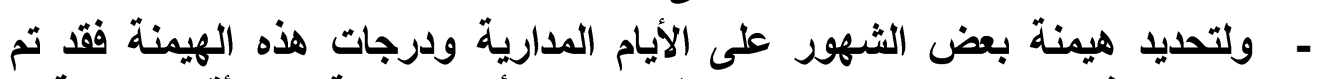

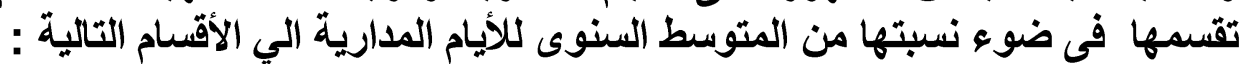

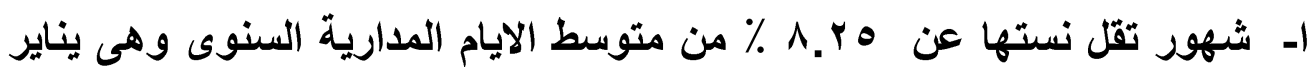

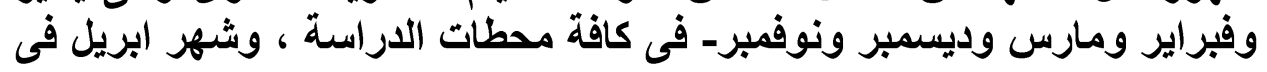


مجلة كلية الآداب، جامعة سوهاج، العدد الخامس والأربعون، الجزء الأول، أكتوبر V I P م

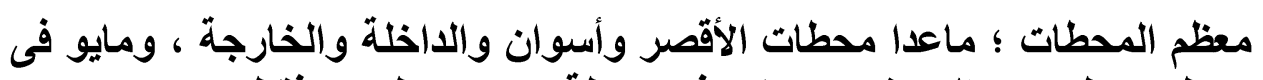

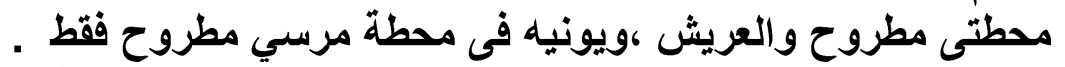

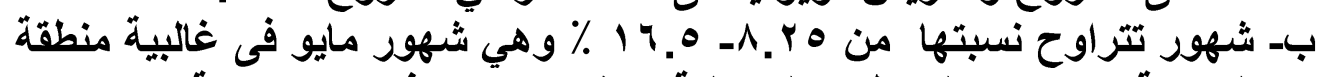

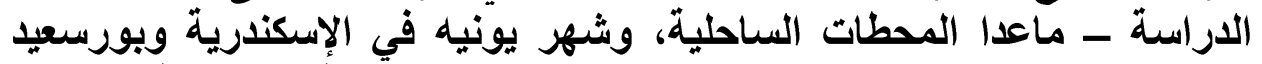

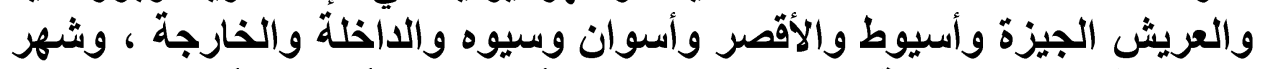

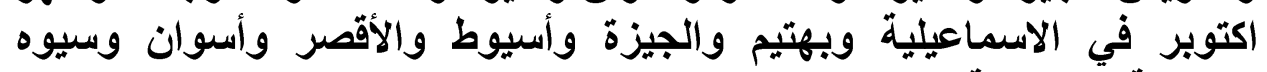

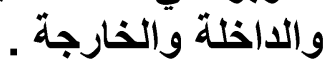
ج- شهور تتراوح نستها من ه.

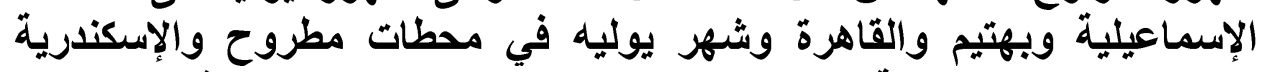

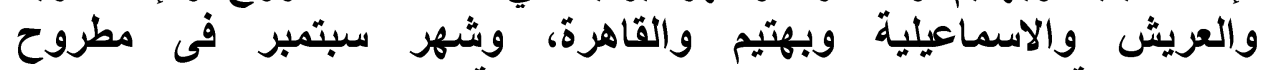

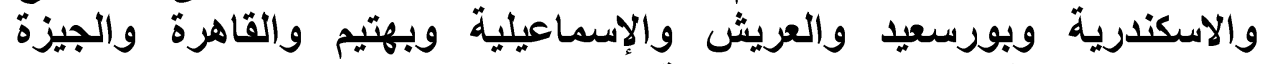

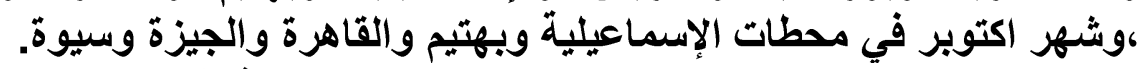

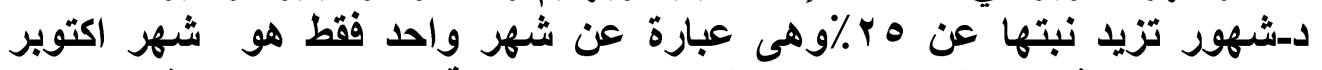

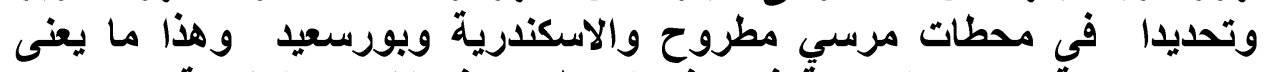

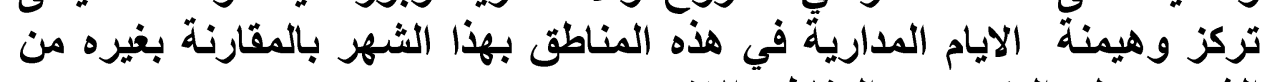

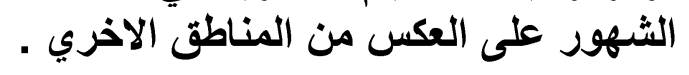

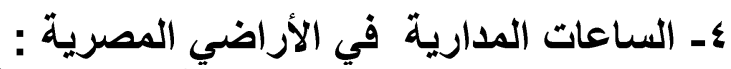

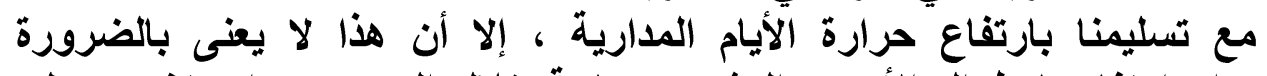

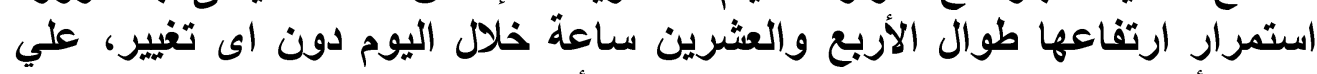

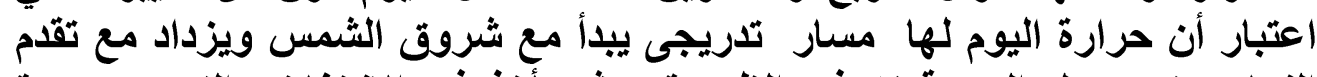

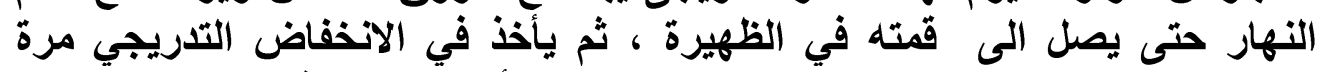

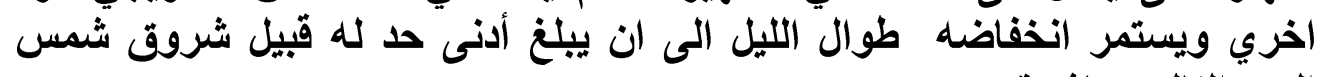

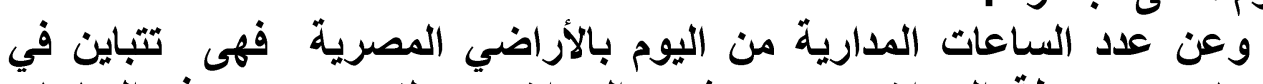

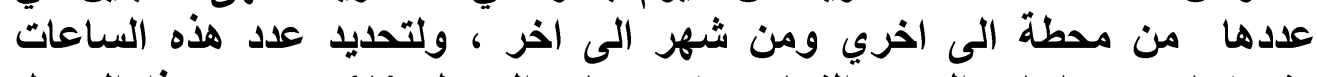

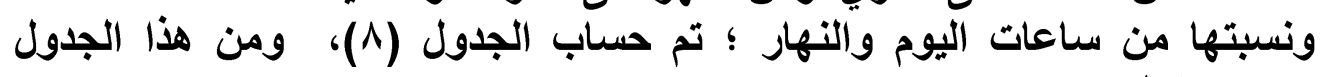

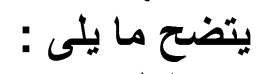

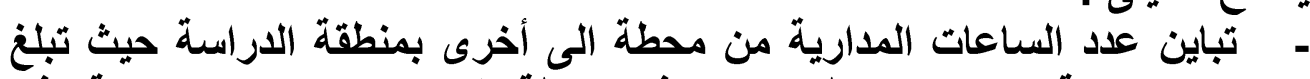

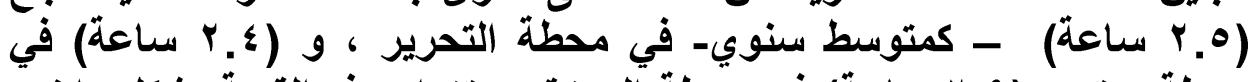

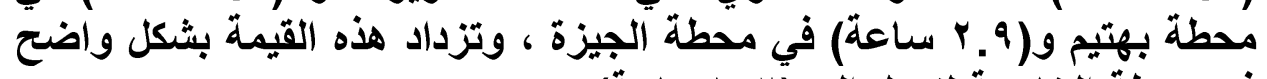

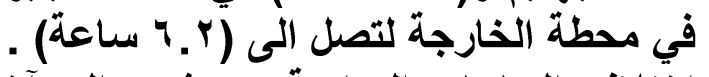

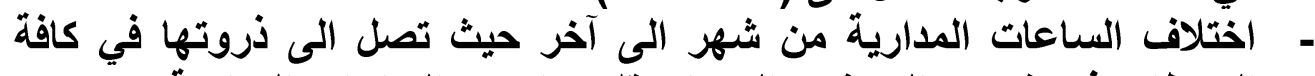

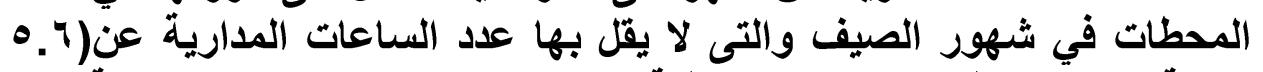

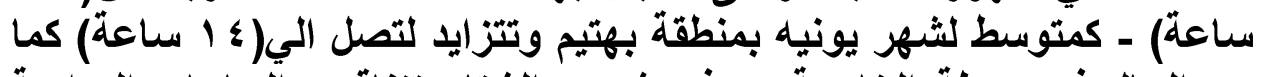

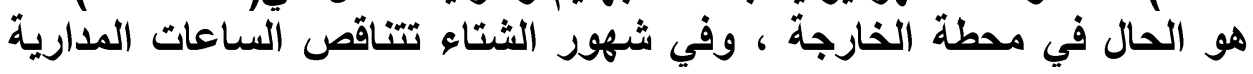


بشكل واضح حيث لا يزيد متوسطها الثهري عن (ع أ. ساعة) كما في محطة

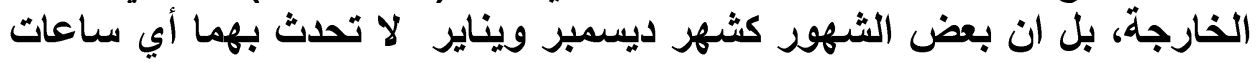

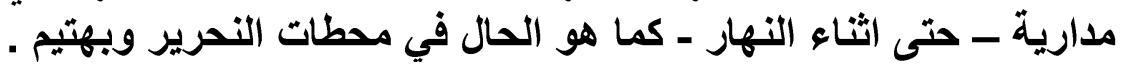

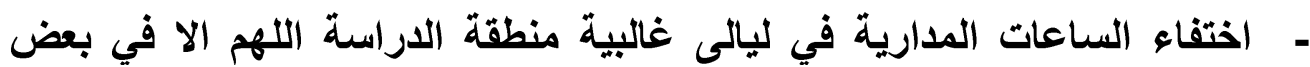

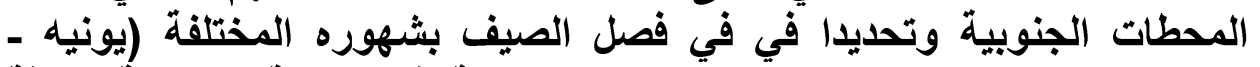

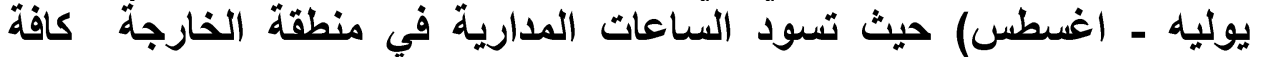

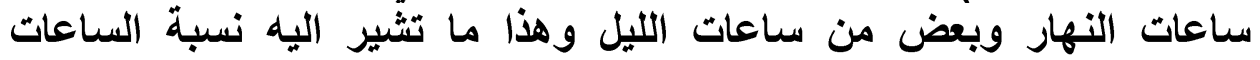

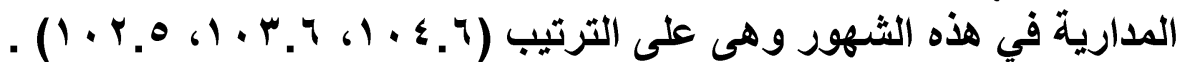

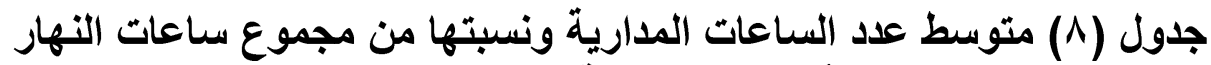

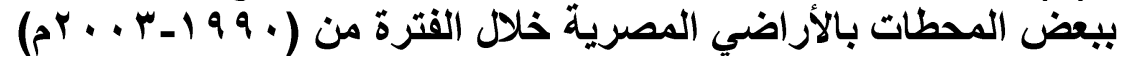

\begin{tabular}{|c|c|c|c|c|c|c|c|c|c|c|c|c|}
\hline \multicolumn{3}{|c|}{ الخارجة } & \multicolumn{3}{|c|}{ الجيزة } & \multicolumn{3}{|c|}{ بهتيم } & \multicolumn{3}{|c|}{ التحرير } & \multirow[b]{2}{*}{ الثهر } \\
\hline$\frac{3}{3}$ & $\begin{array}{l}3 \\
-3 \\
3 \\
3\end{array}$ & $\begin{array}{l}\frac{9}{7} \\
\overline{3} \\
\frac{9}{9} \\
\frac{9}{3} \\
\frac{7}{3}\end{array}$ & $\frac{3}{3}$ & $\begin{array}{l}3 \\
-3 \\
3 \\
3 \\
3\end{array}$ & $\begin{array}{l}\frac{y}{7} \\
\overline{3} \\
\frac{3}{9} \\
\frac{9}{3} \\
\frac{7}{3}\end{array}$ & $\frac{\overrightarrow{3}}{\overline{2}}$ & $\begin{array}{l}3 \\
-3 \\
3 \\
7\end{array}$ & $\begin{array}{l}\frac{9}{7} \\
\overline{3} \\
\frac{9}{9} \\
\frac{9}{3} \\
\frac{7}{7}\end{array}$ & $\frac{3}{3}$ & $\begin{array}{l}3 \\
-3 \\
3 \\
\overline{7} \\
3\end{array}$ & $\begin{array}{l}\frac{9}{7} \\
\overline{3} \\
\frac{3}{9} \\
\frac{9}{9} \\
\frac{9}{3}\end{array}$ & \\
\hline 0.4 & 0.9 & 0.1 & 0.0 & 0.0 & 0.0 & 0.0 & 0.0 & 0.0 & 0.0 & 0.0 & 0 & يناير \\
\hline 1.7 & 3.5 & 0.4 & 0.4 & 0.9 & 0.1 & 0.4 & 0.9 & 0.1 & 0.0 & 0.0 & 0 & فبراير \\
\hline 8.8 & 17.5 & 2.1 & 1.3 & 2.5 & 0.3 & 1.7 & 3.3 & 0.4 & 1.3 & 2.5 & 0.3 & مارس \\
\hline 13.3 & 25.1 & 3.2 & 7.5 & 14.0 & 1.8 & 5.0 & 9.3 & 1.2 & 5.0 & 9.3 & 1.2 & ابريل \\
\hline 44.2 & 79.4 & 10.6 & 15.0 & 26.4 & 3.6 & 12.9 & 22.7 & 3.1 & 12.5 & 21.9 & 3 & مايو \\
\hline 58.3 & 102.5 & 14.0 & 30.8 & 52.7 & 7.4 & 26.7 & 46.0 & 6.4 & 25.8 & 44.1 & 6.2 & يونيه \\
\hline 58.3 & 103.6 & 14.0 & 32.5 & 56.3 & 7.8 & 23.8 & 41.1 & 5.7 & 27.1 & 46.7 & 6.5 & يوليه \\
\hline 56.7 & 104.6 & 13.6 & 32.5 & 59.0 & 7.8 & 23.3 & 24.5 & 5.6 & 28.3 & 51.3 & 6.8 & غسطس \\
\hline 42.9 & 83.7 & 10.3 & 17.5 & 34.0 & 4.2 & 19.6 & $\mathbf{3 8 . 0}$ & 4.7 & 18.3 & 35.6 & 4.4 & سبتمبر \\
\hline 22.5 & 46.7 & 5.4 & 7.5 & 15.7 & 1.8 & 6.7 & 14.0 & 1.6 & 6.7 & 14.0 & 1.6 & أكتوبر \\
\hline 3.8 & 8.2 & 0.9 & 0.8 & 1.9 & 0.2 & 0.4 & 0.9 & 0.1 & 0.4 & 0.9 & 0.1 & نوفمبر \\
\hline 0.4 & 0.9 & 0.1 & 0.4 & 1.0 & 0.1 & 0.0 & 0.0 & 0.0 & 0.0 & 0.0 & 0 & ليسمبر \\
\hline 25.8 & 51.0 & 6.2 & 12.1 & 23.8 & 2.9 & 10.0 & 18.5 & 2.4 & 10.4 & 20.5 & 2.5 & المعل \\
\hline
\end{tabular}

المصدر : الجدول من حساب الباحث اعتمادا على : الهيئة العامة للارصاد الجوية بالقاهرة ، قسم

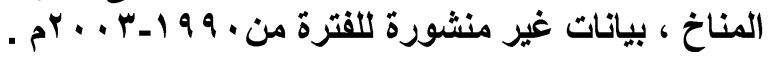




\section{مجلة كلية الآداب، جامعة سوهاج، العدد الخامس والأربعون، الجزء الأول، أكتوبر Y P P}
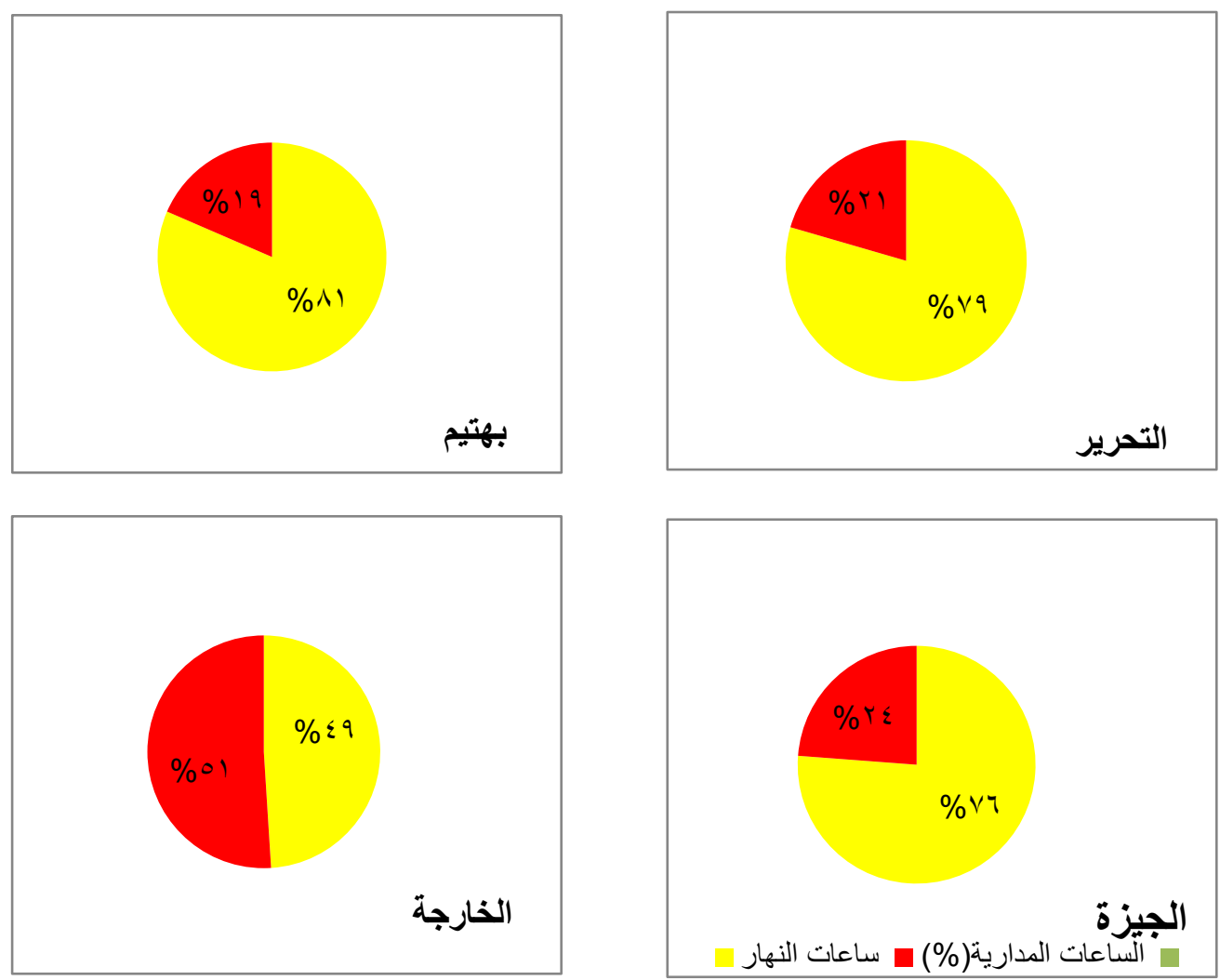

شكل (0) نسبة الساعات المدارية من مجموع ساعات النهار في بعض محطات

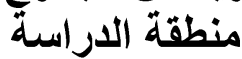

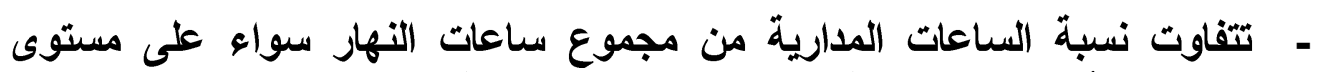

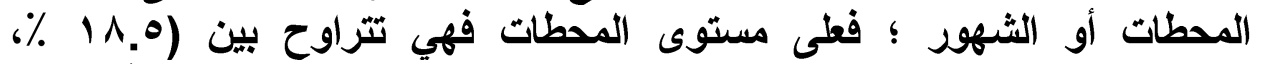

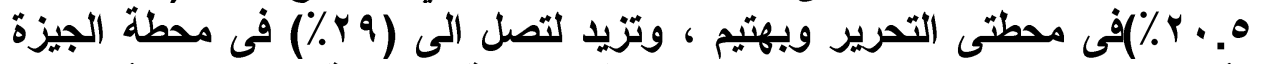

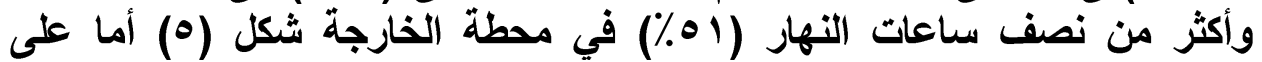

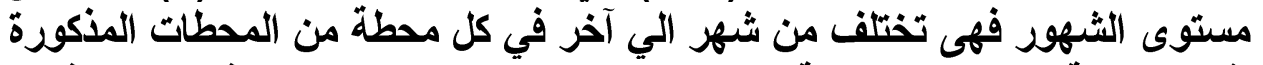

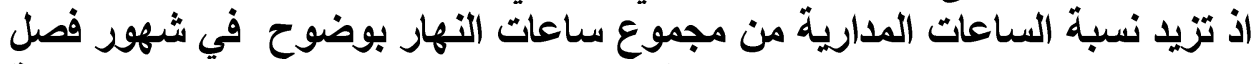

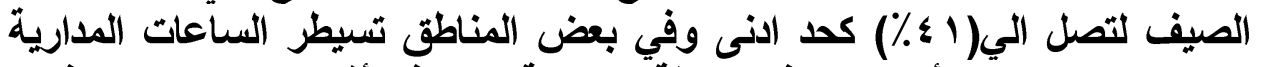

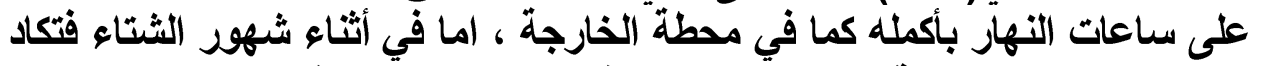

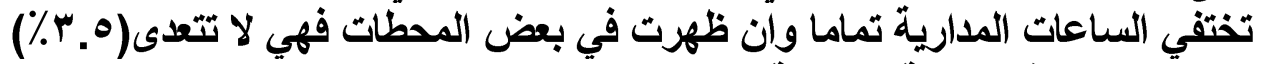
من التهار كما في محطة الخارجة 
المبحث الثاني : السمات الهرارية للأيام المدارية في الاراضى المصرية:

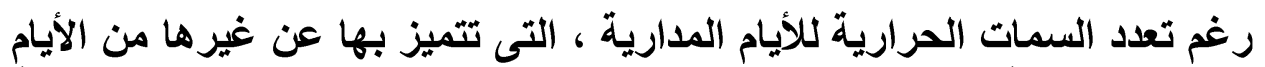

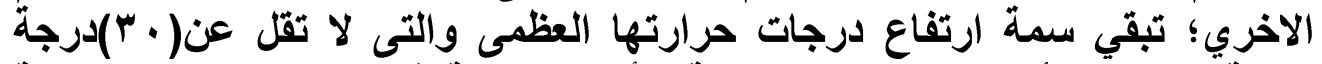

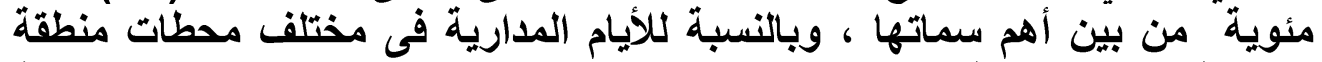

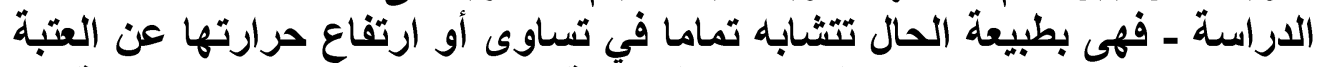

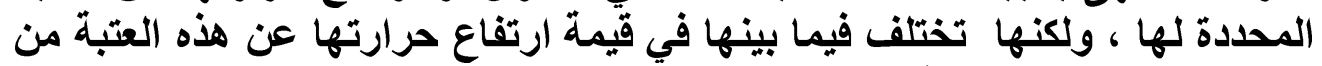

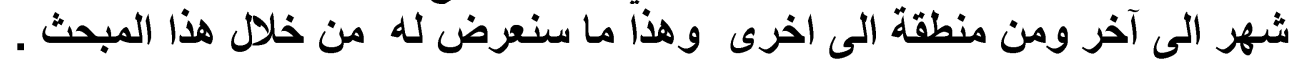

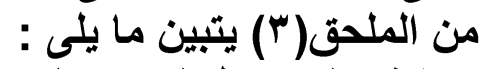

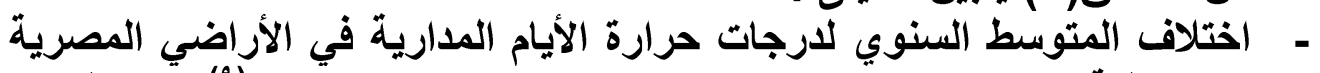

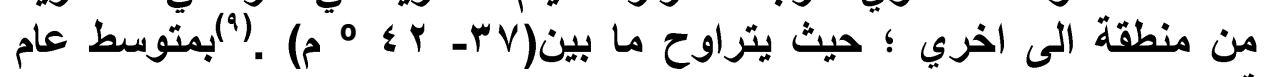

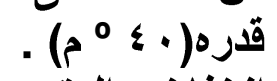
- انخفاض المتوسط السنوي لحرارة الأيام المدارية في مناطق مرسى مطروح

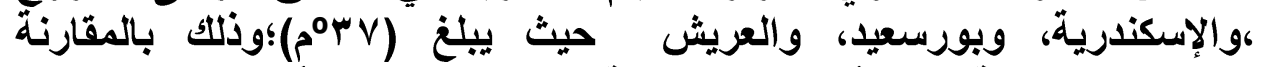

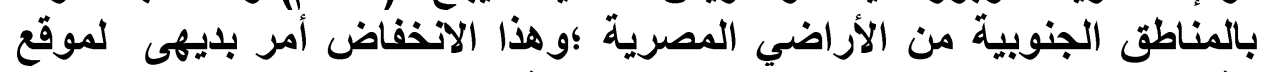

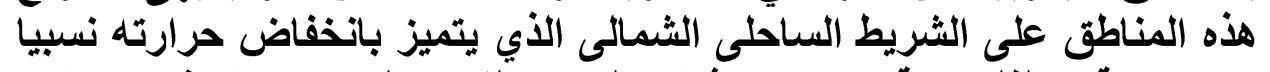

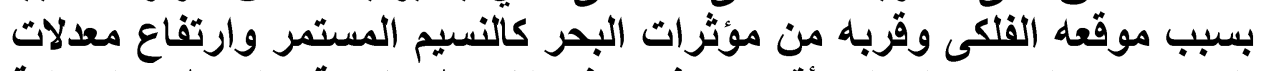

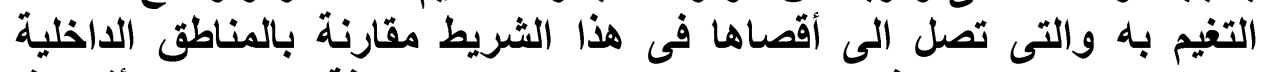

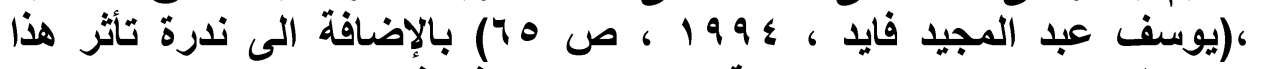

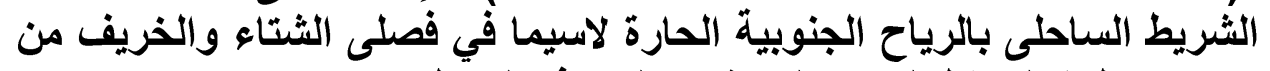

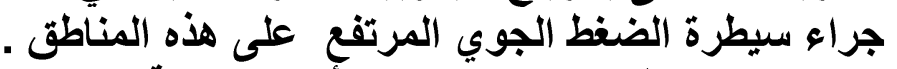

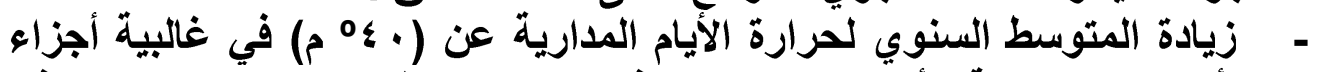

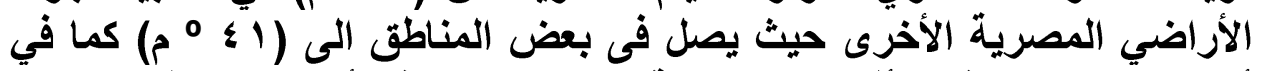

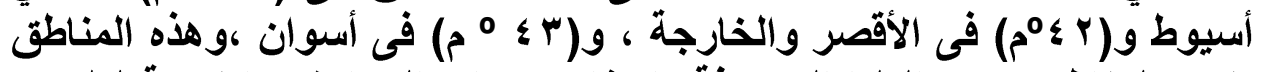

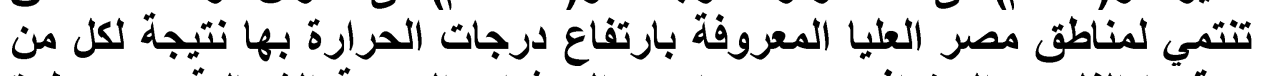

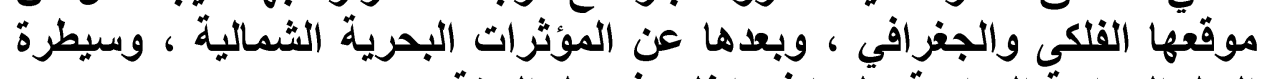

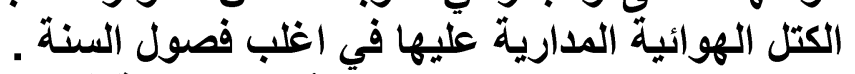

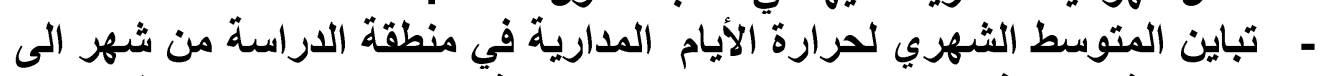

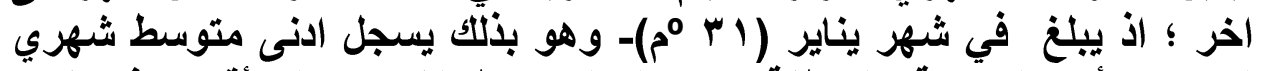

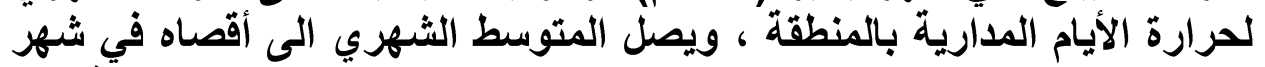

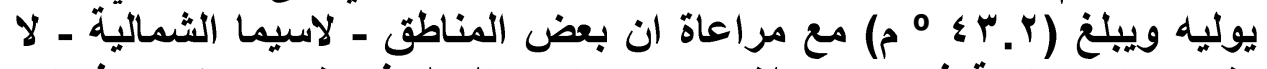

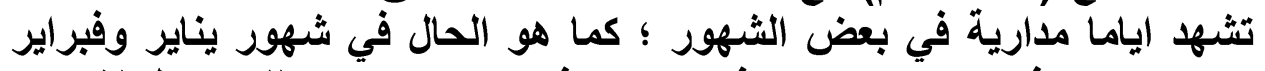

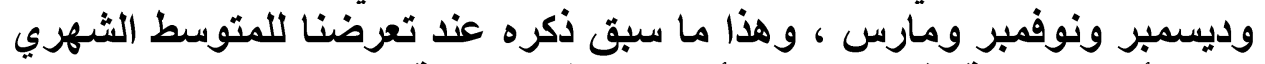

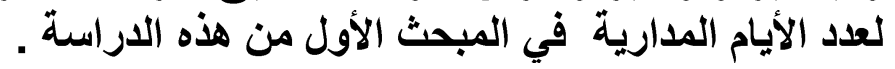

(9) تم حساب متوسط درجة حرارة الايام الددارية من خلال تحليدها اولا ثم جمع قيمها وقسمتها على rVo 
مجلة كلية الآداب، جامعة سوهاج، العدد الخامس والأربعون، الجزء الأول، أكتوبر Y I P م

- تتجانس حرارة الأيام المدارية على امتداد الاراضى المصرية في نصف السنة

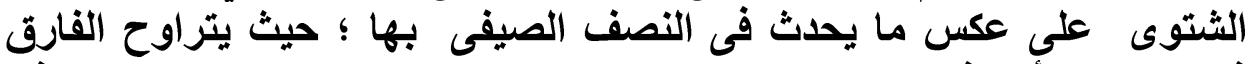

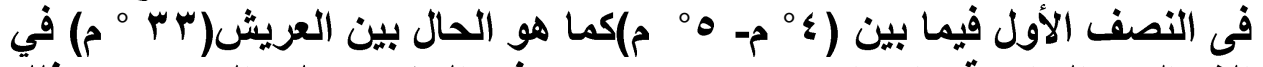

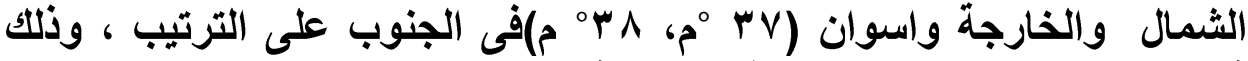

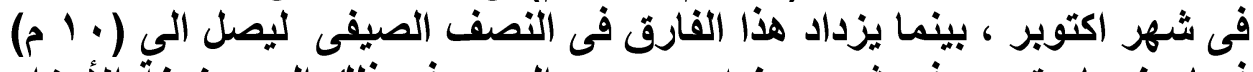

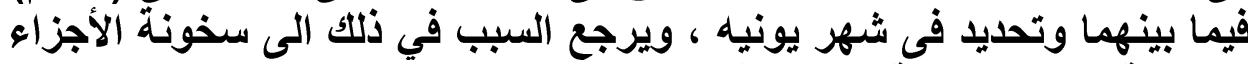

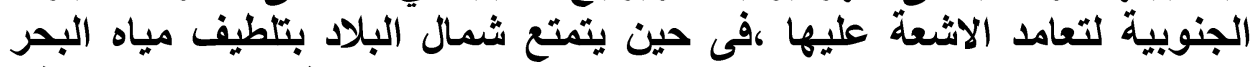

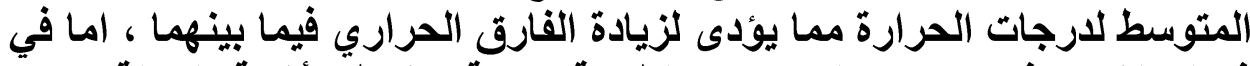

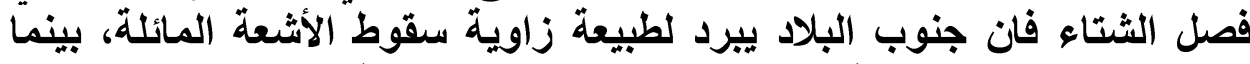

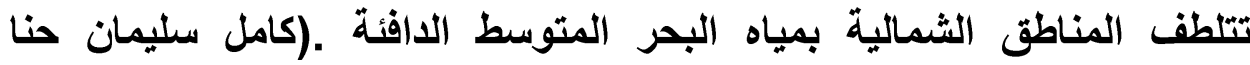

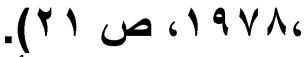

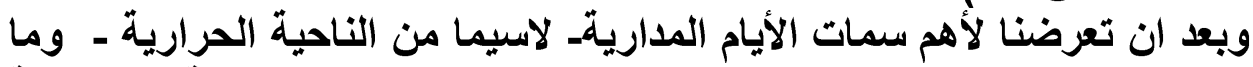

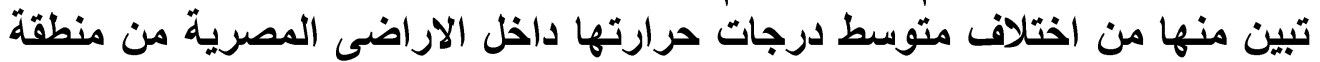

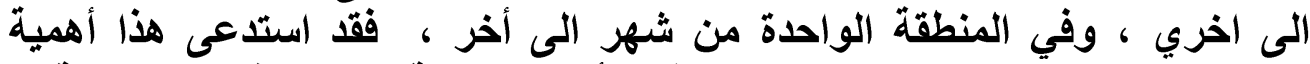

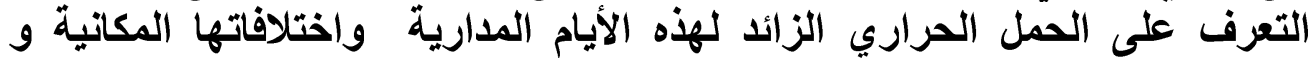

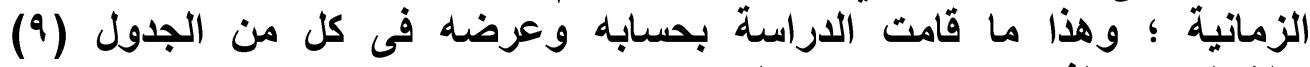

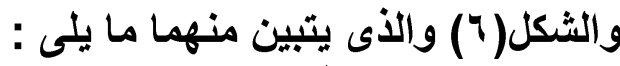

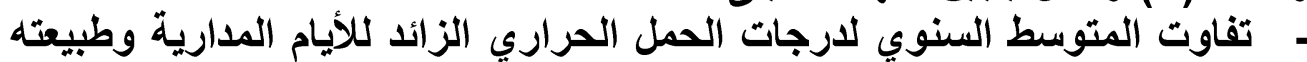

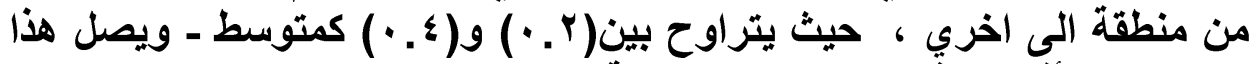

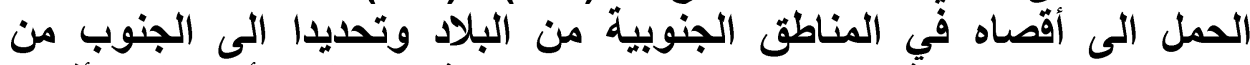

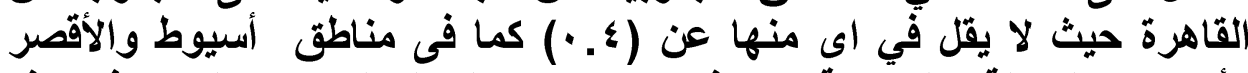

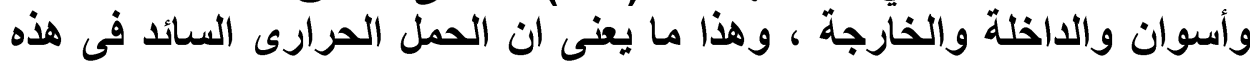

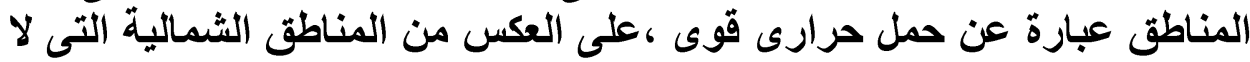

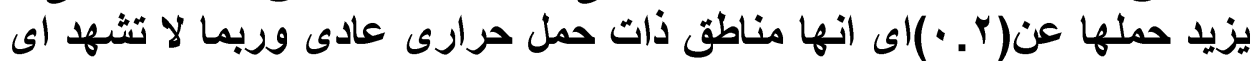

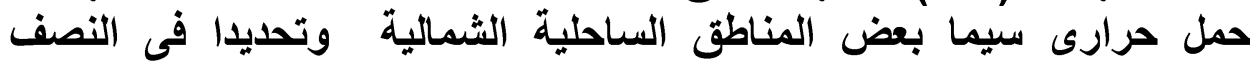

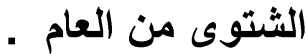

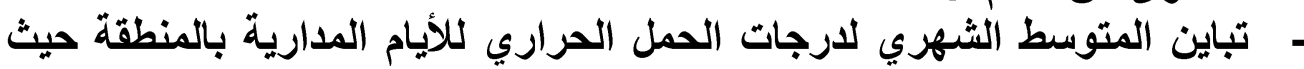

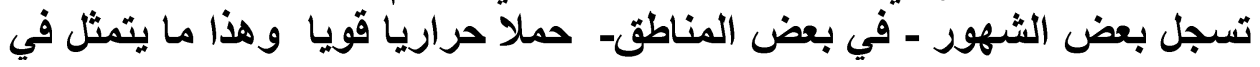

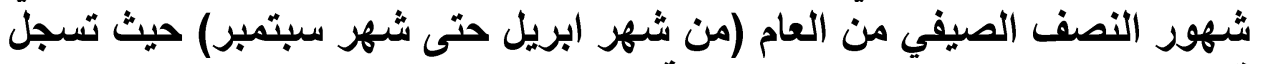

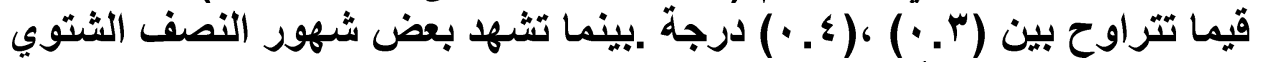

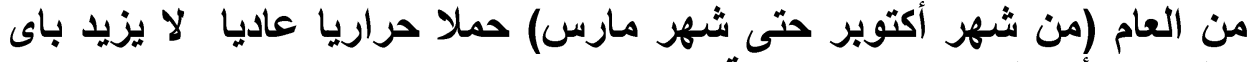

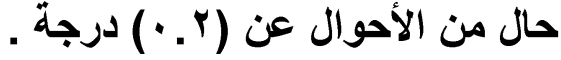


جدول (9) قيمةالحمل الحراري الزائد وطبيعته في بعض المناطق بالأراضي

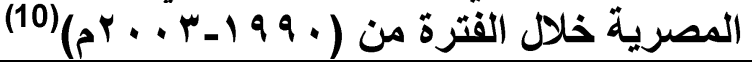

\begin{tabular}{|c|c|c|c|c|c|c|c|c|c|c|c|c|c|}
\hline المتوسط & $د$ & ن & 1 & س - ن & 1 & ي & ي & م & 1 & م & ف & ي & المحطة /الثهر \\
\hline 0.2 & & & 0.2 & 0.2 & 0.3 & 0.3 & 0.2 & 0.1 & & & & & \multirow{2}{*}{ مرسي مطروح } \\
\hline$\varepsilon$ & & & $\varepsilon$ & $\varepsilon$ & ق & ق ق & $\varepsilon$ & $\varepsilon$ & & & & & \\
\hline 0.2 & & & 0.2 & 0.2 & 0.3 & 0.3 & 0.2 & 0.1 & & & & & \multirow{2}{*}{ الإسكندرية } \\
\hline$\varepsilon$ & & & $\varepsilon$ & $\varepsilon$ & ق ق & ق & $\varepsilon$ & $\varepsilon$ & & & & & \\
\hline 0.2 & & & 0.2 & 0.2 & 0.3 & 0.3 & 0.2 & 0.1 & & & & & \multirow{2}{*}{ بورسعيد } \\
\hline$\varepsilon$ & & & $\varepsilon$ & $\varepsilon$ & ق & ق & $\varepsilon$ & $\varepsilon$ & & & & & \\
\hline 0.2 & & 0.1 & 0.2 & 0.3 & 0.3 & 0.3 & 0.2 & 0.2 & 0.1 & & & & \multirow{2}{*}{ العريش } \\
\hline$\varepsilon$ & & $\varepsilon$ & $\varepsilon$ & ق ق & ق ق & ق ق & ق ق & $\varepsilon$ & $\varepsilon$ & & & & \\
\hline 0.3 & & 0.1 & 0.3 & 0.4 & 0.5 & 0.5 & 0.4 & 0.3 & 0.2 & 0.1 & & & \multirow{2}{*}{ الإسماعيلية } \\
\hline ق & & $\varepsilon$ & ق ق & ق & ق ق & ق & ق ق & ق & $\varepsilon$ & $\varepsilon$ & & & \\
\hline 0.3 & & & 0.3 & 0.3 & 0.4 & 0.4 & 0.4 & 0.3 & 0.3 & & & & \multirow{2}{*}{ بهتيم } \\
\hline ق & & & ق ق & ق ق & ق & ق & ق & ق & ق ق & & & & \\
\hline 0.4 & & & 0.3 & 0.4 & 0.4 & 0.5 & 0.4 & 0.4 & 0.2 & 0.1 & & & \multirow{2}{*}{ القاهرة } \\
\hline ق & & & ق & ق & ق & ق & ق & ق & $\varepsilon$ & $\varepsilon$ & & & \\
\hline 0.4 & & 0.2 & 0.3 & 0.4 & 0.5 & 0.5 & 0.5 & 0.5 & 0.4 & 0.1 & & & \multirow{2}{*}{ الجيزة } \\
\hline ق & & $\varepsilon$ & ق ق & ق ق & ق ق & ق & ق & ق ق & ق ق & $\varepsilon$ & & & \\
\hline 0.4 & & 0.1 & 0.3 & 0.4 & 0.5 & 0.5 & 0.5 & 0.5 & 0.4 & 0.2 & 0.1 & & \multirow{2}{*}{ أسيوط } \\
\hline ق & & $\varepsilon$ & ق & ق & ق & ق & ق & ق & ق & $\varepsilon$ & $\varepsilon$ & & \\
\hline 0.4 & 0.1 & 0.2 & 0.4 & 0.5 & 0.5 & 0.5 & 0.5 & 0.5 & 0.4 & 0.3 & 0.1 & & \multirow{2}{*}{ الأقصر } \\
\hline ق & $\varepsilon$ & $\varepsilon$ & ق & ق & ق & ق & ق & ق & ق & ق & $\varepsilon$ & & \\
\hline 0.4 & 0.1 & 0.3 & 0.5 & 0.5 & 0.5 & 0.5 & 0.6 & 0.5 & 0.5 & 0.3 & 0.2 & 0.1 & \multirow{2}{*}{ أسوان } \\
\hline ق & $\varepsilon$ & ق & ق & ق & ق & ق & ق & ق & ق & ق ق & $\varepsilon$ & $\varepsilon$ & \\
\hline 0.3 & & 0.1 & 0.3 & 0.4 & 0.5 & 0.5 & 0.5 & 0.4 & 0.2 & 0.1 & & & \multirow{2}{*}{ سيوه } \\
\hline ق & & $\varepsilon$ & ق & ق & ق & ق & ق & ق & $\varepsilon$ & $\varepsilon$ & & & \\
\hline 0.4 & 0.2 & 0.2 & 0.4 & 0.5 & 0.5 & 0.5 & 0.5 & 0.5 & 0.4 & 0.2 & 0.1 & & \multirow{2}{*}{ الاخلة } \\
\hline ق & $\varepsilon$ & $\varepsilon$ & ق & ق & ق & ق & ق & ق & ق & $\varepsilon$ & $\varepsilon$ & & \\
\hline 0.4 & 0.1 & 0.2 & 0.4 & 0.5 & 0.6 & 0.6 & 0.6 & 0.5 & 0.4 & 0.2 & 0.1 & & \multirow{2}{*}{ الخارجة } \\
\hline ق & $\varepsilon$ & $\varepsilon$ & ق & ق & ق.ج & ق.ج & ق.ج & ق & ق & $\varepsilon$ & $\varepsilon$ & & \\
\hline 0.3 & 0.1 & 0.2 & 0.4 & 0.5 & 0.5 & 0.5 & 0.6 & 0.5 & 0.4 & 0.1 & 0.1 & & \multirow[t]{2}{*}{ المتوسط } \\
\hline & $\varepsilon$ & $\varepsilon$ & ق & ق & ق & ق & ق.ج & ق & ق & $\varepsilon$ & $\varepsilon$ & & \\
\hline
\end{tabular}

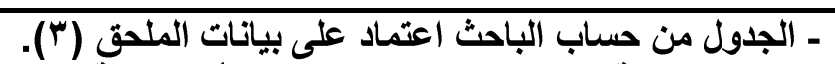

ـ الخانات الخالية بالجدول إثارة الى عام وجود أيام مدارية ومن ثم علم وجود حمل حراري زائد بها.

(· ( ) تثبير الحروف الواردة بالجدول الى طييعة الحمل الحراري حيث يثبير حرف (ع) الى (حمل حرارى عادى) ،

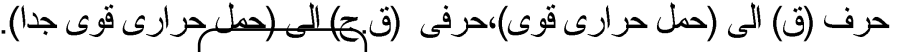


- تكاد لا تثها بعض شهور النصف الشتوي (ديسمبر -يناير - فبراير-نوفمبر)

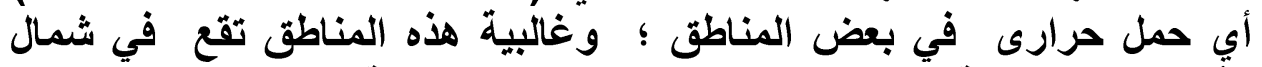

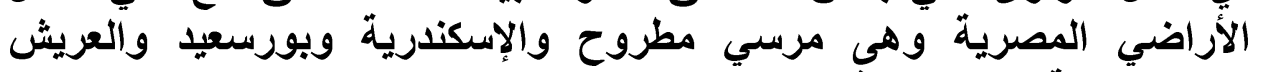

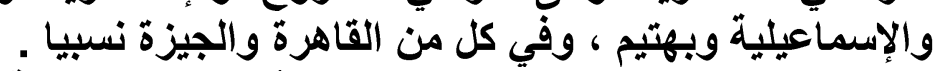

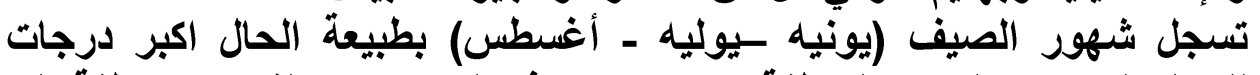

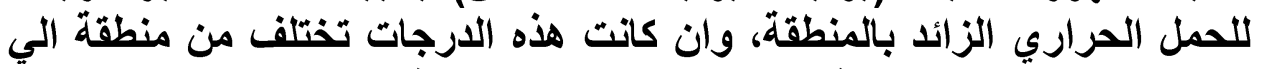

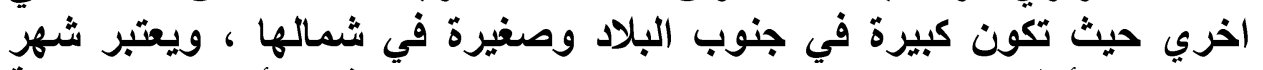

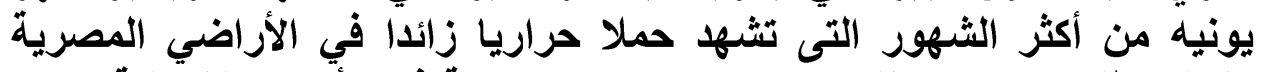

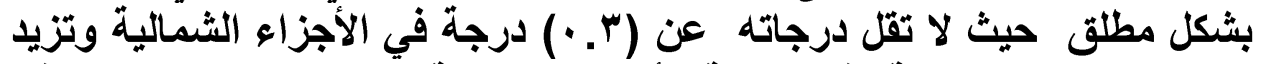

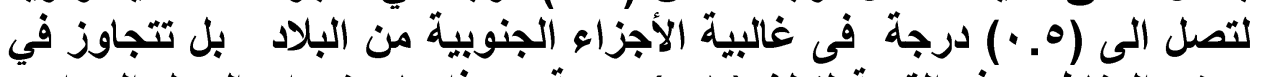

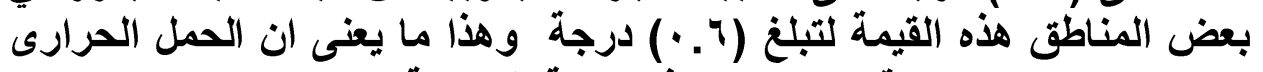

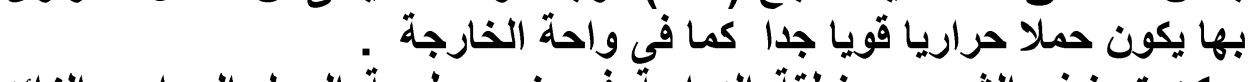

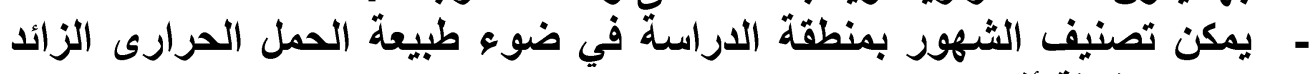

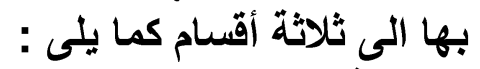

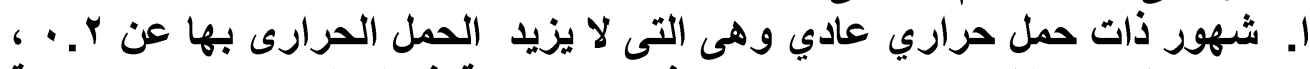

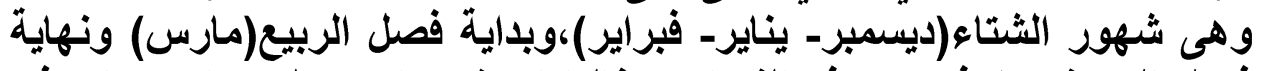

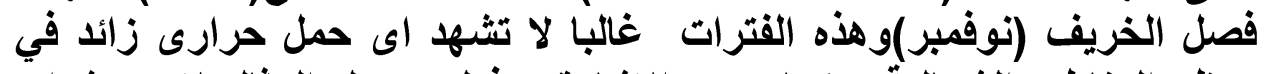

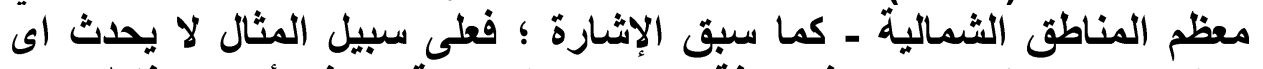

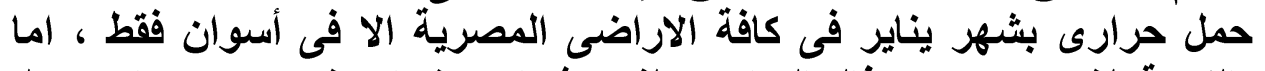

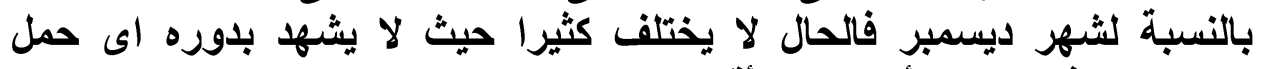

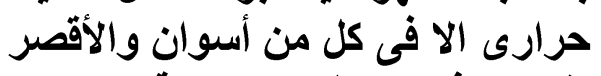

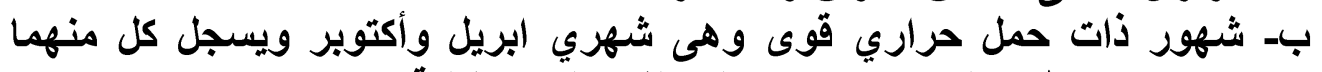

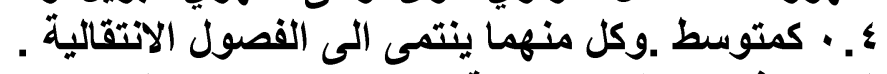

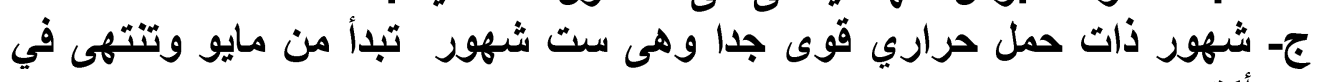

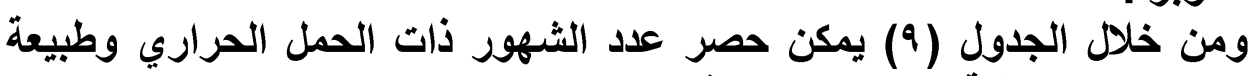

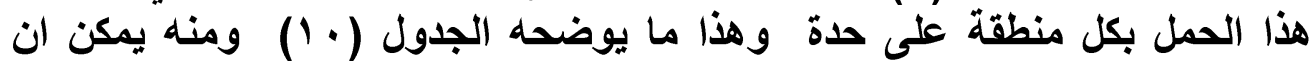

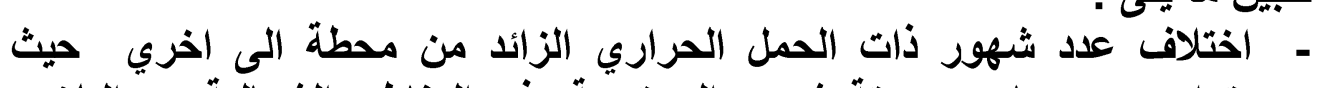

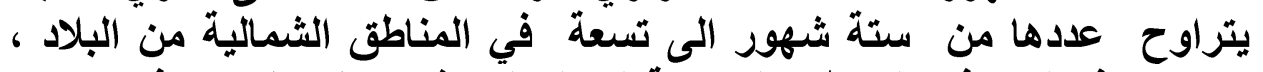

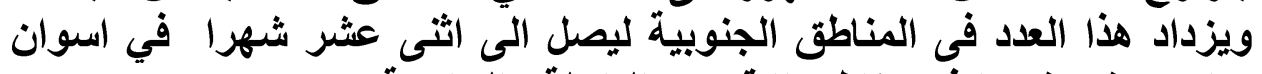

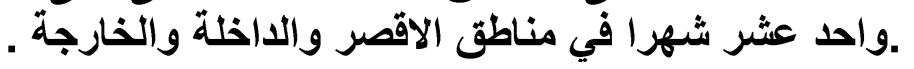




\section{الأيام المدارية في مصر دراسة مناخية}
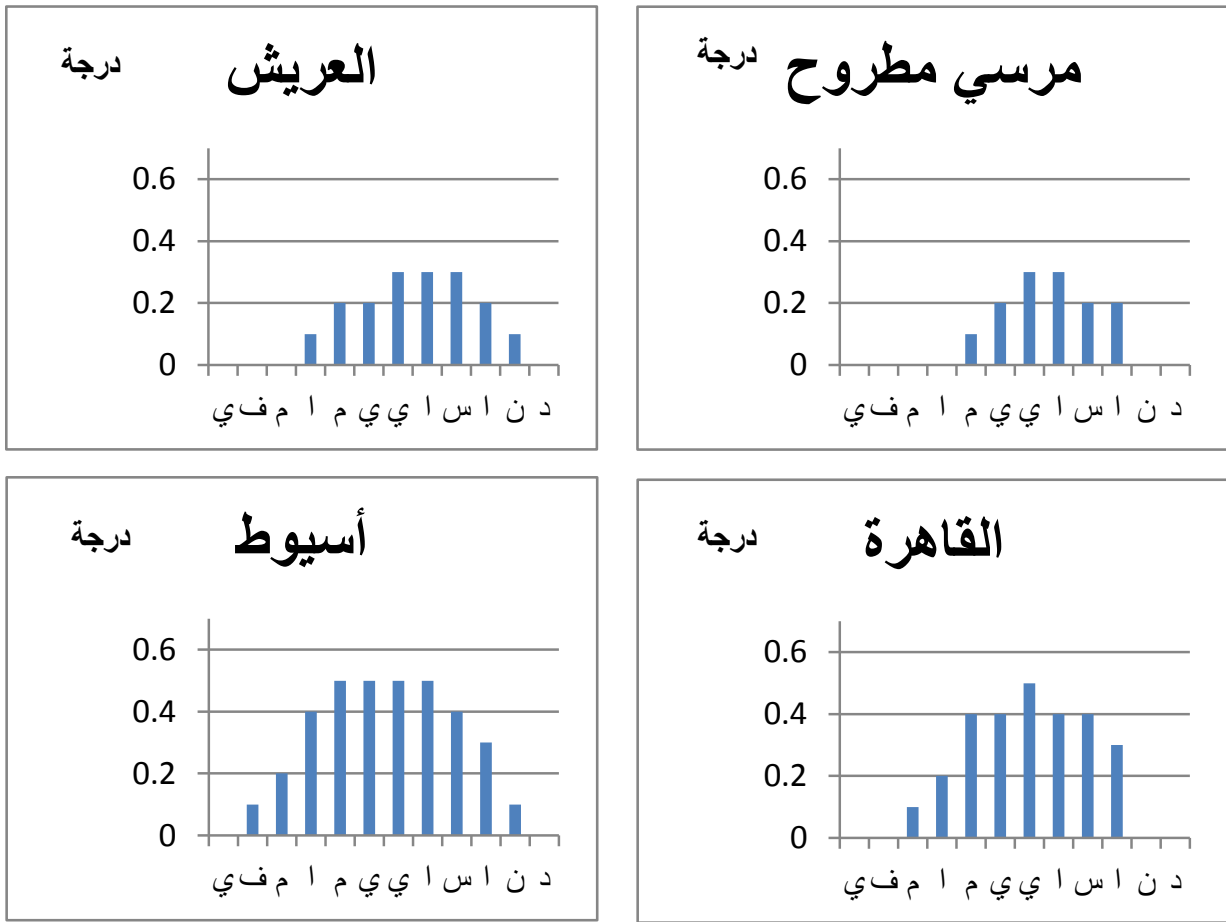

القاهرة
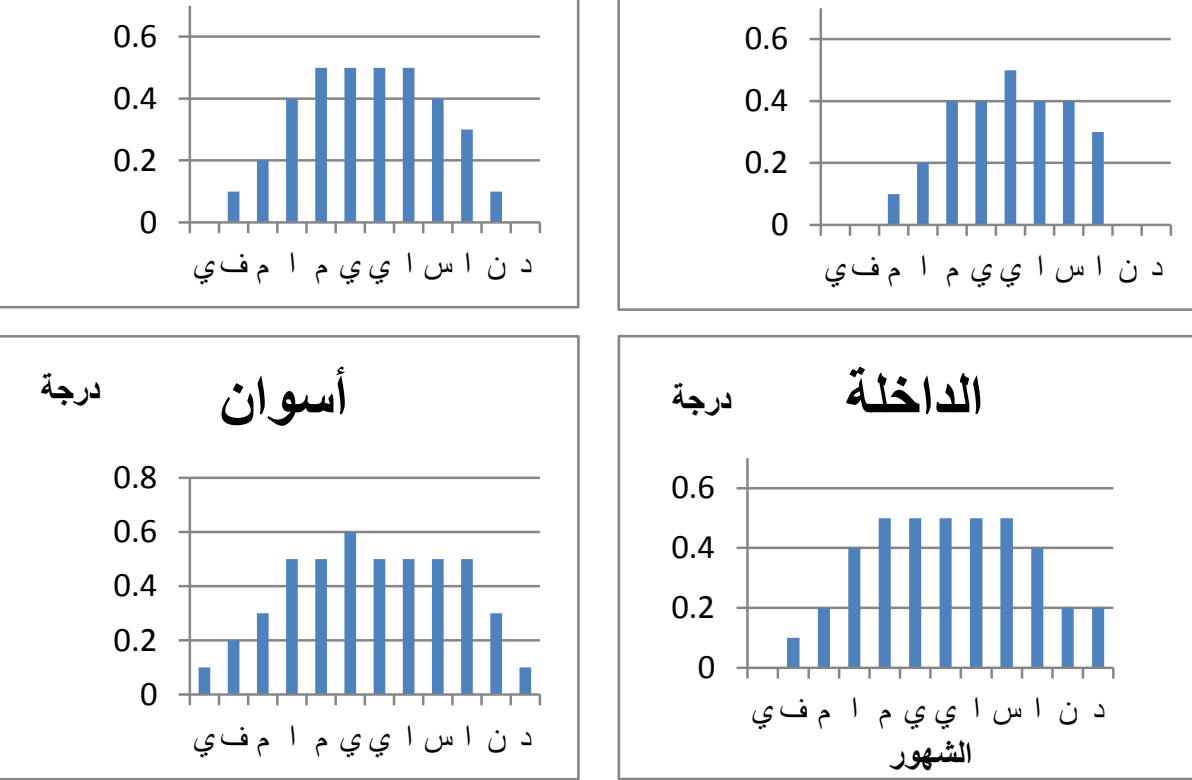

الاخلة

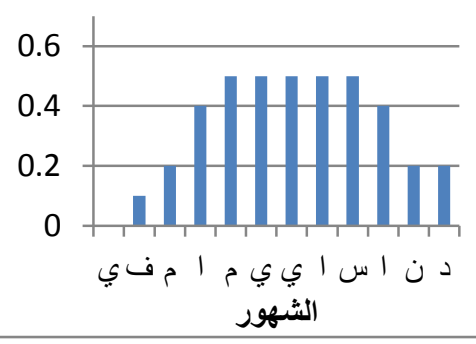

شكل(7) التوزيع الثهري لارجات الحمل الحراري الزائد في مختلف الشهور ببغض المحطات بمنطقة الاراسة المئة 
مجلة كلية الآداب، جامعة سوهاج، العدد الخامس والأربعون، الجزء الأول، أكتوبر V I P م

جدول (· 1) تصنيف الشهور في ضوء طبيعة الحمل الحراري الزائد خلال الأيام

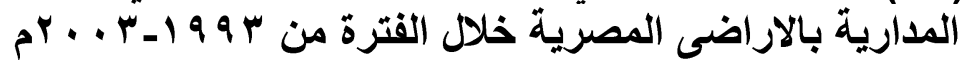

\begin{tabular}{|c|c|c|c|c|c|c|c|c|c|c|c|c|c|c|}
\hline 交 & 霄 & 秀 & $\frac{\overline{3}}{\overline{3}}$ & 离 & 可 & 高 & $\begin{array}{l}\text { 滒 } \\
\text { so } \\
\text { so }\end{array}$ & 变 & 络 & 弯 & 尔 & 羿 & $\begin{array}{l}3 \\
3 \\
3 \\
3 \\
3\end{array}$ & الشهور \\
\hline 11 & 11 & 9 & Ir & 11 & 1. & 9 & $\Lambda$ & V & 9 & $\Lambda$ & 7 & 7 & 7 & شجمور الحراري \\
\hline$\varepsilon$ & $\varepsilon$ & $r$ & $r$ & $r$ & $r$ & $\varepsilon$ & $r$ & $r$ & . & $r$ & 0 & $\varepsilon$ & $\varepsilon$ & عادى \\
\hline$r$ & $r$ & $r$ & 1 & $r$ & $r$ & $r$ & 0 & $V$ & $\varepsilon$ & $r$ & $r$ & $r$ & $r$ & قوى \\
\hline 0 & 0 & $r$ & $\Lambda$ & 0 & $\varepsilon$ & $\varepsilon$ & 1 & . & $r$ & - & . & . & . & قوى جدا \\
\hline
\end{tabular}

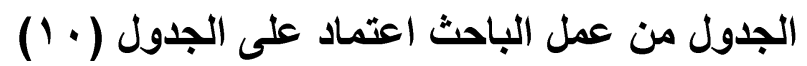

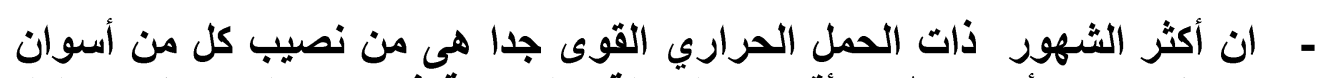

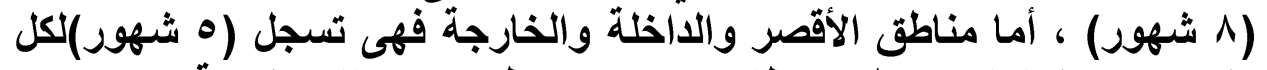

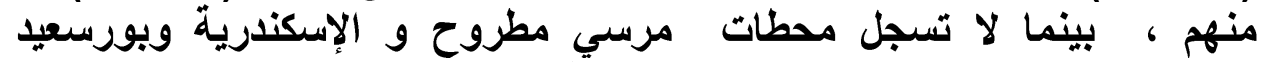

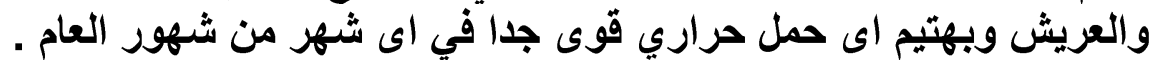

*3

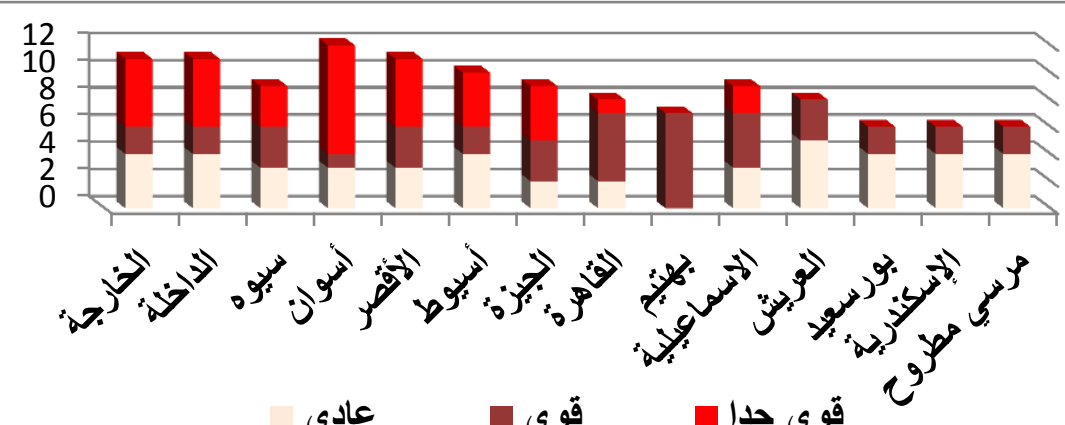

عادي

قوى

قوى جدا

شكل(V) عدد شهور الحمل الحراري وتصنيفها فى عدد من المحطات بالا راضى المصرية

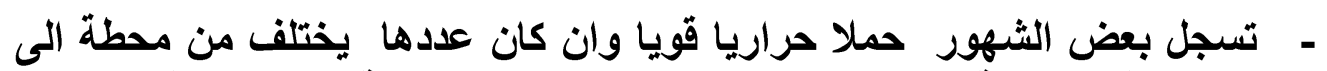

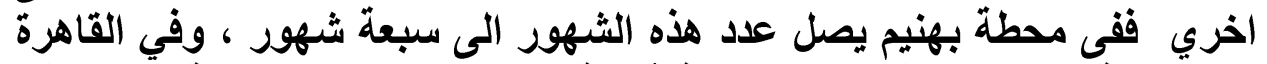

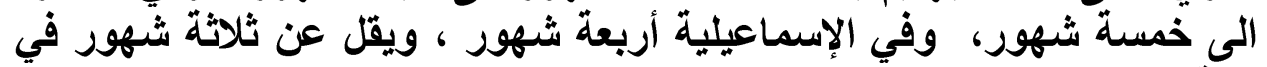
بقية المحطات الاخري.

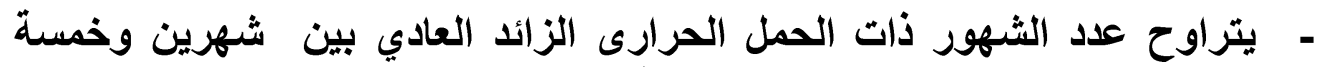

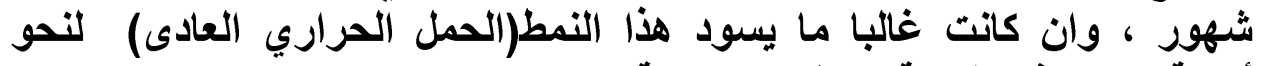

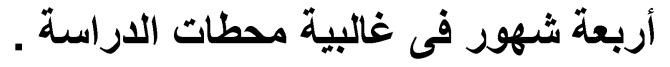


- تعتبر أسوان والأقصر والداخلة والخارجة من أكثر مناطق الاراضي المصرية

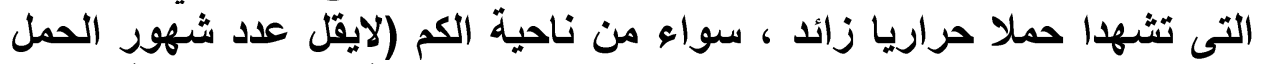

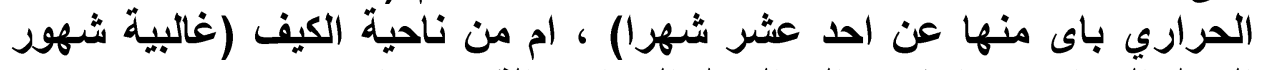

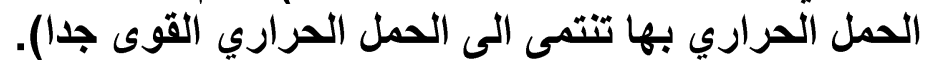

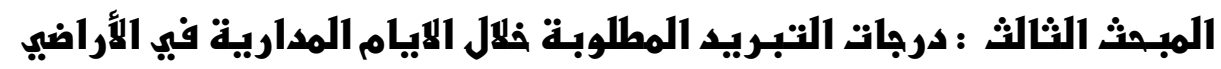
المصرية : الميعية

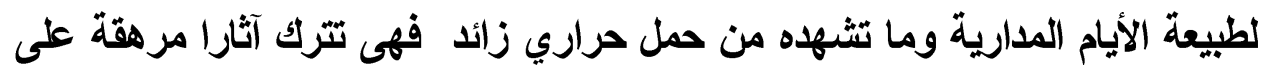

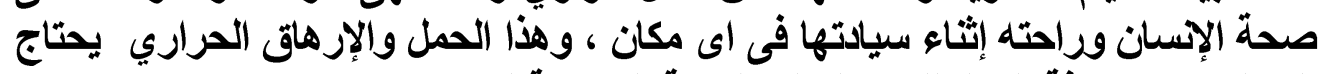

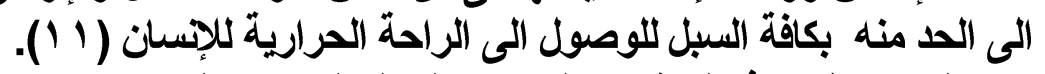

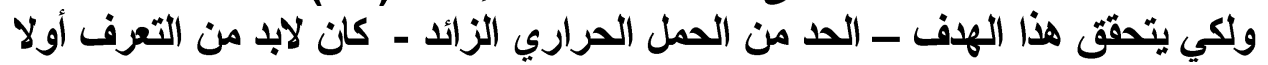

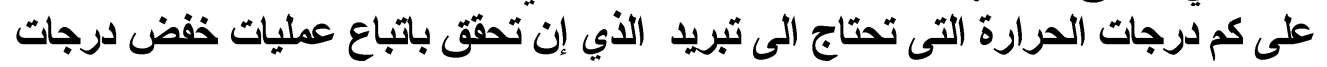

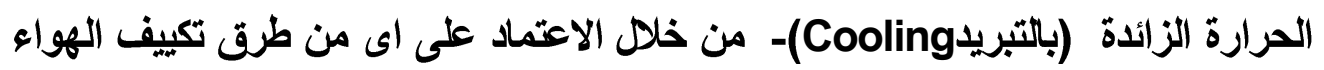

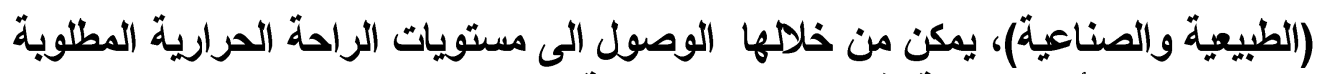

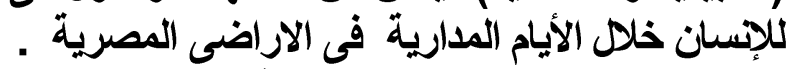

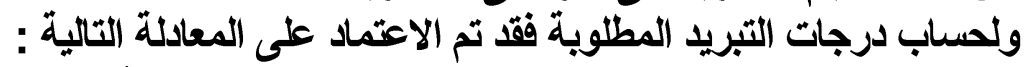

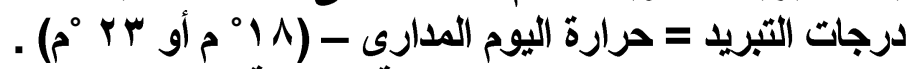

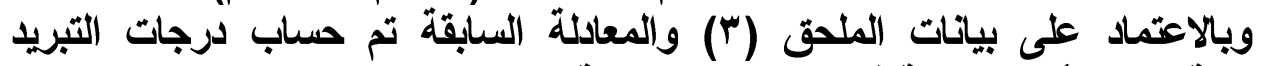

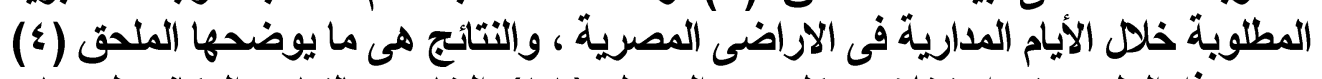

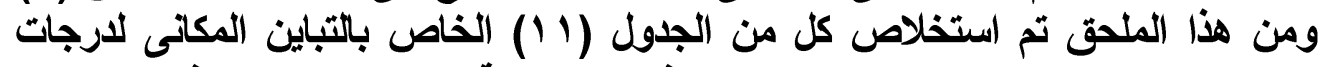

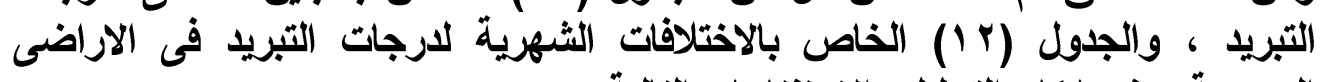

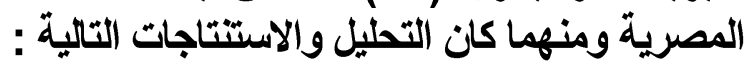

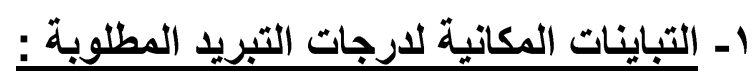

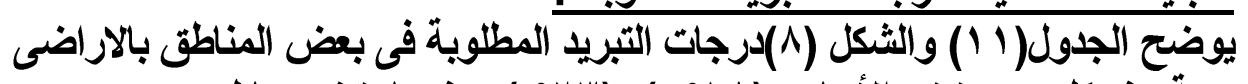

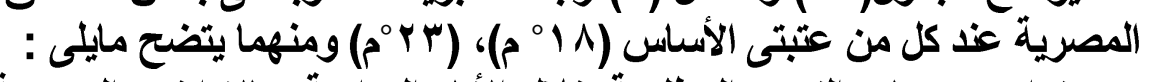

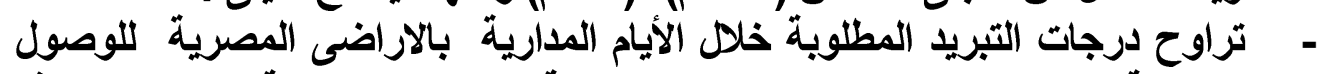

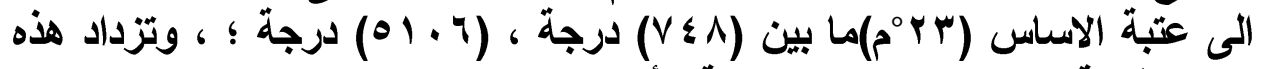

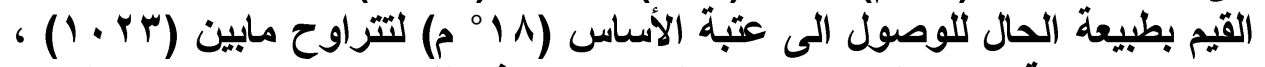

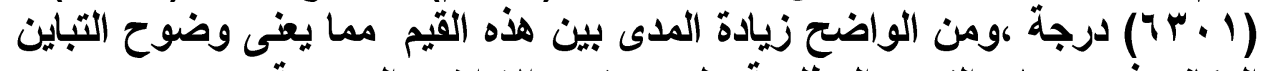

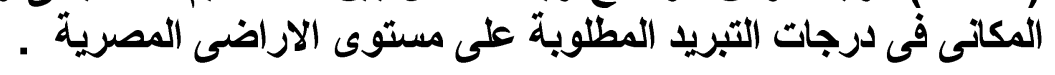

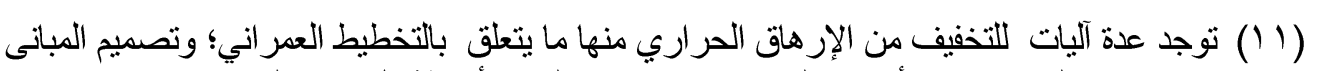

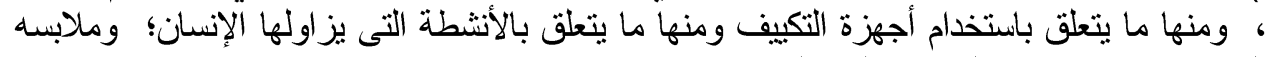




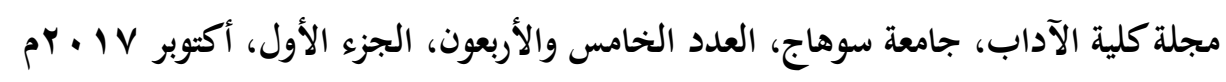

جدول(1 (1) التباين المكانى لارجات التبريد المطلوبة فى بعض المناطق بمصر(م)

\begin{tabular}{|c|c|c|c|c|c|c|c|c|c|c|c|c|c|c|}
\hline$\frac{\overline{7}}{7}$ & 高 & 录 & $\begin{array}{l}\overline{3} \\
\overline{3}\end{array}$ & 高 & 承 & 高 & 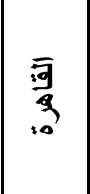 & 事 & 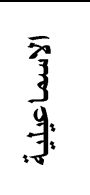 &.$\overline{3}$ & $\begin{array}{l}3 \\
3 \\
3\end{array}$ & 不 & $\begin{array}{l}3 \\
3 \\
3 \\
3 \\
3\end{array}$ & $\bar{y}$ \\
\hline$\Delta ৭ \wedge \wedge$ & ova. & $\leq 71 \%$ & (r. & $7 . .7$ & $\leq q \mu q$ & $\leq 079$ & rq৭A & $r v \cdot r$ & raro & $r r \leqslant 0$ & 1579 & וrrk & $1 . r \mu$ & 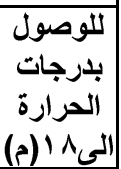 \\
\hline$\leq \Lambda \leq T$ & $\leq 740$ & MTVY & 01.7 & $\leqslant \wedge \leqslant 7$ & $r q \wedge \varepsilon$ & | & $m 101$ & rA५A| & $r .90$ & $1 V 00$ & 1.19 & $9 \wedge \wedge$ & $V \leq \Lambda$ & |للوصول اللىرات \\
\hline $0 \leqslant 17$ & OYYA & $\leqslant 1 \leqslant Y$ & OV. I & $0 \leqslant Y T$ & $\leqslant \leqslant 7 \%$ & $\leqslant 11 \mathrm{~V}$ & rovA & rYAV & rol. & Y.O. & $11 \leq 9$ & 1174 & A & المتوسط \\
\hline
\end{tabular}

الجدول من حساب الباحث اعتمادا على بيانات :الهيئة العامة للأرصاد الجوية بالقاهرة ، قسم

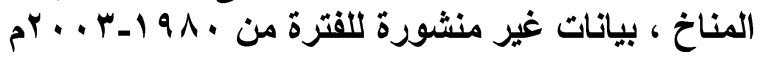

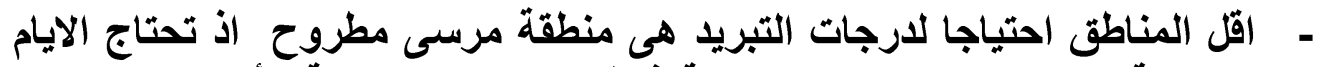

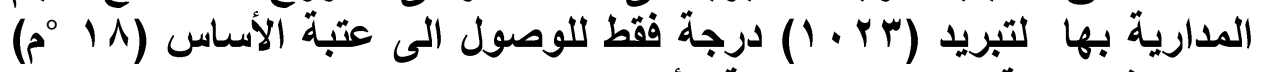

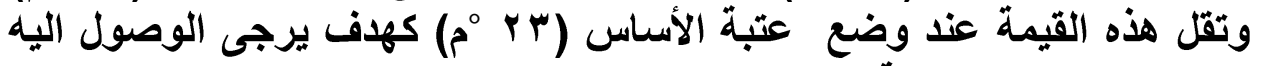

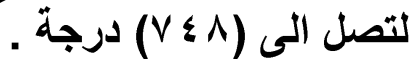

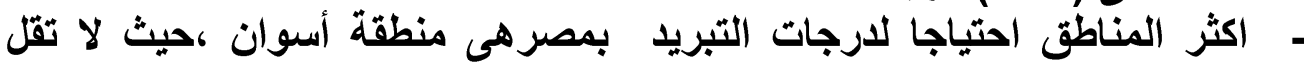

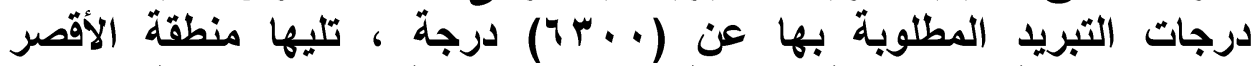

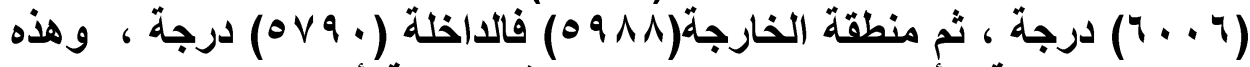

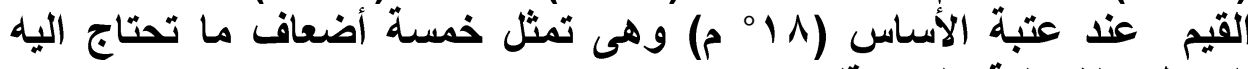

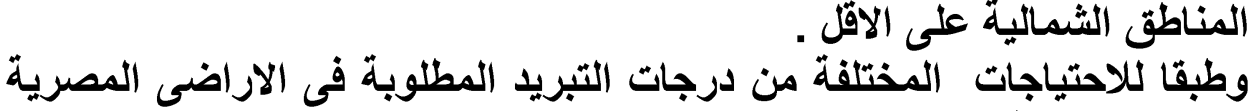

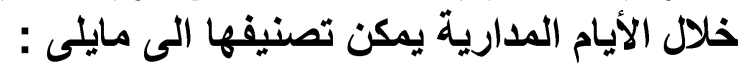

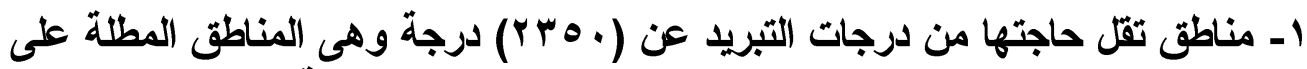

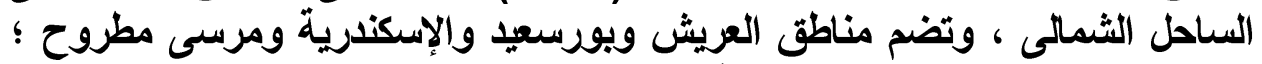

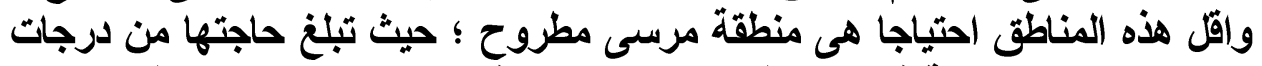

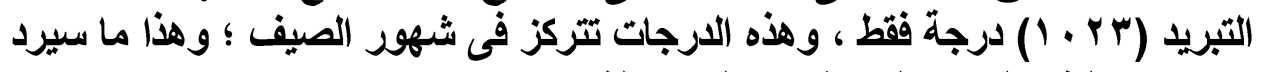

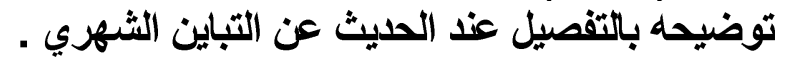

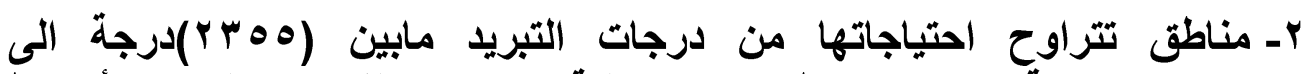

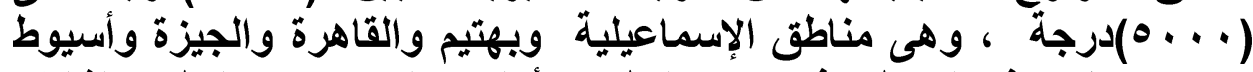

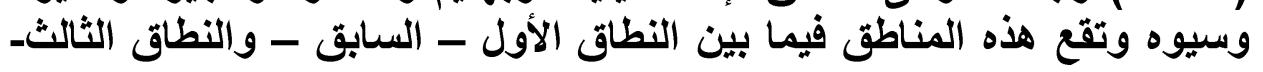


اللاحق؛ اى انها منطقة انتقالية ، وان كان من الواضح زيادة درجات التبريد المطلوبة بها كلما اتجهنا جنوبا.

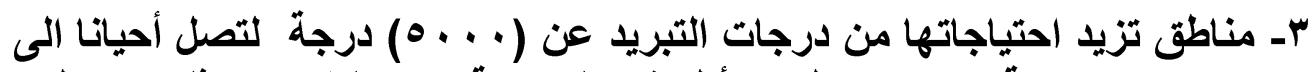

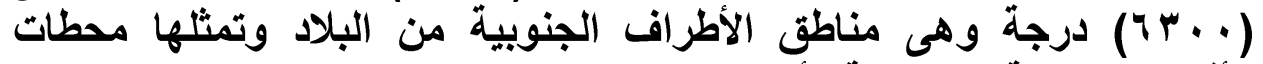
الأقصر والاخلة والخارجة وأسوان الأطراف

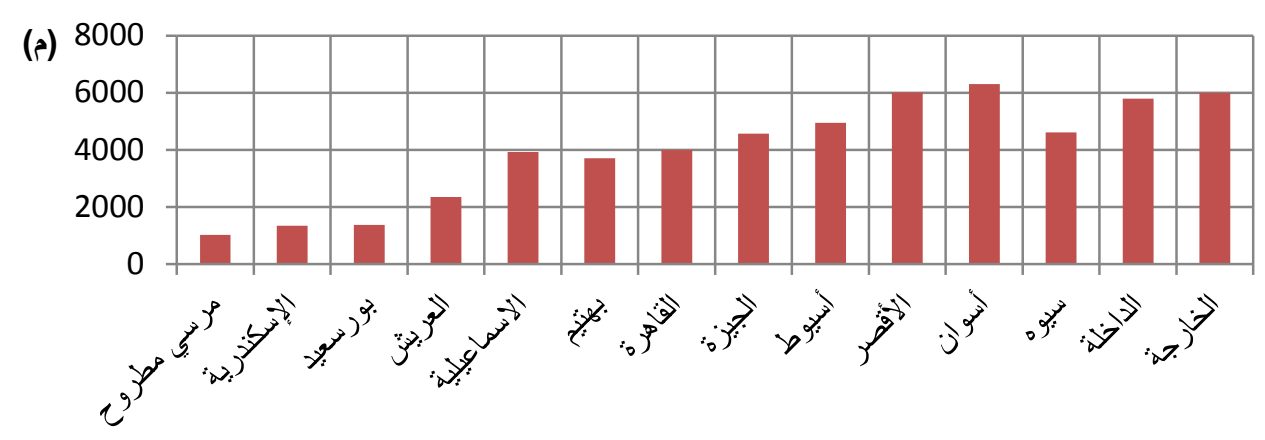

شكل (^) التباين المكانى لارجات التبريد المطلوبة بمصر خلال الأيام المدارية عند

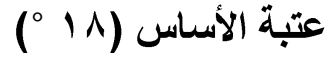

\section{r- الاختلافات الشهرية لارجات التبريد المطلوبة :}

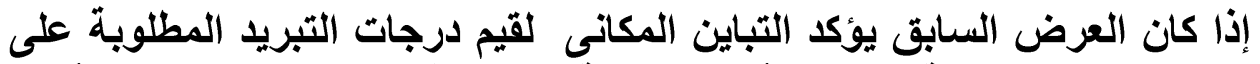

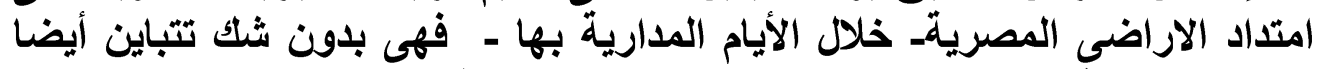

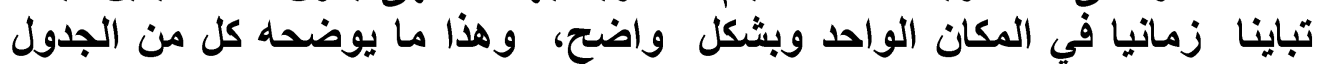

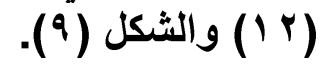

جدول(Y I ) المتوسط الثهري لارجات التبريد المطلوبة فى مصر(م)

\begin{tabular}{|c|c|c|c|c|c|c|c|c|c|c|c|c|}
\hline$د$ & $\dot{U}$ & 1 & س & 1 & ي & ي & م & 1 & م & ف & ي & المحطة /الشهر \\
\hline r & $9 \wedge$ & rys & 7.9 & $V \leq$. & $71 \mathrm{r}$ & 711 & OHY & rq1 & $\wedge \vee$ & $\leqslant 0$ & ir & 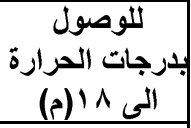 \\
\hline Y & Vr & $r \wedge r$ & $\varepsilon \wedge \varepsilon$ & $79 \leq$ & 00. & $\leqslant 94$ & $\leq r 4$ & rro & $4 r$ & $r v$ & $\wedge$ & 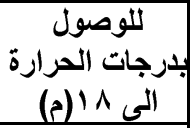 \\
\hline FY & 10 & TrE & $0 \leq V$ & VIV & 917 & OOY & $\leqslant \vee q$ & $r \diamond \wedge$ & Vo & $\leqslant 1$ & 11 & المتوسط \\
\hline
\end{tabular}

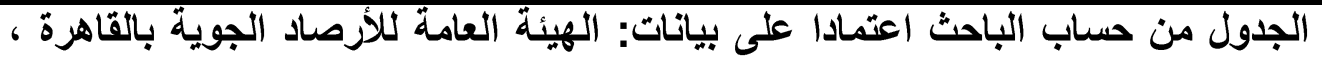

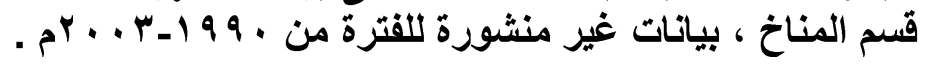

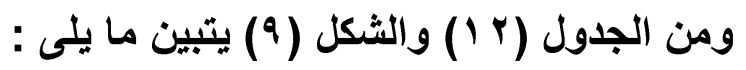




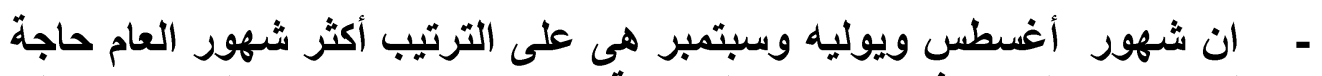

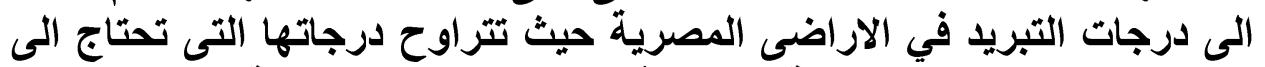

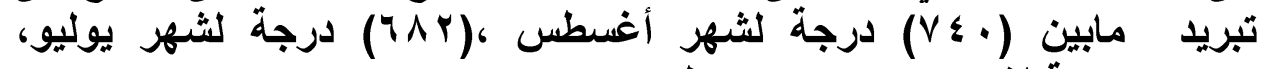

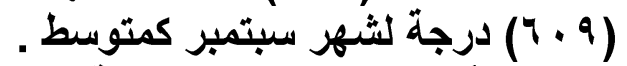

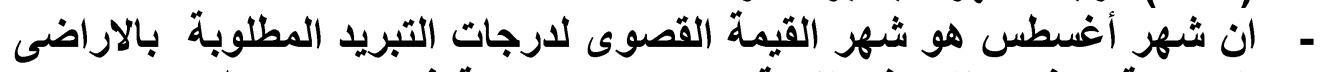

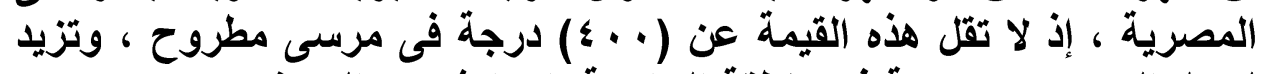

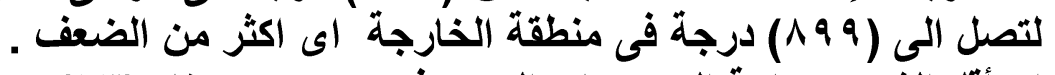

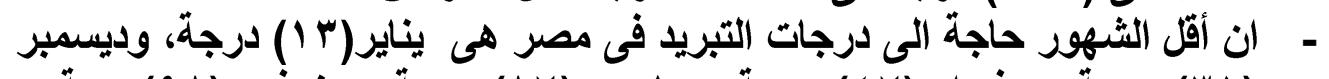

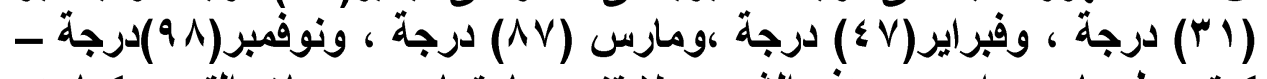

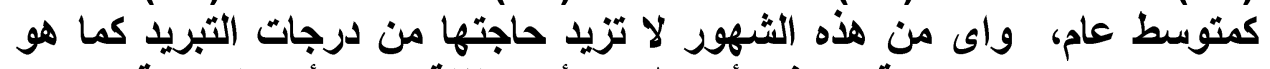

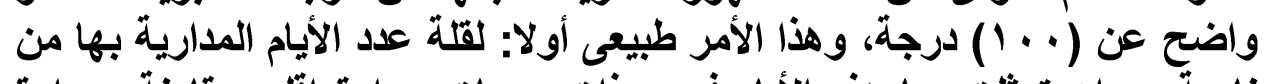

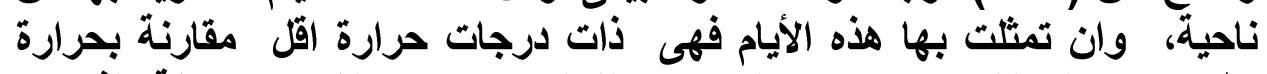

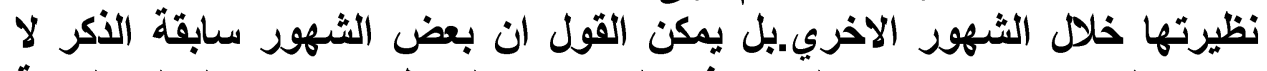

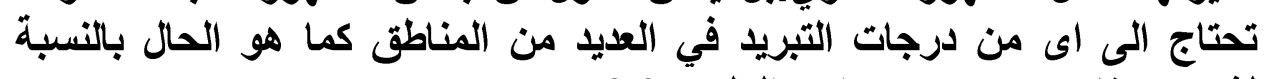

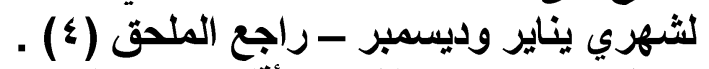

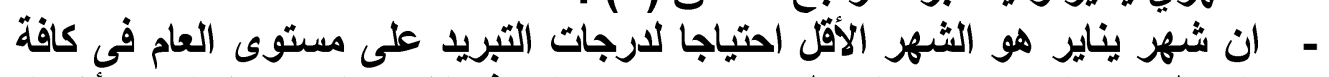

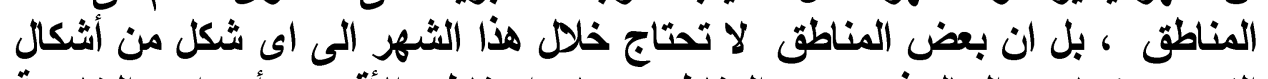

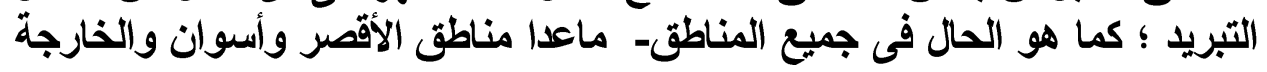

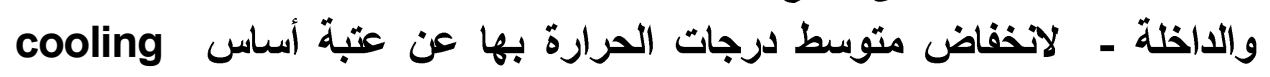

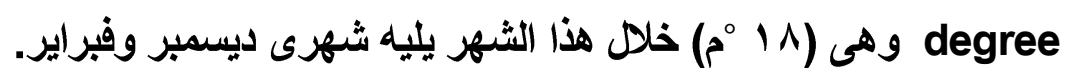

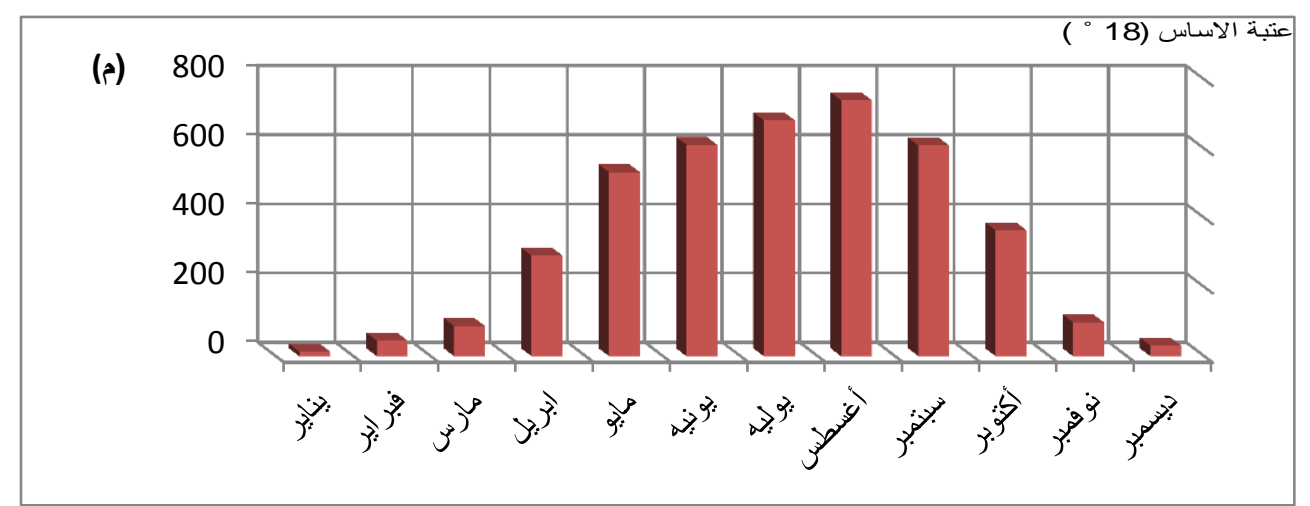

شكل (9)(المتوسط الثهري لارجات حرارة التبريد المطلوبة بمصر خلال الأيام

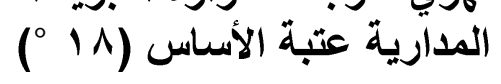

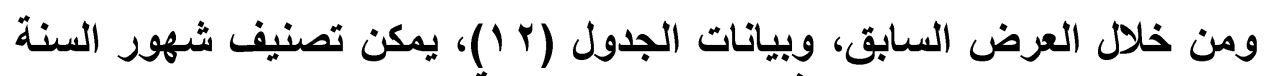
طبقا لحاجتها الى درجات التبريد في الاراضى المصرية كما يلى : 


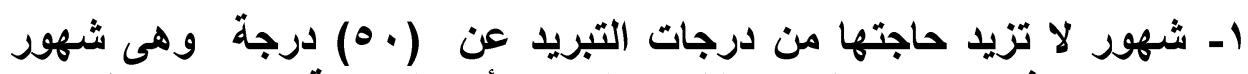

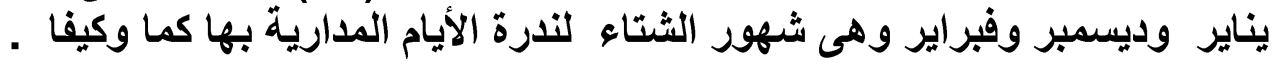

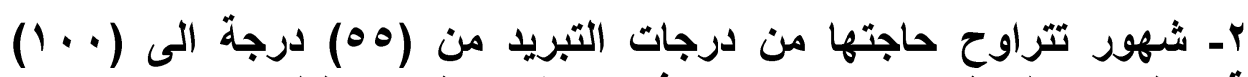

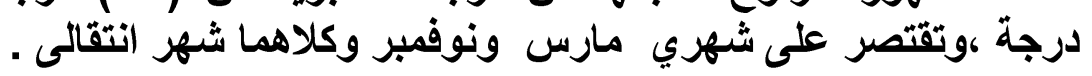

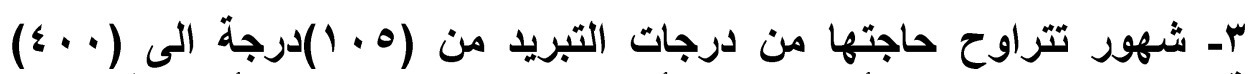

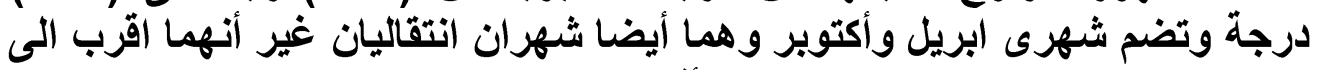

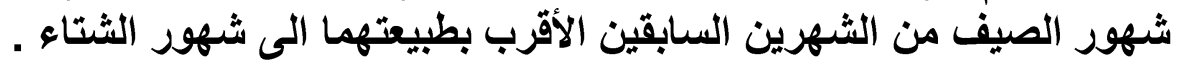

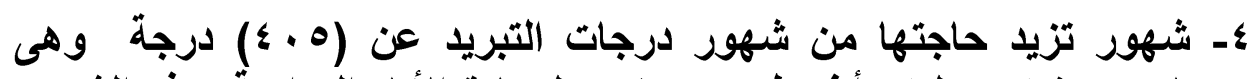

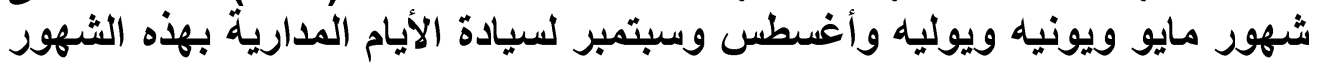
وأخيرا وبعد أن تعرضنا بالتحليل والتفسير للأيام المدارية في الاراضى المصرية

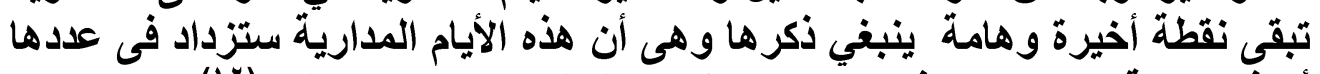

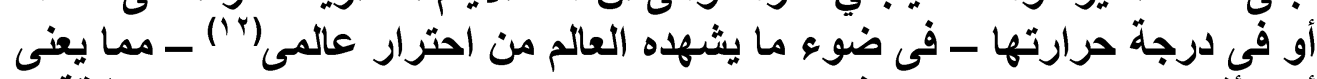

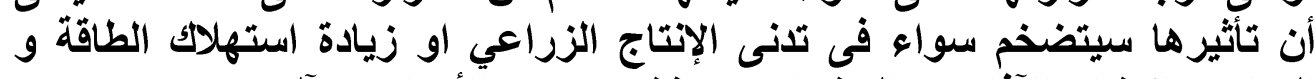

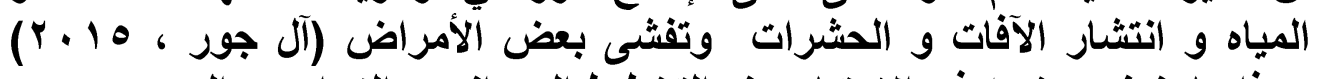

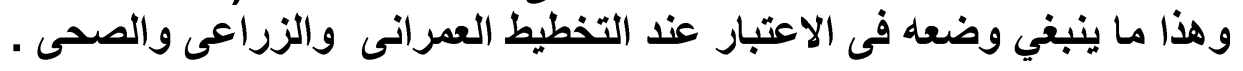

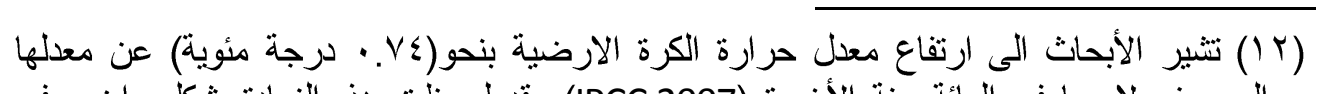

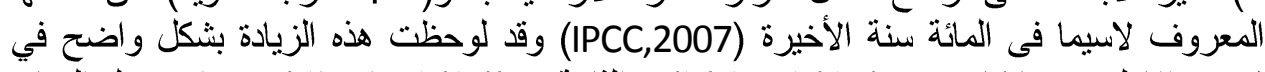

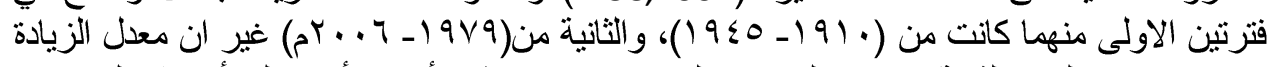

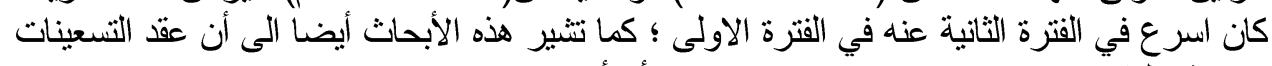

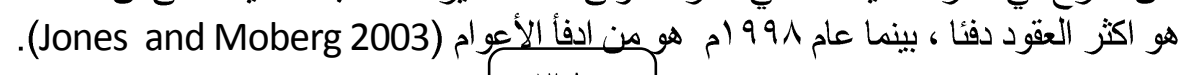




\section{فاتمة البهث (نتنائجه وتوصياته):}

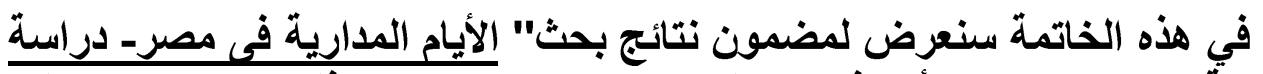

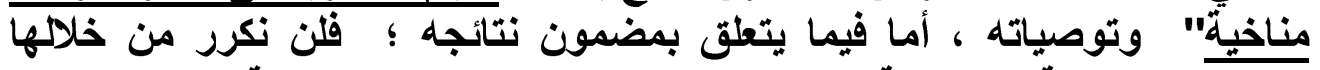

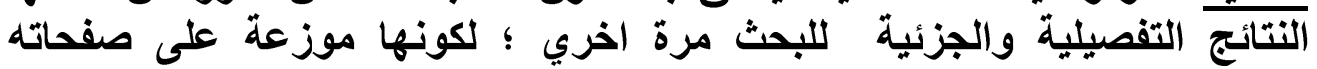

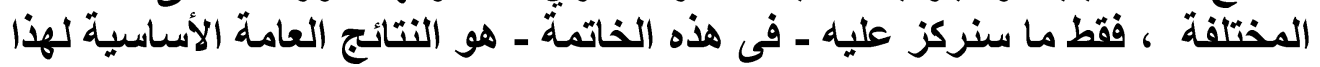

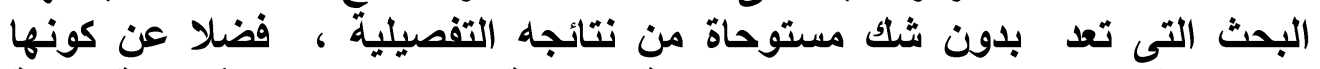

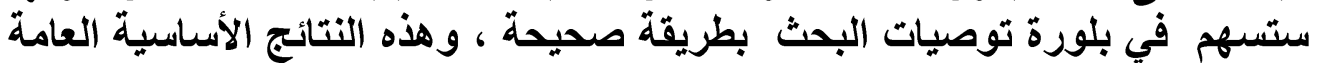

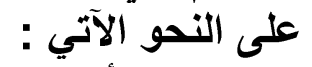

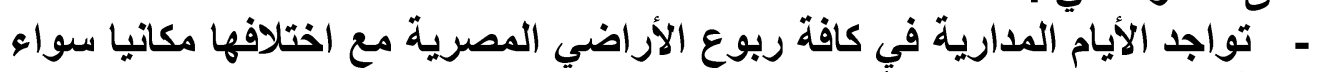

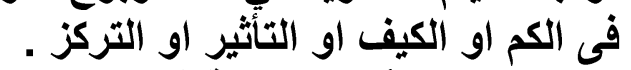

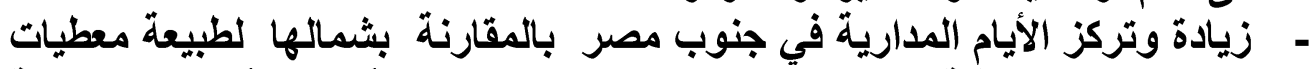

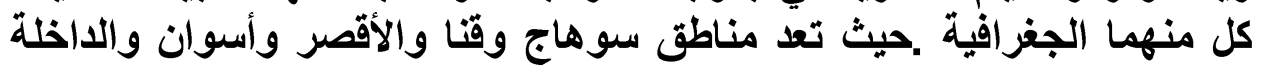

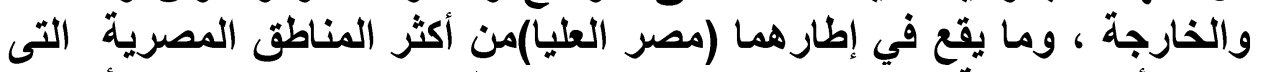

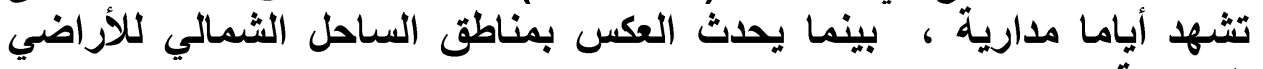

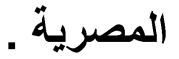
- ت تهيمن الايام المدارية على أيام فصل الصيف في الأراضي المصرية ، ثم على

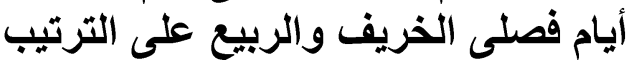

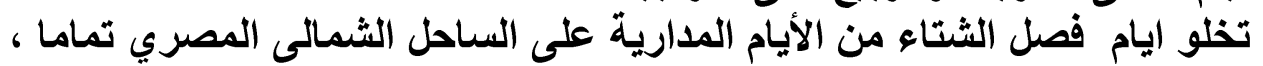

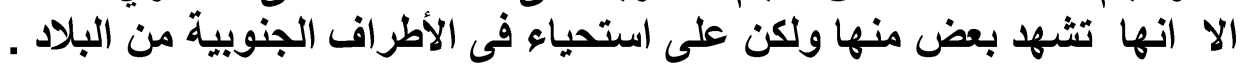

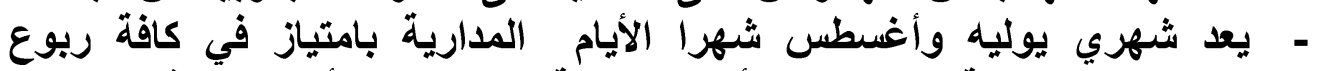

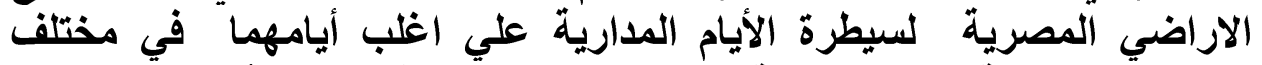

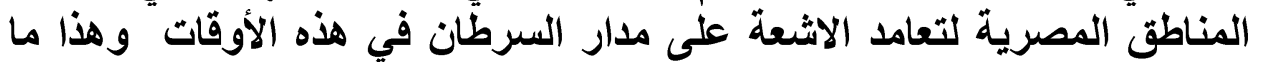

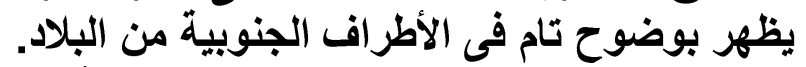

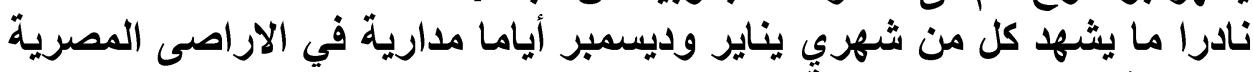

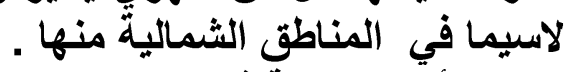

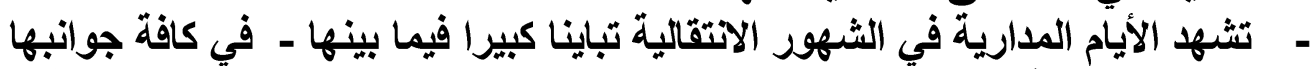

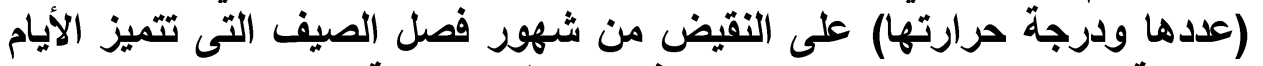

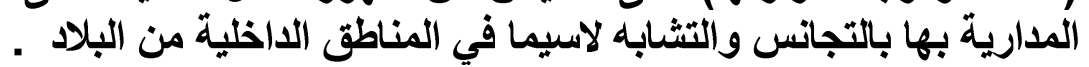

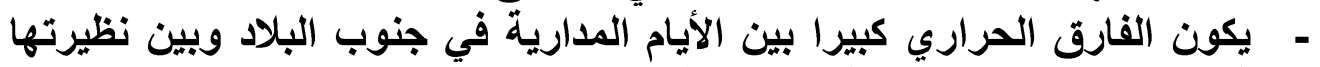

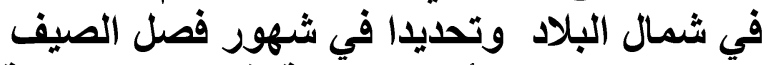

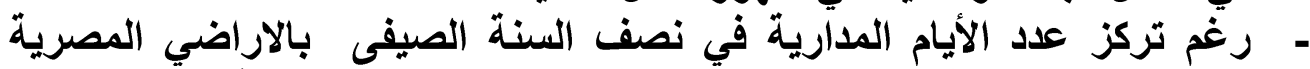

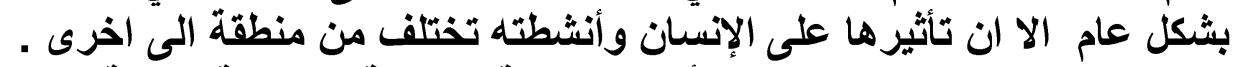

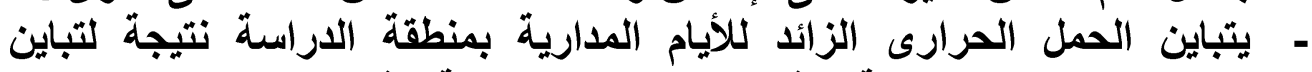

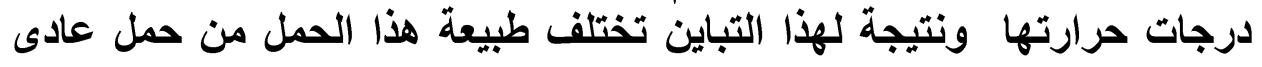


فى المناطق الثمالية الى حمل قوى فى المناطق الوسطى ،وحمل قوى جذا فى بعض المناطق الجنوبية .

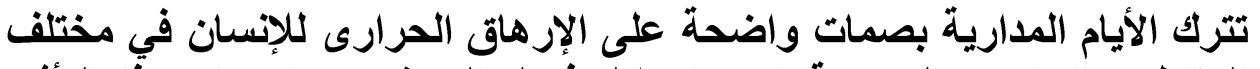

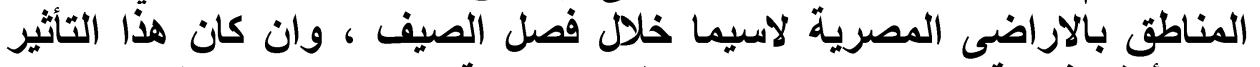

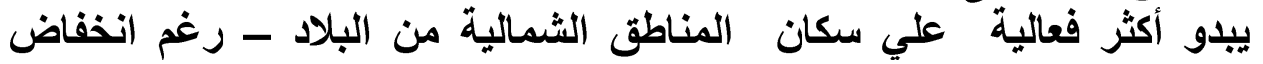

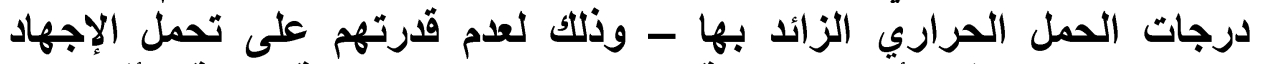

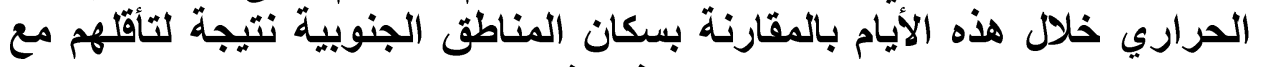

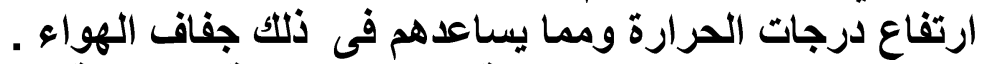

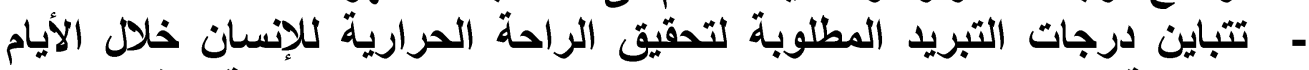

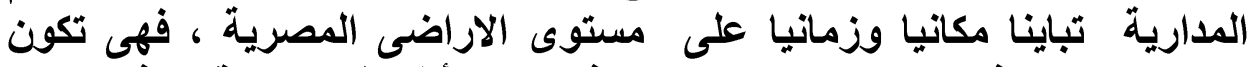

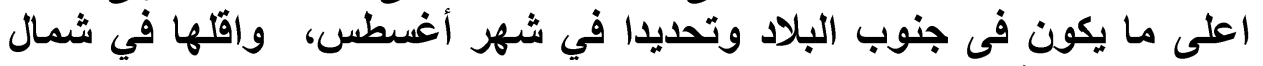

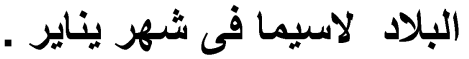

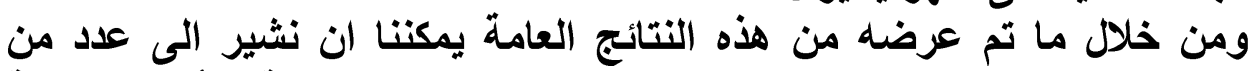

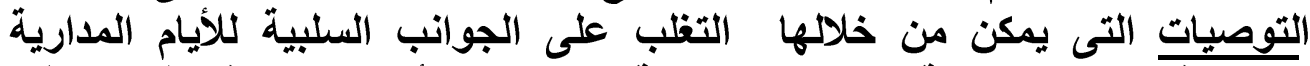

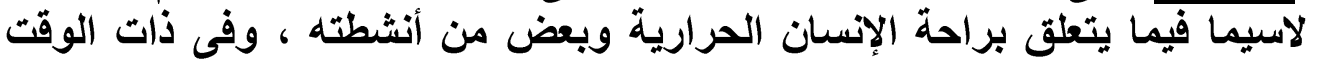

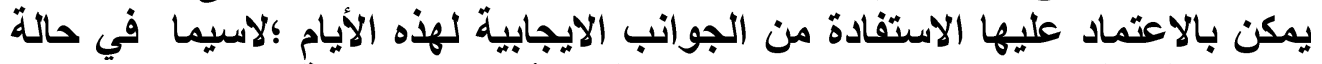

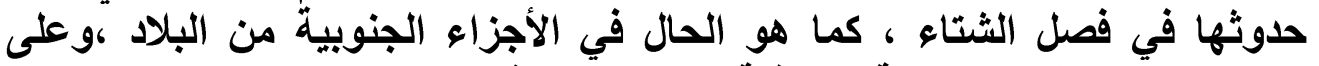

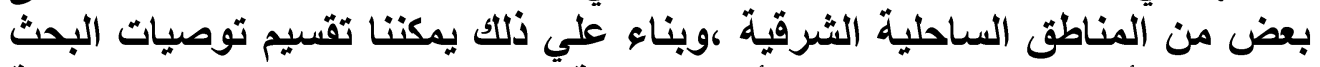

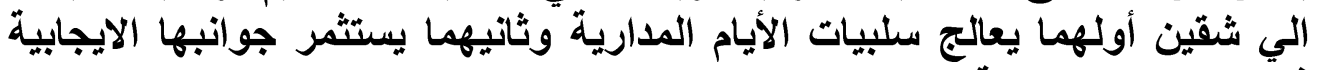
في الاراضى المصرية الميلية أما فيما يتعلق بالتوصيات المتعلقة بمواجهة سلبيات الأيام المدارية فهى كما يلى : ولئية

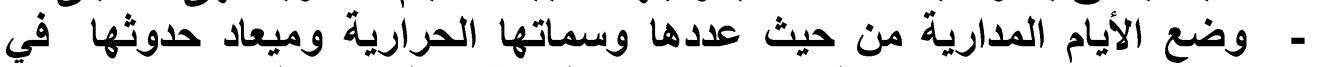

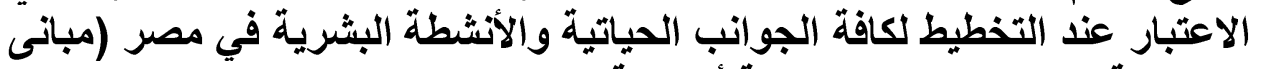

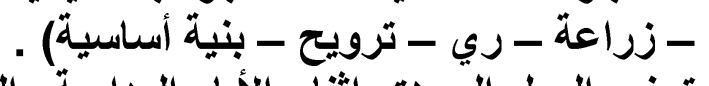

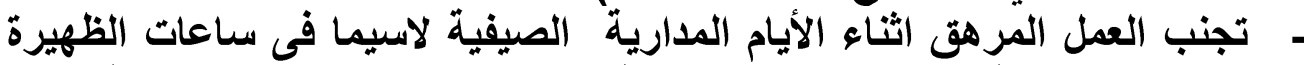

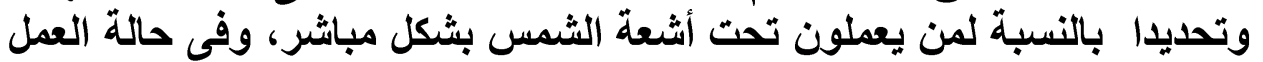

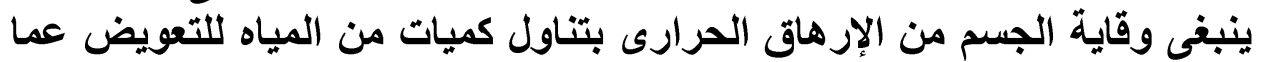

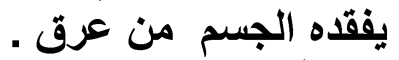
- حتمية توفير متطلبات الراحة الحرارية للإنسان - خلال الأيام المدارية في مناطق العمل .(تهوية، تبريد، تظليل).

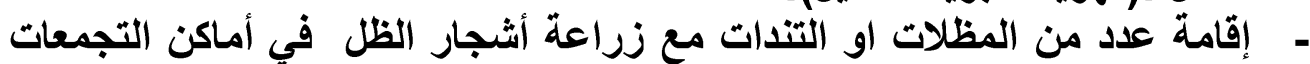

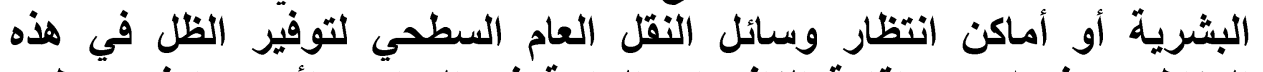
المناطق ، فضلا عن إقامة النافورات المائية في الميادين لأهميتها في ترطيب في النيات الجو وكسر حة درجات الحرارة المرتفعة . 
- استعداد وزارة الكهرباء لتوفير الطاقة الكهربائية اللازمة لساعات الاستهلاك

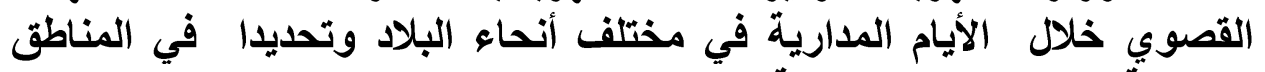

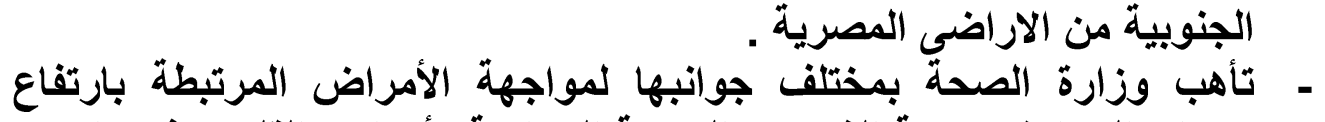

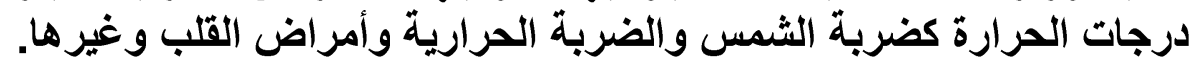

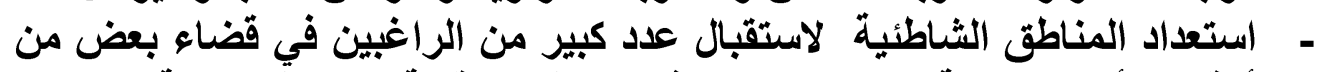

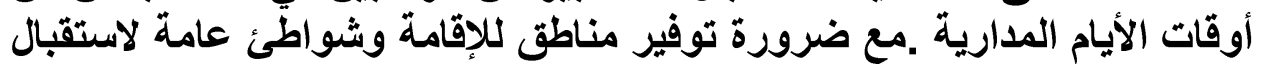

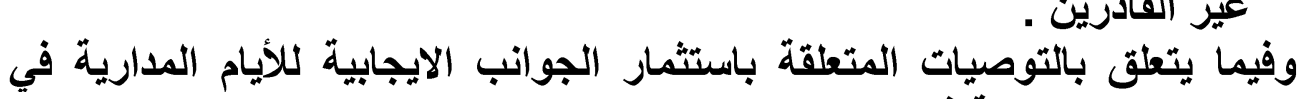

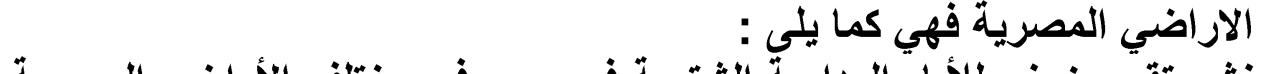

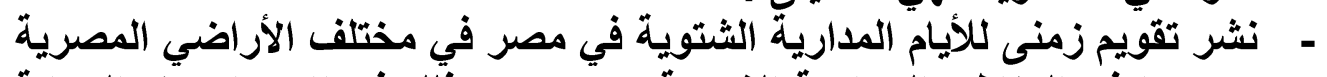

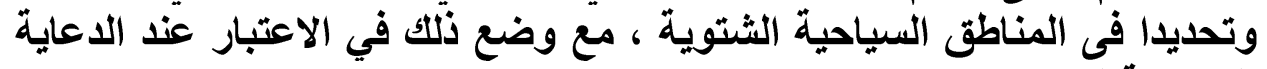

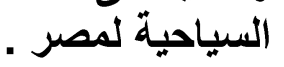

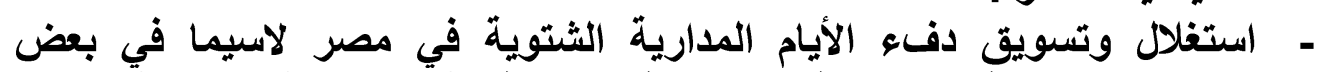

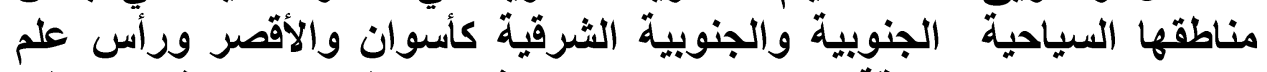

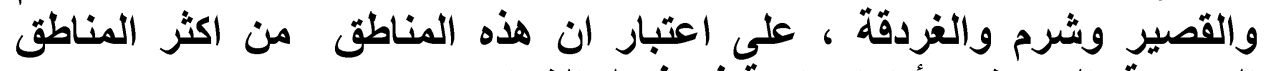

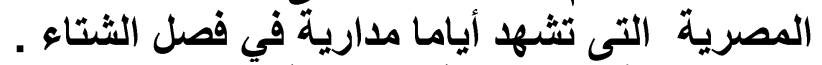

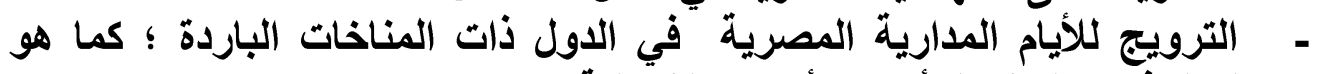

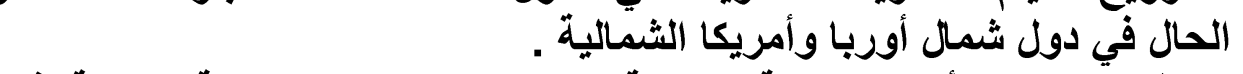

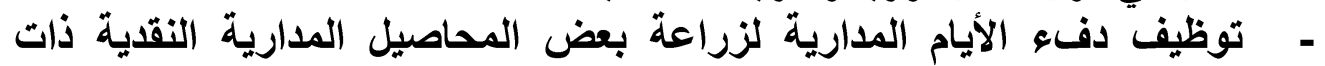

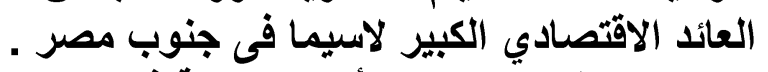
- الاستغلال غير التباثشر للأيام المدارية في توليد الطاقة الثمسية . 


\section{ملاحق البحث}

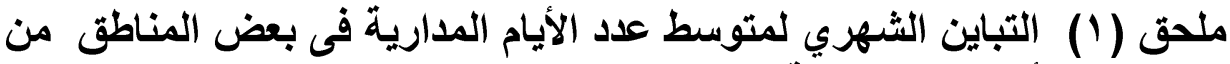

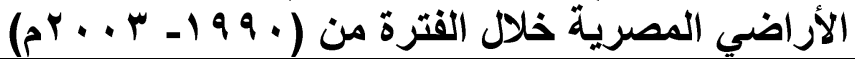

\begin{tabular}{|c|c|c|c|c|c|c|c|c|c|c|c|c|c|}
\hline د & ن & i & س & i & ي & ى & r & $i$ & ? & ف & ي & شهر & المحطة الن \\
\hline 0 & 0 & 3 & 10 & 20 & 11 & 3 & 4 & 4 & 0 & 0 & 0 & | & \multirow{2}{*}{ مطروحي } \\
\hline 0.0 & 0.0 & 5.7 & 18.7 & 36.7 & 20.4 & 5.3 & 6.6 & 6.6 & 0.0 & 0.0 & 0.0 & ن ن & \\
\hline 0 & 0 & 3 & 13 & 24 & 14 & 6 & 6 & 4 & 0 & 0 & 0 & $\varepsilon$ & \multirow{2}{*}{ الإسكندرية } \\
\hline 0.0 & 0.0 & 4.1 & 18.6 & 34.0 & 20.4 & 8.6 & 8.6 & 5.8 & 0.0 & 0.0 & 0.0 & ن ن & \\
\hline 0 & 0 & 2 & 13 & 26 & 18 & 7 & 2 & 2 & 0 & 0 & 0 & $\varepsilon$ & \multirow[t]{2}{*}{ بورسعيد } \\
\hline 0.0 & 0.0 & 2.6 & 18.4 & 36.9 & 25.8 & 10.8 & 2.2 & 3.3 & 0.0 & 0.0 & 0.0 & ن & \\
\hline 0 & 1 & 9 & 21 & 29 & 26 & 17 & 8 & 6 & 1 & 0 & 0 & $\varepsilon$ & \multirow{2}{*}{ العريش } \\
\hline 0.0 & 0.9 & 7.3 & 17.7 & 24.9 & 22.1 & 14.5 & 7.0 & 4.7 & 0.8 & 0.0 & 0.0 & ن & \\
\hline 0 & 1 & 15 & 29 & 31 & 30 & 28 & 22 & 8 & 2 & 0 & 0 & $\varepsilon$ & \multirow{2}{*}{ الاسماعلية } \\
\hline 0.0 & 0.7 & 9.3 & 17.5 & 18.6 & 17.8 & 16.7 & 13.4 & 4.7 & 1.3 & 0.0 & 0.0 & ن ن & \\
\hline 0 & 0 & 15 & 27 & 31 & 29 & 30 & 24 & 9 & 2 & 0 & 0 & $\varepsilon$ & \multirow{2}{*}{ بهتيم } \\
\hline 0.0 & 0.0 & 8.9 & 16.7 & 18.5 & 17.5 & 17.8 & 14.4 & 5.2 & 1.0 & 0.0 & 0.0 & ن ن & \\
\hline 0 & 0 & 14 & 29 & 31 & 30 & 29 & 24 & 9 & 2 & 0 & 0 & $\varepsilon$ & \multirow{2}{*}{ القاهرة } \\
\hline 0.0 & 0.0 & 8.1 & 17.4 & 18.7 & 17.6 & 17.7 & 14.2 & 5.3 & 1.0 & 0.0 & 0.0 & ن ن & \\
\hline 1 & 1 & 19 & 30 & 31 & 30 & 30 & 27 & 11 & 2 & 0 & 0 & $\varepsilon$ & \multirow{2}{*}{ الجيزة } \\
\hline 0.4 & 0.6 & 10.3 & 16.5 & 17.5 & 16.3 & 16.4 & 14.7 & 6.1 & 1.1 & 0.0 & 0.0 & ن & \\
\hline 0 & 3 & 19 & 29 & 31 & 30 & 30 & 29 & 14 & 4 & 2 & 0 & $\varepsilon$ & \multirow{2}{*}{ أسيوط } \\
\hline 0.0 & 1.6 & 10.2 & 15.2 & 16.2 & 15.6 & 15.6 & 15.0 & 7.5 & 2.2 & 0.8 & 0.0 & ن & \\
\hline 1 & 9 & 29 & 30 & 31 & 30 & 30 & 31 & 27 & 10 & 4 & 0 & $\varepsilon$ & \multirow{2}{*}{ الأقصر } \\
\hline 0.3 & 4.0 & 12.4 & 13.0 & 13.4 & 13.0 & 13.0 & 13.4 & 11.5 & 4.3 & 1.5 & 0.0 & ن & \\
\hline
\end{tabular}

الملحق من تجميع وحساب الباحث اعتماد علي بيانات : الهيئة العامة للأرصاد الجوية بالقاهرة ،

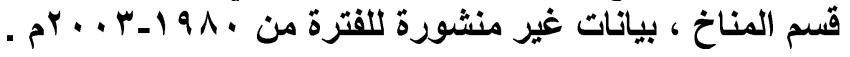

(ب (1) تتير(ع) الى متوسط عدد الأيام المدارية في الثنهر ، وترمز(ن) الى نسبة هذا المتوسط من المعدل 
مجلة كلية الآداب، جامعة سوهاج، العدد الخامس والأربعون، الجزء الأول، أكتوبر VI † Pم

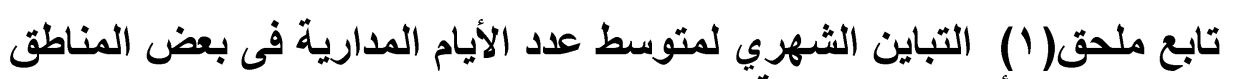

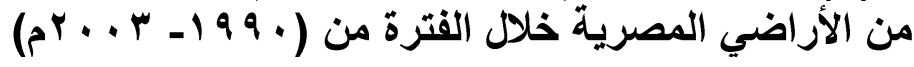

\begin{tabular}{|c|c|c|c|c|c|c|c|c|c|c|c|c|c|}
\hline د & ن & أ & س & i & ي & ى & b & أ & ? & ف & ي & \multicolumn{2}{|c|}{ الثحطرة } \\
\hline 3 & 13 & 28 & 30 & 31 & 30 & 30 & 31 & 26 & 11 & 5 & 1 & $\varepsilon$ & \\
\hline 1.3 & 5.5 & 11.6 & 12.7 & 12.9 & 12.4 & 12.6 & 12.7 & 11.0 & 4.7 & 2.3 & 0.4 & ن & \\
\hline 1 & 3 & 19 & 30 & 31 & 30 & 30 & 29 & 12 & 3 & 0 & 0 & $\varepsilon$ & \\
\hline 0.3 & 1.5 & 10.0 & 16.1 & 16.7 & 16.1 & 16.0 & 15.3 & 6.6 & 1.5 & 0.0 & 0.0 & ن & \\
\hline 2 & 8 & 26 & 30 & 31 & 30 & 30 & 31 & 26 & 7 & 3 & 1 & $\varepsilon$ & \\
\hline 0.8 & 3.8 & 11.4 & 13.4 & 13.8 & 13.3 & 13.3 & 13.8 & 11.4 & 3.3 & 1.3 & 0.4 & ن & \\
\hline 3 & 9 & 27 & 30 & 31 & 30 & 30 & 31 & 26 & 8 & 3 & 1 & $\varepsilon$ & \\
\hline 1.2 & 3.8 & 11.8 & 13.1 & 13.7 & 13.0 & 13.1 & 13.5 & 11.2 & 3.6 & 1.3 & 0.6 & ن & \\
\hline
\end{tabular}


الأيام المدارية في مصر دراسة مناخية

ملحق (r) طول ساعات النهار في بعض المحطات المذكورة في متن البحث وكيفية حسابها

\begin{tabular}{|c|c|c|c|c|c|c|c|c|c|}
\hline \multicolumn{2}{|c|}{ الخارجة } & \multicolumn{2}{|c|}{ الجيزة } & \multicolumn{2}{|c|}{ بهتيم } & \multicolumn{2}{|c|}{ التحرير } & \multirow[b]{2}{*}{$\begin{array}{l}\frac{9}{7} \\
\frac{3}{3}\end{array}$} & \multirow[b]{2}{*}{ 求 } \\
\hline$\frac{-3}{3}$ & 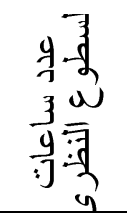 & 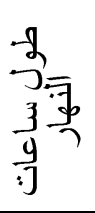 & 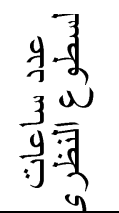 & 年 & 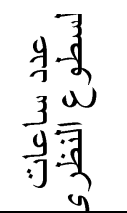 & $\overbrace{}^{-3}$ & 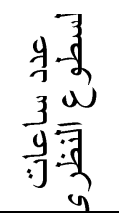 & & \\
\hline 10.8 & 334.1 & 10.5 & 324.2 & 10.5 & 324.1 & 10.4 & 322.5 & 31 & يناير \\
\hline 11.4 & 319.4 & 11.2 & 314.4 & 11.2 & 313.8 & 11.2 & 312.2 & 28 & فبر اير \\
\hline 12.0 & 372.4 & 12.0 & 371.7 & 12.0 & 371.5 & 12.0 & 371.6 & 31 & مارس \\
\hline 12.7 & 382 & 12.9 & 387 & 12.9 & 386.7 & 12.9 & 387.2 & 30 & ابريل \\
\hline 13.3 & 413.8 & 13.7 & 423.4 & 13.7 & 423.6 & 13.7 & 424.5 & 31 & مايو \\
\hline 13.7 & 409.8 & 14.1 & 421.6 & 13.9 & 417 & 14.1 & 422.2 & 30 & يونيه \\
\hline 13.5 & 418.8 & 13.9 & 429.8 & 13.9 & 429.8 & 13.9 & 431.1 & 31 & يوليه \\
\hline 13.0 & 403 & 13.2 & 409.5 & 22.9 & 709.6 & 13.2 & 410.7 & 31 & أغسطس \\
\hline 12.3 & 369 & 12.4 & 370.5 & 12.4 & 370.6 & 12.4 & 370.6 & 30 & سبتمبر \\
\hline 11.6 & 358.8 & 11.4 & 354.8 & 11.5 & 355 & 11.4 & 354.7 & 31 & أكتوبر \\
\hline 10.9 & 328.2 & 10.7 & 320 & 10.7 & 320 & 10.6 & 318.9 & 30 & نوفمبر \\
\hline 10.6 & 329.2 & 10.2 & 317 & 10.6 & 329.5 & 10.2 & 316.8 & 31 & ديسمبر \\
\hline
\end{tabular}

الملحق من اعداد الباحث اعتمادا على بيانات : - الهيئة العامة للارصاد الجوية بالقاهرة ، قعم المناخ ، بيانات غير منشورة

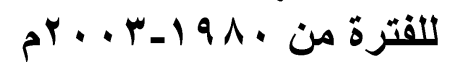

( ) ()لحساب طول النهار اعتمد الباحث على قسمة عدد الساعات النظرية في كل محطة على عدد أيام كل 
مجلة كلية الآداب، جامعة سوهاج، العدد الخامس والأربعون، الجزء الأول، أكتوبر V I P م

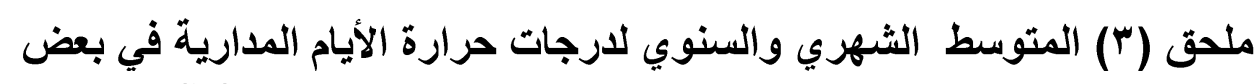

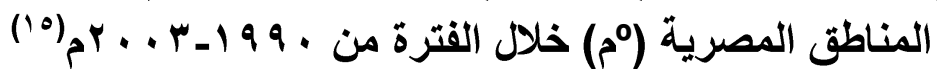

\begin{tabular}{|c|c|c|c|c|c|c|c|c|c|c|c|c|c|}
\hline المتوسط & د & $\dot{ن}$ & 1 & س & 1 & ي & ي & 5 & 1 & 5 & ف & ي & المحطة \\
\hline rV & & & ro & rv & rᄉ & rᄉ & די & Tr & $r$. & & & & مطروسي \\
\hline rv & & & ro & rv & rq & rᄉ & ra & $r \varepsilon$ & ri & & & & الإسكندرية \\
\hline rV & & & ro & rv & rq & rᄉ & ri & rr & W & & & & بورسعيد \\
\hline rv & & Tr & rv & rᄉ & $\varepsilon$. & rq & rv & ro & rt & $r$. & & & العريش \\
\hline$\varepsilon$. & & Tr & rᄉ & $\varepsilon r$ & $\varepsilon \varepsilon$ & $\varepsilon \varepsilon$ & $\varepsilon r$ & $\varepsilon$. & r & rt & & & الإسماعيلية \\
\hline$\varepsilon$. & & & rA & $\varepsilon$. & $\varepsilon 1$ & $\varepsilon r$ & $\varepsilon 1$ & rq & rᄉ & M & & & بهتيم \\
\hline$\varepsilon 1$ & & & rᄉ & $\varepsilon r$ & $\varepsilon r$ & $\varepsilon \varepsilon$ & $\varepsilon r$ & \& & r & rt & & & القاهرة \\
\hline$\varepsilon 1$ & & ro & $\varepsilon$. & $\varepsilon r$ & $\leqslant 0$ & $\varepsilon 0$ & $\varepsilon \varepsilon$ & $\varepsilon \leqslant$ & $\leqslant 1$ & rs & & & الجيزة \\
\hline$\varepsilon r$ & & $r \varepsilon$ & $\varepsilon$. & $\varepsilon r$ & $\leqslant 0$ & $\varepsilon 7$ & $\leqslant 7$ & $\leqslant 0$ & $\varepsilon r$ & ro & Tr & & أسيوط \\
\hline$\varepsilon r$ & rr & ri & $\varepsilon r$ & $\leqslant 0$ & $\leqslant 7$ & $\leqslant 7$ & $\leqslant 7$ & $\leqslant 0$ & $\varepsilon r$ & rᄉ & $r \varepsilon$ & & الأقصر \\
\hline$\varepsilon r$ & rT & rA & $\varepsilon \varepsilon$ & $\varepsilon 0$ & $\varepsilon 7$ & $\varepsilon 7$ & $\varepsilon V$ & $\varepsilon 7$ & $\varepsilon \varepsilon$ & $r q$ & $r$ & rr & أسوان \\
\hline$\varepsilon$. & $r$. & Tr & rᄉ & $\varepsilon r$ & $\varepsilon \varepsilon$ & $\varepsilon 7$ & $\leqslant 0$ & $\varepsilon r$ & rv & rT & & & سيوه \\
\hline$\xi 1$ & ro & $r V$ & $\varepsilon r$ & $\varepsilon 0$ & $\leqslant 7$ & $\leqslant 7$ & $\leqslant 7$ & $\varepsilon 0$ & \&1 & $r V$ & Tr & $r$. & الداخلة \\
\hline$\varepsilon r$ & $r \varepsilon$ & $r v$ & $\varepsilon r$ & 20 & $\varepsilon V$ & $\varepsilon V$ & $\varepsilon V$ & $\varepsilon 7$ & ह1 & $r v$ & $r r$ & $r$. & الخارجة \\
\hline 40.0 & 28.1 & 35.1 & 38.9 & 41.5 & 43.1 & 43.2 & 42.3 & 40.6 & 37.4 & 34.4 & 33.4 & 31 & مثوسط \\
\hline
\end{tabular}

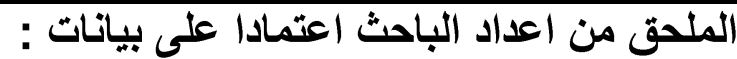

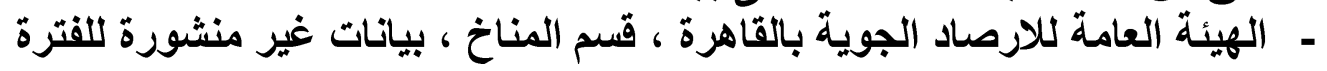

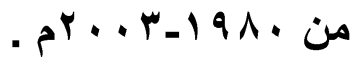
- الخانات الخالية تعنى عدم وجود ايام مدارية . .

- - (10) تم حساب متوسط درجات حرارة الأيام الدارية من خلال تحديدها اولا ، ثم جمع درجاتها 
ملحق ( ) المتوسط الثهري لارجات التبريد المطلوبة فى بعض الإنام المناطق بمصر

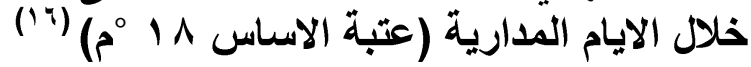

\begin{tabular}{|c|c|c|c|c|c|c|c|c|c|c|c|c|}
\hline د & ن & أ & س & I & ي & ي & 5 & I & 5 & ف & ي & المحطة \\
\hline & & 51 & 190 & 400 & 220 & 54 & 60 & 48 & & & & مطروسي \\
\hline & & 51 & 247 & 504 & 280 & 108 & 96 & 52 & & & & الإسكندرية \\
\hline & & 34 & 247 & 546 & 360 & 126 & 30 & 26 & & & & بورسعيد \\
\hline & 15 & 171 & 420 & 638 & 546 & 323 & 136 & 84 & 12 & & & العريش \\
\hline & 15 & 300 & 696 & 806 & 780 & 672 & 484 & 144 & 28 & & & الإسماعيلية \\
\hline & & 300 & 594 & 713 & 696 & 690 & 504 & 180 & 26 & & & بهتيم \\
\hline & & 280 & 696 & 775 & 780 & 725 & 552 & 162 & 28 & & & القاهرة \\
\hline & 17 & 418 & 720 & 837 & 810 & 780 & 702 & 253 & 32 & & & الجيزة \\
\hline & 48 & 418 & 725 & 837 & 840 & 840 & 783 & 350 & 68 & 30 & & أسيوط \\
\hline 14 & 162 & 696 & 810 & 868 & 840 & 840 & 837 & 675 & 200 & 64 & & الأقصر \\
\hline 45 & 260 & 728 & 810 & 868 & 840 & 870 & 868 & 676 & 231 & 90 & 15 & أسوان \\
\hline 12 & 45 & 380 & 750 & 806 & 840 & 810 & 696 & 228 & 45 & & & سيوه \\
\hline 34 & 152 & 624 & 810 & 868 & 840 & 840 & 837 & 598 & 133 & 42 & 12 & الداخلة \\
\hline 48 & 171 & 648 & 810 & 899 & 870 & 870 & 868 & 598 & 152 & 42 & 12 & الخارجة \\
\hline
\end{tabular}

(7 ( ) لحساب درجات حر ارة التبريد المطلوبة فى مختلف الثهور فقد تم اتباع ما يلى :

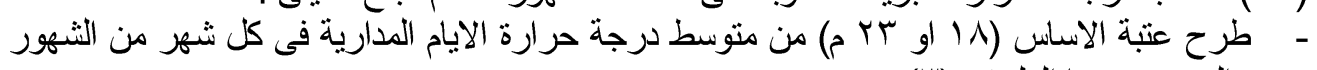

كوالتى يوضحها الملحق (r)

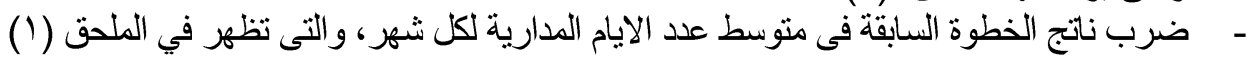


مجلة كلية الآداب، جامعة سوهاج، العدد الخامس والأربعون، الجزء الأول، أكتوبر IV I I

تابع ملحق ( ))المتوسط الثهري لارجات التبريد المطلوبة فى بعض المناطق بمصر خلال الأيام المدارية لاتبرية

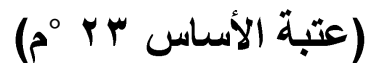

\begin{tabular}{|c|c|c|c|c|c|c|c|c|c|c|c|c|}
\hline د & ن & i & س & i & ي & ي & r & i & r & ف & ي & المحطة \\
\hline & & 36 & 140 & 300 & 165 & 39 & 40 & 28 & & & & مطروسي \\
\hline & & 36 & 182 & 384 & 210 & 78 & 66 & 32 & & & & الإسكندرية \\
\hline & & 24 & 182 & 416 & 270 & 91 & 20 & 16 & & & & بورسعيد \\
\hline & 10 & 126 & 315 & 493 & 416 & 238 & 96 & 54 & 7 & & & العريش \\
\hline & 10 & 225 & 551 & 651 & 630 & 532 & 374 & 104 & 18 & & & لاسماعيلية \\
\hline & & 225 & 459 & 558 & 551 & 540 & 384 & 135 & 16 & & & بهنيم \\
\hline & & 210 & 551 & 620 & 630 & 580 & 432 & 117 & 18 & & & القاهرة \\
\hline & 12 & 323 & 570 & 682 & 660 & 630 & 567 & 198 & 22 & & & الجيزة \\
\hline & 33 & 323 & 580 & 682 & 690 & 690 & 638 & 280 & 48 & 20 & & أسيوط \\
\hline 9 & 117 & 551 & 660 & 713 & 690 & 690 & 682 & 540 & 150 & 44 & & الأقصر \\
\hline 30 & 195 & 588 & 660 & 713 & 690 & 720 & 713 & 546 & 176 & 65 & 10 & أسوان \\
\hline 7 & 30 & 285 & 600 & 651 & 690 & 660 & 551 & 168 & 30 & & & سيوه \\
\hline 24 & 112 & 494 & 660 & 713 & 690 & 690 & 682 & 468 & 98 & 27 & 7 & الداخلة \\
\hline 33 & 126 & 513 & 660 & 744 & 720 & 720 & 713 & 468 & 112 & 27 & 7 & الخارجة \\
\hline
\end{tabular}

الملحق من حساب الباحث اعتمادا على بيانات :

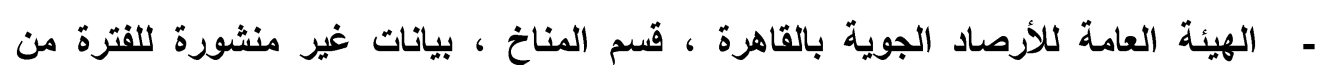

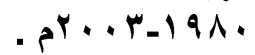

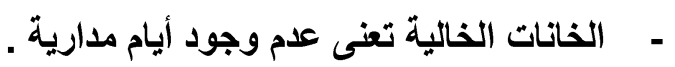


المصادر والمراجه:

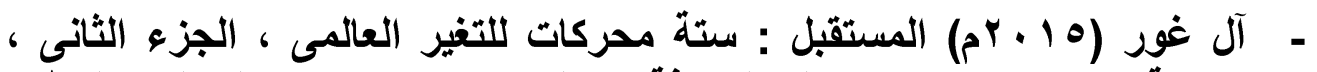

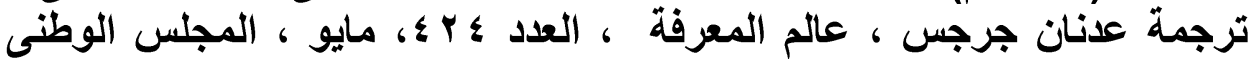

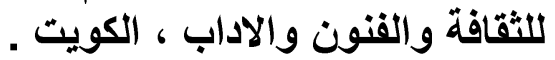

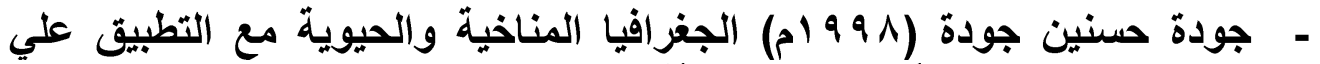

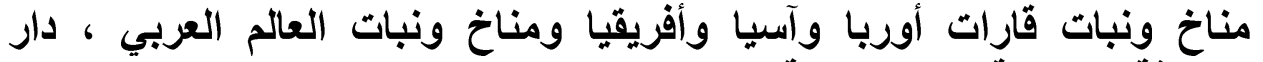
المعرفة الجامعية ، الإسكندرية . المبات

- الإسكندرية .

- حمدى احمد الديب (14 + آم) فى جغرافية الحضر منظور معاصر ، الانجلو

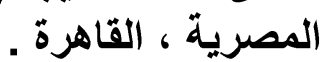

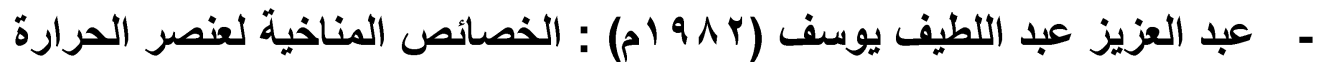

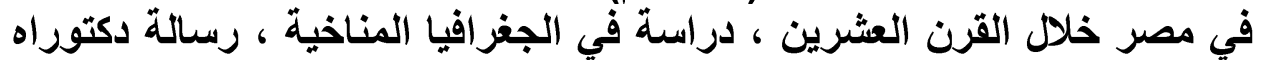

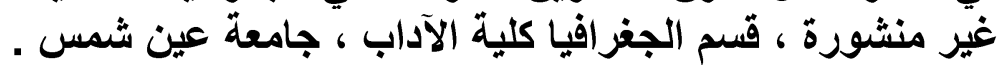

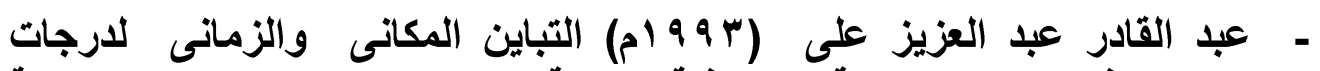

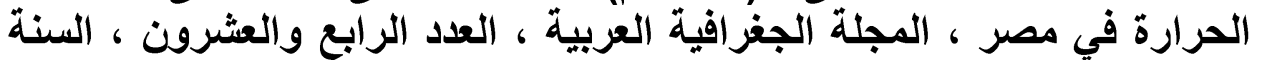

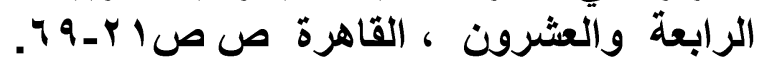

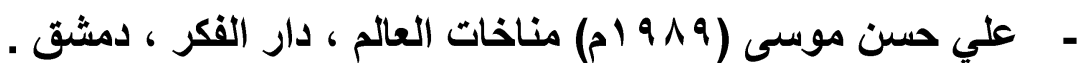

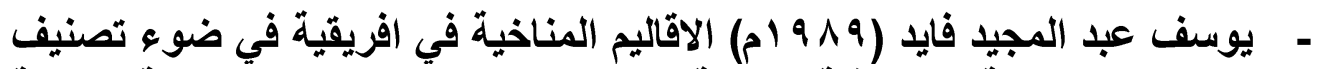

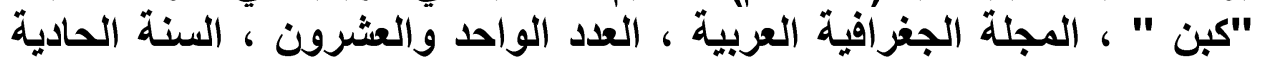

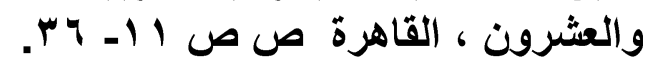

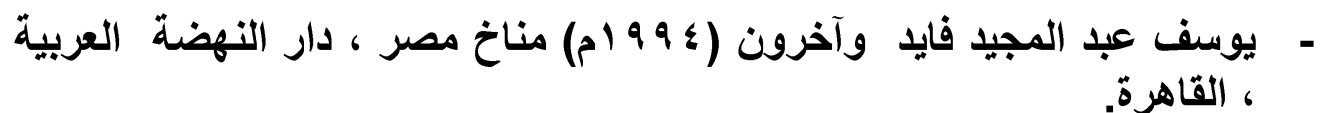

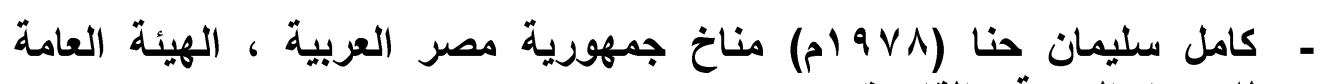

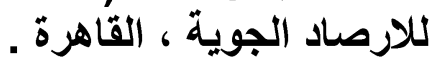

- Agnew, C.T.(1998): " Climate, Agriculture and Vegetation in the Tropics" in "Webster,C.C.,Wilson,P.N.(1998):Agriculture In Tropics, Second Edition, Longman, London. 
مجلة كلية الآداب، جامعة سوهاج، العدد الخامس والأربعون، الجزء الأول، أكتوبر IV P P

- Carapiperis P (1959) Contribution to the study of tropical days in Athens. Bulletin of Army Geographical Service2: pp:61-68.

- Dikaiakos J, Nastos P (1991) The climatic and bioclimatic regime of the tropical days in Athens. Annals Geologiques des Pays Helleniques 35: pp: 471-488

- Faniran,A. ,Jeje,L. K.(1983):Humid tropical geomorphology ,Longman, London.

- Feely, R. and Sweeny ,J., (2008) Statistical downscaling of temperature, radiation and potential evapotranspiration for a selection of sites in Ireland ,Irish Geography, Vol.41.No.1 March .

- Goudie, et al. (eds),(1994) The Encyclopedic Dictionary of Physical Geography ,Second Edition ,Blackwell, Oxford, London.

- Gregory,S.(1978):Statistical methods and the geographer ,Fourth Edition ,Longman, London.

- Kenworthy,J.(1966) Temperature condition in the tropical highland climates of east Africa , E.Afr.Geog.Rev.No.4 April,pp1-11.

- Lockwood,C. J. (1982):World Climatology, Edward Arnold, London.

- Lutgens F. \& Tar buck E. (2001): the Atmosphere , An introduction to Meteorology, Elighth edition , prentice Hall , New Jersey .

- McGregor,G. R., Nivwolt ,S.,(1998): Tropical climates ,An introduction to the climates of the low latitudes,John Wiley \&Sons, New York.

- Nastos,P.T. ,Matzarakis,A.P.(2008): Variability of tropical days over Greece within the second half of the twentieth century, Theoretical and Applied Climatology,93,pp:75-89. 
- Oliver,E. ,editor ,(2004)Encyclopedia of world climatology, New York.

- Storch,V. H. And Zwierss,W.F.(2004): Statistical Analysis in Climate Research, Cambridge University Press, London.

- Strahler ,A.N. ;(1969):Physical Geography , , ,edition. New York.

- Strahler, A. \&Strahler, A.(1994): Introducing Physical Geography ,John Wiley\&Sons,inc., New York

- Suzuki,C.etal,(1999):Meteorological data At the 15 M observational tower in Tokyo metropolitan university, Geographical Reports,N.34 .pp:73-80

- The Egyptian Meteorological Authority Climatological Normals for A.R.E Egypt to 1975 .

- The Egyptian Meteorological Authority : Daily weather reports For the period $(1990-2003)$.

- The Egyptian Meteorological Authority : Monthly weather reports for the period $(1990-2003)$.

- The Egyptian Metrological Authority (1996) Climate Atlas of Egypt

- Webster,C.C.,\&Wilson,P.N.,(1992) Second Ed., Agriculture in the tropics, Longman, London.

- Whittow ,.J.B(1984): Dictionary Of Physical Geography, Penguin Books, London. 